\title{
Clinical implementation of serological markers in heart failure
}

Citation for published version (APA):

van Kimmenade, R. R. (2006). Clinical implementation of serological markers in heart failure. [Doctoral Thesis, Maastricht University]. Universiteit Maastricht. https://doi.org/10.26481/dis.20060519rk

Document status and date:

Published: 01/01/2006

DOI:

10.26481/dis.20060519rk

Document Version:

Publisher's PDF, also known as Version of record

\section{Please check the document version of this publication:}

- A submitted manuscript is the version of the article upon submission and before peer-review. There can be important differences between the submitted version and the official published version of record.

People interested in the research are advised to contact the author for the final version of the publication, or visit the DOI to the publisher's website.

- The final author version and the galley proof are versions of the publication after peer review.

- The final published version features the final layout of the paper including the volume, issue and page numbers.

Link to publication

\footnotetext{
General rights rights.

- You may freely distribute the URL identifying the publication in the public portal. please follow below link for the End User Agreement:

www.umlib.nl/taverne-license

Take down policy

If you believe that this document breaches copyright please contact us at:

repository@maastrichtuniversity.nl

providing details and we will investigate your claim.
}

Copyright and moral rights for the publications made accessible in the public portal are retained by the authors and/or other copyright owners and it is a condition of accessing publications that users recognise and abide by the legal requirements associated with these

- Users may download and print one copy of any publication from the public portal for the purpose of private study or research.

- You may not further distribute the material or use it for any profit-making activity or commercial gain

If the publication is distributed under the terms of Article $25 \mathrm{fa}$ of the Dutch Copyright Act, indicated by the "Taverne" license above, 
Clinical Implementation of

Serological Markers in Heart Failure 
(C) Roland van Kimmenade, Maastricht 2006

ISBN-10: 90-5278-527-9

ISBN-13: 978-90-5278-527-1

Cover design made by Jon Cahill (www.stelliollc.com)

Cover illustration provided by Linda Bucklin (www.lindabucklin.com)

Printed by Datawyse / Universitaire Pers Maastricht (www.datawyse.nl) 


\title{
Clinical Implementation of \\ Serological Markers in Heart Failure
}

\author{
PROEFSCHRIFT \\ ter verkrijging van de graad van doctor \\ aan de Universiteit Maastricht \\ op gezag van de Rector Magnificus, \\ Prof. mr. G.P.M.F. Mols \\ volgens het besluit wan het College van Decanen, \\ in het openbaar te verdedigen \\ op vrijdag 19 mei om 16:00 uur \\ door \\ Roland Renier Jozef van Kimmenade \\ geboren op 20 juni 1977 te Weert
}

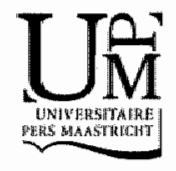




\section{Promotores}

Prof. dr. Y.M. Pinto

Prof. dr. M.P. van Dieijen-Visser

\section{Beoordelingscommissie}

Prof. dr. M.H. Prins (voorzitter)

Dr. L. Hofstra

Prof. dr. P.W. de Leeuw

Prof. dr. A.M. Richards Christchurch School of Medicine and Health Sciences, New Zealand Prof. dr. C.D.A. Stehouwer

Financial support by the RESCAR foundation, the Interuniversity Cardiology Institute of the Natherlands ( $(C \mathrm{CN})$, Roche Diagnostics, AstraZeneca, Pfizer, Novartis Pharma and MSD for the publication of this thesis is gratefully acknowledged. 
"I had come to an entirely erroneous conclusion, which shows my dear Watson, how dangerous it always is to reason from insufficient data"

Sherlock Holmes in "The Speckled band" 



\section{CONTENTS}

Introduction

PART I: NT-proBNP in Patients with Acute Dyspnea

Chapter 1 NT-proBNP testing for diagnosis and short-term prognosis in acute destabilized heart failure: an international pooled analysis of 1256 patients

Chapter 2 Dyspnea with Intermediate Amino-terminal pro-Braïn

Natriuretic Peptide Levels: A Comprehensive Analysis

PART II: NT-proBNP and Renal Function

Chapter 3 Amino-terminal Pro-Brain Natriuretic Peptide, Renal

Function and Outcomes in Acute Heart Faillure

Chapter 4 Renal Handling of BNP and NT-proBNP in Hypertensive

Subjects

\section{Part III: NT-proBNP and Obesity}

Chapter 5 Brain Natriuretic Peptide Production is Decreased in Obese Subjects

Part IV: the Multi-Marker Approach in Heart Failure

Chapter 6 Utility of NT-proBNP, Galectin-3, and Apelin for the

Evaluation of Patients with Acute Congestive Heart Failure

Chapter 7 Hemoglobin and N-terminal Pro-Brain Natriuretic Peptide: Independent and Synergistic Predictors of Mortality in Patients with Acute Heart Failure

General Discussion

Summary

Samenvatting

Dankwoord

Curriculum Vitae 


\section{INTRODUCTION}

Descriptions of the disease we nowadays call "heart failure" already exist from the ancient Egypt, Greece and India, while Roman physicians already prescribed foxglove (digitalis) to their patients as doctors still do in our days.

Despite this long tradition in Medicine in fighting heart failure, the prevalence of this disease in the modern western world is rather increasing ${ }^{2}$ and since heart fallure is responsible for $20 \%$ of the admissions in the population older than 65 years, with a life time risk for heart failure being 1 in $5,^{3}$ the syndrome of heart failure is all but banned from our society.

Moreover, this increase in prevalence combined with its raising costs especially due to all kinds of new technical therapeutic options, (e.g. left ventricular assist devices, biventricular implantable cardioverter-defibrillators, etc.) will make heart failure, more than ever, a daily concern and a challenge for health-care workers, managers, patients and their relatives.

"The very essence of cardiovascular practice is the early detection of heart failure". This quotation by one of the pioneers in Cardiology, sir Thomas Lewis (1933), very adequately points out that in order to both effectively and efficiently treat heart failure, the utter most important thing is to diagnose or exclude heart failure as soon as possible. However, despite the fact that heart failure is highly prevalent, due to the lack of true pathognomonic clinical symptoms and signs, it remains difficult for physicians to immediately make the proper diagnosis in, especially the acutely dyspnoeic patients.

Unfortunately, the quickest and most easy available diagnostic test in cardiology namely the electrocardiography, has only limited value in the diagnosis of heart failure. Therefore, other kinds of diagnostic tests need to be explored in order to obtain an easy but reliable diagnostic tool for clinicians.

After the introduction of the serum marker Aspartate Amino Transferase (ASAT) in 1955 for the diagnosis of myocardial infarction, heart failure would be the ideal next cardiovascular pathology were a serological marker could be a helpful tool for clinicians.

One of the first publications comprehending serological diagnostic testing in heart failure, was published in 1962 by Braunwald and colleagues, who described that plasma norepinephrine concentrations were elevated in some patients with heart lailure but rose to abnormal levels during exercise in all patients. ${ }^{5,6}$. Although valuable for the understanding of the pathophysiology of heart failure, this discovery was less useful as a diagnostic test, since it lacked specificity and is impossible to perform in acutely dyspnoeic patients.

An important finding was the discovery by de Bold and colleagues in 1981 that an injection of atrial tissue extracts increased urinary sodium and water excretion in rats, despite an decrease in atrial pressure. ${ }^{7}$ Soon afterwards, the amino acid sequence of the responsible peptide, Atriall Natriuretic Factor (later on called Atrial Natriuretic Peptide, ANP) was described. ${ }^{8}$ This ANP is primarily produced by cardiomyocytes from the atria and the dominant stimulus for its release from storage granules into the circulation 
is an increase in atrial-wall tension, which reflects increased intravascular volume." These characteristics, namely a quick release of a substance into the circulation regulated by an overload related stimulus are the ideal qualities for a serological marker in heart failune. Alas, since ANP is rapidly cleared by the Natriuretic Peptide Receptor type $C$ (NPR-C) and degraded by neutral endopeptidases, it has a half-life of only 3 minutes, which makes it less suitable as a clinically applicable diagnostic test. ${ }^{10-12}$

The next landmark was the isolation by Sudoh and colleagues of a substance that had natriuretic and diuretic responses similar to ANP but was found to be primarily synthesized in the ventricle. Since this peptide was firstly discovered in the porcine brain, it was called Brain Natriuretic Peptide (BNP). ${ }^{13.14}$ BNP is a 32-amino-acid peptide that is structurally similar to ANP and contains a 17-amino-acid ring structure common to all natriuretic peptides. ${ }^{15}$ The stimulus of release of BNP is also similar to ANP, i.e. the stretching of the cardiomyocyte, but the regulation of secretion differs between the two peptides. 916,17 Whereas the secretion of ANP is controlled on the level of its release from storage granules, is the release of BNP into the circulation regulated on the level of its gene expression. ${ }^{18}$ Furthermore, while BNP is cleared in the same manner as ANP, the NPR-C has a lower affinity for BNP, which contributes to a longer plasma half-life in humans of 22 minutes and consequently more stable plasma levels. ${ }^{10,15,19}$ Therefore, BNP was introduced as a possible serological marker in heart failure and fotnd to be superior to any single clinical parameter. ${ }^{20-22}$

When cardiomyocytes are stretched, the production of proBNP (108 amino acids) is rapidly upregulated. This proBNP is enzymatically cleaved to form BNP (32 amino acids) and aminoterminal pro-BNP (NT-proBNP) (76 amino acids) which are both released into the circulation. ${ }^{23}$ Thus, both molecules reflect the same proces, namely the stretching of (ventricular) cardiomyocytes, which naturally occurs in the overfilled heart. The main difference is, that while BNP is cleared by the NPR-C, neutral endopeptidases and the kidneys, NT-proBNP is only cleared by the kidneys, which leads to a plasma half-life of $70-120$ minutes. ${ }^{24-26}$

NT-proBNP testing was also introduced in clinical practice and has shown to be of equal diagnostic value as BNP. ${ }^{21,27-29}$

\section{Aim of the Thesis}

Several factors, such as renal impairment and obesity, influence the interpretation of: NT-proBNP concentrations in humans. The aim of my thesis was to evaluate these factors to establish practical cut-off values and to study the utility of NT-proBNP in combination with serum markers that reflect more chronic processes in heart failure.

In Chapter 1, cut-off values for NT-proBNP serum concentrations in acute dyspnoeic patients are evaluated. We recommend a general rule-out cut-off value (i.e. $300 \mathrm{pg} / \mathrm{ml}$ ) combined with age-dependent rule-in cut-offs. In Chapter 2 we discuss more in detail the characteristics of the acutely dyspnoeic patients with a intermediate NT-proBNP concentration, i.e. a NT-proBNP concentration in between their rule-in and rule-out cutoff values and explore which clinical information offers assistance in making the correct diagnosis in this subset of patients.

An important issue in the interpretation of NT-proBNP serum concentrations is the influence of renal function. Chapter 3 shows that NT-proBNP still has diagnostic 
significance in the presence of renal impaiment, while Chapter 4 discusses our mechanistic study of the renal handling of NT-proBNP and BNP.

Chapter 5 is a small interventional study that illustrates that the negative correlation between BNP or NT-proBNP versus Body Mass Index (BMI) is due to a lower production of these peptides in obese subjects, rather than an increase in clearance.

In Chapter 6 we demonstrate that, though NT-proBNP is superior as a marker for diagnosing heart failure in acutely dyspnoeic patients, the prognosis of these patients is better reflected by a novel serum marker of inflammation in heart failure, namely Galectin-3. Chapter 7 shows that adding a traditional serum marker to NT-proBNP serum concentrations i.e. hemoglobin in heart failure patients, can improve the prognostification of these patients.

\section{REFERENCES}

1. Davis RC, Hobbs FD, Lip GY. ABC of heart fai lure. History and epidemiology. BMJ. 2000;320:39-42.

2. Jessup M, Brozena S. Heart failure. N Engl I Med. 2003;348:2007-18.

3. Lloyd-Jones DM, Larson MG, Leip EP, Beiser A, D'Agostino RB, Kannel WB, Murabito JM, Vatsatio RS, Benjamin EJ, Levy D. Lifetime risk for developing congestive heart failure: the Framingham Heat Study. Circulation. 2002;106:3068-72.

4. Karmen A, Wroblewski F, Ladue JS. Transaminase activity in human blood. J Clin Inwest. 1955;34:12631.

5. Chidsey $\mathrm{C}$, Harrison D, Braunwald E. Augmentation of the plasma norepinephrine response to exercise in patients with congestive heart failure. N Engl J Med. 1962;267:650-4.

6. Braunwald $\mathbb{E}$. The Denolin lecture. Congestive heart fallure: a thalf century perspective. Eur Heart J. 2001:22:825-36.

7. de Bold A.J, Borenstein HB, Veress AT, Sonnenberg H. A rapid and potent natriuretic response ta intravenous injection of atrial myocardial extracts in rats. Life Sci. 1981;28:89-94.

8. de Bold A. Atrial natriuretic factor of the rat heart. Studies on isolation and properties. proc Soc Exp Biol Med. 1982;170:133-138.

9. Edwards BS, Zimmerman RS, Schwab TR, Heublein DM, Burnett JC, Jr. Atrial stretch, not pressure, is the principal determinant controlling the acute release of atrial natriuretic factor. Circ Res. 1988;62:191. 5 .

10. Mukoyanta M, Nakao K, Hosoda K. Suga S, Saito Y, Ogawa Y, Shirakani G, Jougasaki M, Obata K. Yasue $H_{*}$ et all. Brain natriuretic peptide as a novel cardiac hormone in humans. Evidence for an exquisite dual natriuretic peptide system, atrial natriuretic peptide and brain natriuretic peptide, I Clin invest. 1991;87:1402-12.

11. Sonnenberg J, Sakane Y, Jeng AY, Koehn JA, Ansell JA. Wennogle LP, Gthai RD. Identilication of protease 3.4.24.11 as the major atrial natriuretic factor degrading enzyme in the rat kidney. Peptides. 1988;9:173-80.

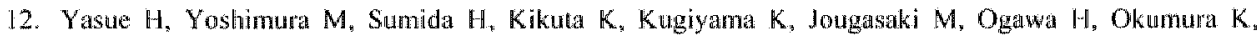
Mukoyama M, Nakao $K$. Localization and medhanism of secretion of B-type natrunctic peptide in comparison with those of A-type natriuretic peptide in normal subjects and patierits with heart failure. Circulation. 1994;90:195-203.

13. Sudoh $T$, Kangawa $K$, Minamino $N$, Matsuo $H A$ new natriuretic peptide in porcine brain. Wature. 1988; 332:78-81.

14. Hosoda K, Naká K, Mukoyama M, Saito $Y$, Jougasaki M. Shirakami G, Suga S, Ogawa Y, Yasue H, Imura $\mathrm{H}$. Expression of brain natriusetic peptide gene in human heart. Production in the veratricle. Hypertension. 1991:17:1152-5.

15. Ruskoaho H. Cardiac homones as diagnostic tools in heart failure. Endocr Rev. 2003:24:341-56.

16. Bruneau BG, Piazza LA, de Bold AJ. BNP gene expression is specifically modulated by stretch and ET-I in a new model of isolated rat atria. Am I Physiol. 1997;273:H2678.86. 
17. Mizuno Y, Yoshinura M, Harada L, Nakayama M, Sahamoto T, Shimasaki Y, Ogawa H. KugY,ama K. Saito $Y$; Naka $K$, Yasue $\mathbb{H}$. Plasma levels of $A$ - and B-iype natriuretic peptides in patients writh hypertrophic cardomyopathy or idiopathic dilated cardionyopathy. Am J Cardiol. 2000,86:1036-40, All.

18. Onuoha $\mathrm{GN}$, Noholls $\mathrm{DP}$, Paturson $\mathrm{A}$, Beringer $\mathrm{T}$. Neuropeptide secretion in exercise. Neuropeptides. $1998,32 \cdot 31925$

19. Yandle To. Hiochentstry of nathuretic peptides. I Intern Med. 1994,$235 ; 561-76$.

20. Morison LK, Harison A, Krishnaswamy P, Kaxanegra $R$. Clopton P, Maisel A. Utility of a rapud Bnatrutetic peptide ansay in differentiating congestive heart failure from lung disease in patients presenting with dyspnea $\mathrm{Am}$ Coll Cardiol. 2002;39:202-9.

21. Cowie MR, Struthers AD, Wood DA, Coats AJ, Thompson SG, Poole-Wilson PA, Suton GC Walue of natriuretic peptides in assessment of patients with possible new heart fallure in primary care. Lancet. $1997 ; 350: 1349.53$.

22. Maisel AS, Krishnaswamy $P$, Nowak RM, McCord $d_{i}$ Hollander JE, Duc $P$, Omland $T$, Storrow AB, Abrahan WT, Wu AH, Clopton P, Steg PG, Westheim A, Knudsen CW, Perez A, Kazanegra R, Hermann $H C$, MoCullough PA. Rapid measurement of B-type natriuretic peptide in the ennergency diagnosis of heart failure. N Engl J Med, 2002;347:161-7.

23. Sawada Y, Suda M, Yokoyama H. Kanda T, Sakamaki T, Tanaka S, Nagai R, Abe S, Takeuchi T, Stretch-induced hypertrophic growth of" cardiocytes and processing of brain-type natriuretic peptide are controlled by proprotein-processing endoprotease furin. J Biol Chem. 1997;272:20545-54.

24. MlcCullough PA, Duc P, Omland $T$, McCord J, Nowak RM, Hollander JE, Hermann HC, Steg PG, Westhein $A$, Knudsen CW, Storrow AB, Abrahan WT, Lamba $S$, Wu AH, Perez A, Clopton P. Krishnaswarny P, Kazantgra R. Maisel AS. B-type natriuretic peptide and renal function in the diagnosis of heart failure; an analysis from the Breathing Not Properly Multinational Study. Am I Kidney Dis. $2003 ; 41571-9$

25. McCullough PA, Sandberg KR. B-type natriuretic peptide and renal disease. Heart Fail Rev. 2003;8:3558.

26. Pemberton CI, Johnson ML, Yandle TG, Espiner EA. Deconvolution analysis of cardiac natuiuretic peptides during acute volume overload. Hypertension. 2000;36:355-9.

27. Hunt PJ RA, Nicholls MG, Yandle TG, Doughty RN, Espiner EA. Immunoreactive amino-lerminal probrain natritretic peptide (NT-PROBNP): a new marker of cardiac impairment. Clinical Endocrinology. $1997 ; 47: 287-296$

28. Januzzi JL, Jr, Camargo CA, Anwaruddin S, Baggish AL, Chen AA, Krauser DG, Tung R, Cameron R, Nagumey JT, Chae CU, Lloyd-Jones DM, Brown DF. Foram-Melanson: S, Sluss PM, Lee-Lewandrowski E. Lewandrowshi KB. The N-terminal Pro-BNP" Investigation of Dysptea in the Emergency department (PRUDE) study. Am J Candiot. 2005:95:948-54.

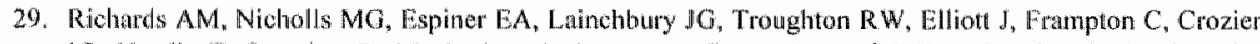

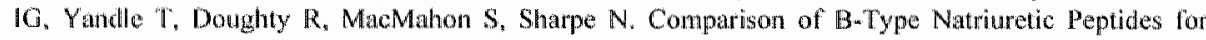
Assessment of Cardiac function and Prognosis in Stable 1 schemic Heart Disease. I Am Coll Caurdiot. $2006,47 \cdot 52-60$ 


\section{NT-proBNP Testing for Diagnosis and Short- Term Prognosis in Acute Destabilized Heart Failure: An International Pooled Analysis of 1256 Patients}

\section{The International Collaborative of NT-proBNP (ICON) Study}

J Januzzi $\mathrm{Jr}^{*}, \mathrm{R}$ van Kimmenade ${ }^{\dagger}$, J Lainchbury, A Bayes-Genis J Ordonez-Llanos", M Santalo-Bell, Y Pinto", M Richards,

"Massachusetts General Hospital, Boston, USA

${ }^{\dagger}$ University Hospital Maastricht, Maastricht, The Netherlands

* Christchurch School of Medicine and Health Sciences, Christchurch, New Zealand

Hospital de la Santa Creu i Sant Pau, Barcelona, Spain

Eur Heart J 2006;27:330-337

Drs. Januzzi and van Kimmenade contributed equally to this manuscript. 


\section{ABSTRACT}

Aims: Experience with amino-terminal pro-brain natriuretic peptide (NT-proBNP) testing for evaluation of dyspneic patients with suspected acute heart failure (HF) is limited to single-center studies. We wished to establish broader standards for NTproBNP testing in a study involving 4 sites in 3 continents.

Methods and Results: Differences in NT-proBNP levels anong 1256 patients with and without acute HF and the relationship between NT-proBNP levels and HF symptoms were examined. Optimal cut-points for dliagnosis and prognosis were identified and verified using bootstrapping and multivariable logistic regression techniques. 720 subjects $(57.3 \%)$ had acute HF, whose median NT-proBNP were considerably higher than those without ( $4639 \mathrm{vs} 1.08 \mathrm{pg} / \mathrm{ml}, \mathrm{p}<0.001$ ), and levels of NT-proBNP correlated with HF symptom severity $(\mathrm{p}=0.008$ ). An optimal strategy to identify acute HF was to use age-related cut-points of $450 \mathrm{pg} / \mathrm{ml}, 900 \mathrm{pg} / \mathrm{ml}$, and $1800 \mathrm{pg} / \mathrm{ml}$ for ages $<50$ years, $50-75$ years, and $>75$ years of age, which yielded $87 \%$ sensitivity, and $83 \%$ specificity for acute HF. An age-independent cut-point of $300 \mathrm{pg} / \mathrm{ml}$ had $98 \%$ negative predictive value to exclude acute HF. Among those with acute HF, a presenting NT-proBNP concentration $>5180 \mathrm{pg} / \mathrm{m} \|$ was strongly predictive of death by 76 days (odds ratio $=5.2$, $95 \% \mathrm{CI}=2.2-8.1, \mathrm{p}<0.001$ ).

Conclusions: In this multi-center, international study, NT-proBNP testing was valuable for diagnostic evaluation and short-term prognosis estimation in dyspneic subjects with suspected or confirmed acute HF, and should establish broader standards for use of NTproBNP in dyspneic patients.

Keywords: natriuretic peptides, diagnosis, prognosis 


\section{INTRODUCTION}

Recently, use of both B-type natriuretic peptide (BNP) and its amino-terminal fragment $\mathrm{N}$-terminal pro-Brain natriuretic peptide (NT-proBNP), has been found to be useful as an adjunct to standard clinical evaluation for the diagnosis and triage of dyspneic patients, ${ }^{1.3}$ as these markers are considerably higher in patients with acute destabilized heart failure (HF). As such, the utility of serum testing for the natriuretic peptides has been recognized and incorporated in consensus documents and guidelines for diagnosis and management of $\mathrm{HF}^{4-6}$

Large-scale experience with BNP was reported previously, in a study of 1586 patients, ${ }^{2}$ providing useful information regarding this marker in a heterogeneous, multi-national patient population. While several similarly-designed studies have been published supporting the use of NT-proBNP for the evaluation of dyspneic patients, ${ }^{1,7.8}$ each were restricted to single centers, and on occasion had limited numbers of patients. As such, optimal NT-proBNP concentrations for confirming or excluding the presence of acute destabilized HF in acutely dyspneic patients have yet to be definitively established. Further, the prognostic utility of NT-proBNP at presentation in the setting of acute, destabilized $\mathrm{HF}$, where very high levels of natriuretic peptides at presentation might obscure the prognostic value of the marker, remains undefined.

In order to clarify these issues, we performed this international multicenter analysis of 1256 subjects to establish optimal NT-proBNP cut points for diagnosis or exclusion of acute HF, and to evaluate the prognostic significance of elevated NT-proBNP in the setting of acute HF.

\section{METHODS}

\section{Component Studies}

The study population consisted of patients from three previously reported prospective clinical trials of NT-proBNP testing from Christchurch, New Zealand, Barcelona, Spain, and Boston, Massachusetts, USA, each performed to explore the use of NT-proBNP testing in dyspneic Emergency Department (ED) patients. ${ }^{1,7,8}$ All three prospective trials had compatible inclusion/exclusion criteria, and obtained similar clinical information. In addition, prospectively-gathered data from 367 patients in a previously unpublished registry of patients with acute HF enrolled at the University Hospital of Maastricht, The Netherlands were included to complete the ICON dataset.

The Christchurch study ${ }^{8}$ comprised 205 patients presenting with dyspnea to the ED. In this trial, the results of blinded NT-proBNP concentration were compared to a final adjudicated diagnosis, rendered utilizing the European Society of Cardiology guidelines. ${ }^{6}$ For the purposes of the present study, 195 subjects had complete data and were included for analysis. The Barcelona study ${ }^{7}$ consisted of 100 dyspneic patients presenting to the ED, and blinded NT-proBNP results were subsequently compared to final diagnosis, which was assigned by a panel of physicians utilizing all available clinical data pertaining to each subject. Of the original 100 patients, 95 had complete 
data, and were included in this study. Similar to the above trials, the ProBNP Investigation of Dyspnea in the Emergency Department (PRIDE) study was a prospective, blinded study of NT-proBNP testing performed in Boston, Massachusetts, which examined 599 dyspneic subjects in the ED. Similar to the New Zealand and Barcelona studies, the final diagnosis for each patient was assigned by study cardiologists blinded to NT-proBNP levels, using available clinical data from presentation to 76 day follow up. All patients from PRIDE were eligible for the present analysis:

The final source of data for the present analysis was the Second Maastricht Registry of Congestive Heart Failure (MARCH II). This prospective registry consists of patients with acute $\mathrm{HF}$ consecutively admitted to the University Hospital of Maastricht, between the dates of January $1^{\text {st }}, 2003$ through March $15^{\text {th }} 2004$. During this period, 419 patients with acute $\mathrm{HF}$ and dyspnea of varying severities were recruited. Of those enrolled, 367 had presenting NT-proBNP data available for andlysis, and were included for the present analysis.

\section{Pooled Methodology}

All four component data sets had comparable information available, including standard demographics, past medical history and drug therapy, presenting symptoms and signs (including severity of breathlessness by the New York Heart Association [NYHA] classification), physical examination, and results of serum chemistry tests, radiographic studies (typically plain chest radiographs), electrocardiography results, and finally the results of NT-proBNP testing. Glomerular Filtration Rate (GFR) was estimated utilizing the Modified Diet in Renal Disease (MDRD) equation."

Follow-up for vital status among HF subjects was complete in $100 \%$ of subjects with acute HF from ICON through 76 days from presentation. In subjects from Christchurch, vital status was ascertained via review of hospital records as well as contact with caregivers or patients, when appropriate. In each case, data were corroborated utilizing the New Zealand Hospital Information Service and the Canterbury District Health Board Patient Management System database. In subjects from Barcelona, vital status was ascertained via review of medical records and phone follow-up with each subject. In subjects from Boston, follow-up was achieved utilizing review of hospital records and phone follow-up with each patient and/or their physicians. Deaths were corroborated using the Social Security Death Index. Lastly, among subjects from Maastricht, follow-up was achieved utilizing hospital records as well as city hall reports for all deaths in Mastricht.

\section{NT-proBNP Testing}

For each trial, blood was collected into EDTA tubes, and NT-proBNP was measured using a validated, commercially available immunoassay (Elecsys ${ }^{\text {B }}$ ProBNP, Roche Diagnostics, Indianapolis, IN), using established methodology. This assay has been reported to have $<0.001 \%$ cross-reactivity with bioactive BNP, and in the constituent studies in this report, this assay had inter-mon coefficients of variation ranging from 
$0.9 \%$ to $5.5 \%$. For the purposes of this report, NT-proBNP levels are expressed in pg/ml (to convert $\mathrm{pg} / \mathrm{ml}$ to pmol/l, multiply $\mathrm{x} 0.118$ ).

Measurement of troponin T (cTnT, Troponim T Stat\&, Roche Diagnostics, Indianapolis, IN) was performed at each institution using standard methodology.

\section{Statistical Analyses}

Comparisons of clinical characteristics between patients across all four studies were performed utilizing $\chi^{2}$ tests for categorical data and the Wilcoxon rank-sum test for continuous data. Similar methods were subsequently used to compare clinical characteristics between patients with and without acute HF in the final pooled analysis. Correlations between left ventricular ejection fraction and log-transformed NT-proBNP concentrations were performed using Spearman correlation. Comparisons of NT. proBNP levels between groups categorized by NYHA symptom severity as well as by final diagnostic categories were performed using the Kruskal-Wallis test. For these analyses, SPSS software (SPSS Inc., Chicago, I11., USA) was utilized.

\section{Cut-points for Diagnosis or Exclusion of Acute HF}

Candidate NT-proBNP diagnostic cut points were determined with the use of logistic regression analyses, with resulting ROC curves. In each case log-transformed NTproBNP concentrations were used as the single independent variable in the logistic regressions, and to ensure that there were no spurious significant regression results due to multiple comparisons, the Bonferroni inequality was used to set the alpha threshold for declaring the $\log (\mathrm{NT}$-proBNP) regression coefficient significantly different from zero (i.e. the critical $\propto$ value for a significant tail-probability was set at 0.01 for each of the determinations, so that all cut points would enjoy at most a joint 0.05 probability of a type I error).

For each logistic regression, log-transformed NT-proBNP results were entered in a single forward step with tail-probability to enter set at $p=0.01$ and to remove the effect from the regression at $p=0.02$. These analyses were carried out with the STATA statistics package (STATA Corp, College Station, TX, USA).

Each of the estimation procedures was coded in the STATA programming language then subjected to the STATA bootstrap prefix command for 100 bootstrap repeated random samples with replacement to estimate $95 \%$ confidence limits for each of the estimated cut points in NT-proBNP. These limits are expressed as (lower 95\% confidence limit, upper $95 \%$ confidence limit). The bootstrap sample size was 1256 (the size of the entire data set). Each of the estimation procedures determined the threshold in estimated probability of acute HF that maximized predictive accuracy subject to different constraints on sensitivity or speciffcity for each of the cut points. This threshold was then transformed with the use of the estimated logistic equation to a $\log (\mathrm{NT}$-proBNP) threshold, which was then, in turn, transformed to a diagnostic cut point in NT-proBNP expressed at $\mathrm{pg} / \mathrm{ml}$.

The constraints on cut point optimization were dictated by clinical considerations. The study population was divided into 3 clinically distinct sub-populations based upon age. For patients under 50 years, a minimum sensitivity of the NT-proBNP cut point for diagnosing acute $\mathrm{HF}$ was set at $95 \%$ because of the recognition of lower expected 
values in the setting of $\mathrm{HF}^{5}$ in younger subjects, together with the large potential adverse outcome of missing a young patient with acute $\mathrm{HF}$. At the other extreme, patients alder than 75 years required the emphasis on optimal specificity because of the recognition of the known age-related increase in basal NT-proBNP and the undesirability of incorrectly diagnosing and/or treating older patients for acute HF. In the intermediate group of patients, those 50 to 75 years old, a balance in sensitivity and specificity was required (while maximizing predictive accuracy within these constraints). As gender has known independent effects on NT-proBNP levels, ${ }^{\text {} 0}$ we also examined further categorization by gender (and age) to improve accuracy of NT-proBNP for diagnosis.

For determining the cut point for ruling out acute $\mathrm{HF}$, a similar procedure as for diagnosis was used to identify an NT-proBNP concentration yielding optimal negative predictive value. As negative predictive value is subjected to a constraint based on specificity, a minimal, reasonable degree of specificity was required, and this constraint was set at $60 \%$ in bootstrap replications. In addition, we similarly examined the manufacturer-recommended cut-points for excluding $\mathrm{HF}$.

\section{Cut-points for Short-term Prognosis in Acute HF}

To determine a single prognostic cut point for prediction of mortality at 76 days, again, using $\log (\mathrm{NT}$-proBNP) as the sole predictor variable, predictive accuracy was maximized subject to a minimal specificity constraint, using bootstrap replications as was done for identifying optimal cut-points for diagnosis. Once identified, the optimal cut-point was entered into multivariable logistic regression analysis.

The STATA validation bootstrapping program, SWBOOT, was used to perform 100 bootstrapped repeats of multivariable stepwise logistic regression on candidate predictors of 76-day mortality. Factors entered into the analysis included source of data, elements from past and present medical history, symptoms and signs, medication use, as well as results of diagnostic studies including radiographic studies, electrocardiography, lhematology, and blood chemistries (including NT-proBNP results). In this validation run, the above logistic regression procedure was used, except that the alpha tailprobability for an independent variable to enter the model was set as the conventional. screening level of 0.05 and to remove of 0.1 .

After the SWBOOT run, the resulting validated candidate independent variables were again entered stepwise into a logistic model in the same fashion described for the diagnostic cut-points. Again, using the Bonferroni inequality to protect against type I errors, the tail probability of the test statistic was set at 0.01 to enter and 0.02 to remove the effect from the model. STATA bootstrap estimation was used to estimate $95 \%$ confidence intervals $(\mathrm{CI})$ for the odds ratios computed for the remaining independent predictors of 76-day mortality.

Linearity of the logit of proportion of patients with adjudicated acute HF or with 76 day mortality in $\log (\mathrm{NT}$-proBNP) was judged not to be an important issue because each logistic regression fit was confirmed to be adequate by application of the HosmerLemeshow goodness of fit test.

Kaplan-Meier survival curves were constructed to compare 76-day mortality rates in groups divided as a function of NT-proBNP concentrations, using the log-rank test to compare the significance of the rates of mortality. 
For all statistical analyses, all $\mathrm{p}$ values are two-sided, with composite results $<0.05$ considered significant.

\section{RESULTS}

The baseline demographics, past medical history, medication use, synuptoms/signs, and lab results of the four study cohorts were reflective of the prevalence of acute HF in each study (Table 1). Notably, study subjects from the Boston trial were younger than the Christchurch, Barcelona, and Maastricht patients $(p<0.001)$. Table 1 details the demographics, past medical histories, medication use, symptoms/signs, results of physical examination, and outcomes of laboratory testing, as a function of the source of the data.

\section{Diagnoses, Symptom Severity, and NT-proBNP Concentration}

Of the 1256 dyspneic subjects in this pooled analysis, $720(57.3 \%)$ had acute HF, while $536(42.7 \%)$ did not. Of those without acute HF exacerbation at the time of enrollment, 55 subjects (4.4\% overall) had a prior diagnosis of HF. The results of NT-proBNP testing between those with and without acute $\mathrm{HF}$ are detailed in Figure 1. The median NT-proBNP concentration of those patients with acute HF exacerbation (4639 pg/ml) was significantly higher than those with neither acute nor prior $\mathrm{HF}(108 \mathrm{pg} / \mathrm{ml}, \mathrm{p}<0.00 \Perp$ for difference). Notably, within the subjects without acute HF, 55 subjects were present with prior HF without acute exacerbation at the time of study enrollment. These 55 subjects had higher NT-proBNP concentrations $(949 \mathrm{pg} / \mathrm{ml}, \mathrm{IQR}=269-2590 \mathrm{pg} / \mathrm{ml}$ ) than those without prior HF, however the NT-proBNP concentrations among those with acute destabilized. HF were nonetheless significantly higher than in the 55 subjects nonacute HF subjects with prior heart failure $(p<0.001$ for difference).

Of those patients with acute $\mathrm{HF}$ at the time of enrollment $(\mathrm{n}=720), 55(7.6 \%) \mathrm{had}$ NYHA Class II symptoms, while 348 (48.3\%) had Class III symptoms, and $3 \| 7$ (44.0\%) had Class IV symptoms. Figure 2 demonstrates the significant relationship between NYHA symptom severity and NT-proBNP levels; as symptom severity rose; a significant increase in median NT-proBNP levels was observed $(p=0.008)$, although significant overlap existed between the three groups. 
Table 1: Baseline demographics, past medical history, symptoms, signs, resufts of physical examination and laboratory testing of the 1256 study subjects, categarized with respect to the center of origin.

\begin{tabular}{|c|c|c|c|c|c|}
\hline Gharadterstic & $\begin{array}{l}\text { Bostor } \\
(n-599)\end{array}$ & $\begin{array}{l}\text { Earcelona } \\
(n=95)\end{array}$ & $\begin{array}{l}\text { Christehurch } \\
(n=195)\end{array}$ & $\begin{array}{l}\text { Maastricht } \\
(n=367)\end{array}$ & 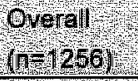 \\
\hline Scup hoart fulure & $350 \%$ & $642 \%$ & $338 \%$ & $100 \%$ & $57 \%$ \\
\hline Ale. meantso & $625+171$ & $70.9 \pm 113$ & $70.8+14$ & $760+11$ & 683.1 \\
\hline Male gender & $50.8 \%$ & $600 \%$ & $487 \%$ & $51 \%$ & $51 \%$ \\
\hline Arrican othinisty & $7,7 \%$ & 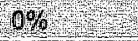 & 601.5 & $0.5 \%$ & $37 \%$ \\
\hline Prorthistory & & & & & \\
\hline Hpartanion & $487 \%$ & $642 \%$ & $46.7 \%$ & $68.0 \%$ & $63 \%$ \\
\hline Coronary artery di 1 ease & $279 \%$ & $337 \%$ & $426 \%$ & $60.5 \%$ & $40 \%$ \\
\hline Plor nyocardial nifarcton & $130 \%$ & $25.3 \%$ & $267 \%$ & $42,4 \%$ & $25 \%$ \\
\hline Proplf & $250 \%$ & $44.2 \%$ & $262 \%$ & $50.7 \%$ & $34 \%$ \\
\hline copaprastrima & $361 \%$ & $516 \%$ & $55 \% \%$ & $238 \%$ & $37 \%$ \\
\hline Tobacco use (past or present) & $62.4 \%$ & $56.8 \%$ & $697 \%$ & $43.1 \%$ & $56 \%$ \\
\hline Loop diuretic use & $29.6 \%$ & $48.4 \%$ & $306 \%$ & $62.3 \%$ & $42 \%$ \\
\hline Symptoms signs & & & & & \\
\hline PNo & $\sqrt{12.4 \%}$ & $611 \%$ & $138 \%$ & $28.1 \%$ & $21 \%$ \\
\hline Othopnet & $17.4 \%$ & 8110 & $39.6 \%$ & $514 \%$ & $36 \%$ \\
\hline Hower extrenity ederna & $172 \%$ & $647 \%$ & $32 \%$ & $493 \%$ & $32 \%$ \\
\hline Chestpain & $427 \%$ & $29.5 \%$ & $51,3 \%$ & $30,9 \%$ & $40 \%$ \\
\hline cough & $369 \%$ & S5 8\% & $467 \%$ & $248 \%$ & $36 \%$ \\
\hline fover $2 x^{2}$ & $93 \%$ & $63 \%$ & $72 \%$ & $6.2 \%$ & $8 \%$ \\
\hline Splivin production & $95 \%$ & $656 \%$ & $475 \%$ & $136 \%$ & $19 \%$ \\
\hline Phyical exainination & & & & & \\
\hline Puse rate, neantsG. & 8764221 & 9781264 & $907+257$ & $964+266$ & $91: 4+250$ \\
\hline Juguiar venous olistension & $245 \%$ & $537 \%$ & $308 \%$ & $66.2 \%$ & $33 \%$ \\
\hline (ing exant. & $330 \%$ & $632 \%$ & $482 \%$ & $745 \%$ & $49 \%$ \\
\hline Wheeving on lung exam & $142 \%$ & $38.9 \%$ & $318 \%$ & $101 \%$ & $23 \%$ \\
\hline sogallop & $0.8 \%$ & $117 \%$ & $128 \%$ & $49 \%$ & $5 \%$ \\
\hline Lower oxtromity edeme & $24.6 \%$ & $547 \%$ & $328 \%$ & $632 \%$ & $39 \%$ \\
\hline EGG findings & & & & & \\
\hline shus ny hn, & $705 \%$ & $579 \%$ & $700 \%$ & $624 \%$ & $87 \%$ \\
\hline brilution or fluter & $125 \%$ & $337 \%$ & $186 \%$ & $373 \%$ & $22 \%$ \\
\hline Left ventricular lyyertrophy & $40 \%$ & $95 \%$ & 4166 & $128 \%$ & $7 \%$ \\
\hline Loft bunde branch block & $67 \%$ & 14.7\% & $10.3 \%$ & $183 \%$ & $11 \%$ \\
\hline Chost radiogiaphy tholings & & & & & \\
\hline Interstital gdena & $16.9 \%$ & $66.3 \%$ & $155 \%$ & $23.4 \%$ & $22 \%$ \\
\hline Infltrateipieumonia & $142 \%$ & $15 \% \%$ & 6.6\% & $84 \%$ & $11 \%$ \\
\hline Pleciralefiusion & $72 \%$ & $168 \%$ & $179 \%$ & $19.1 \%$ & $18 \%$ \\
\hline Gephalization of vossols & $80 \%$ & $66.3 \%$ & $17,4 \%$ & $330 \%$ & $31 \%$ \\
\hline Cardiomegal & $183 \%$ & $69.5 \%$ & $33.3 \%$ & $330 \%$ & $24 \%$ \\
\hline 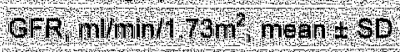 & $740 \pm 303$ & $80.7 \pm 227$ & $967+30.0$ & $551 \pm 235$ & $725 \pm 3118$ \\
\hline Troponin T nglmil mean $+\mathrm{SB}$ & $004 \pm 026$ & $000+027$ & 025113 & 0201064 & $012+062$ \\
\hline
\end{tabular}


Figure 1: NT-proBNP values between diagnostic groups in the lCON study:

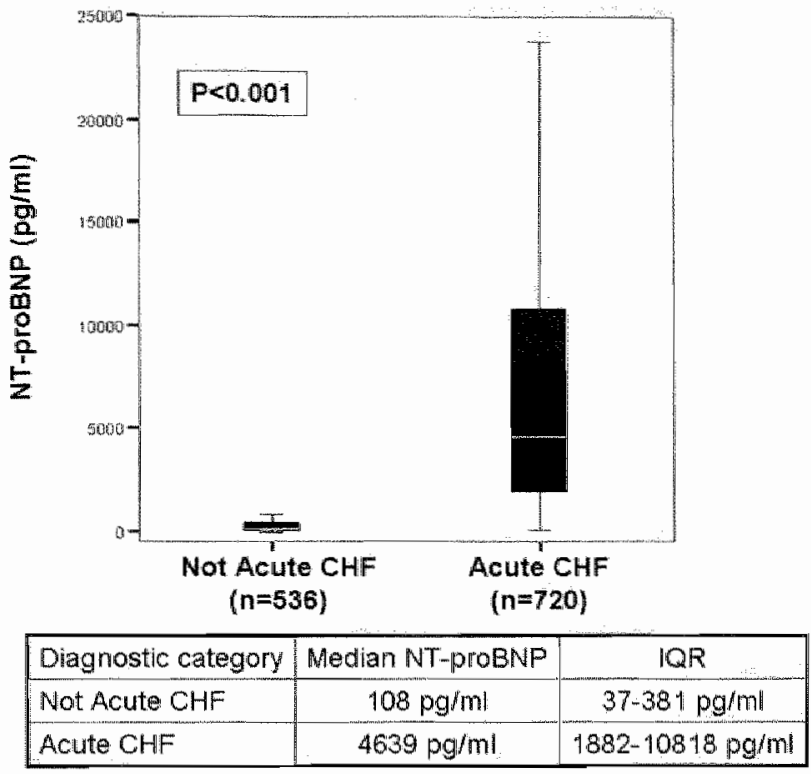

Figure 2: Median NT-proBNP concentrations in subjects with acute heart falure, expressed as a function of New York Heart Association (NYHA) symptom severity. Boxes represent inter-quartile ranges, while whiskers the $5^{\text {th }}$ and $95^{\text {th }}$ percentile in each category

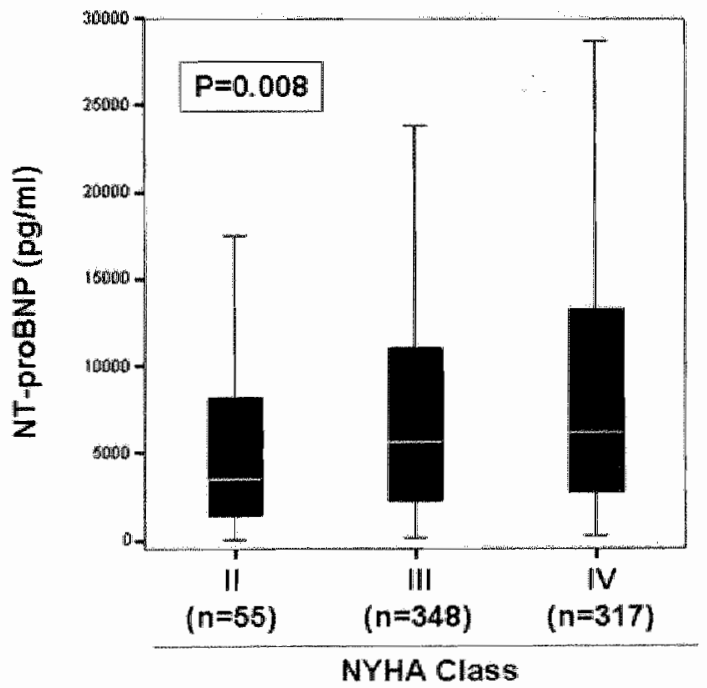

\begin{tabular}{|l|c|c|}
\hline NYHA Class & Median NT-proBNP & IQR \\
\hline II & $3512 \mathrm{pg} / \mathrm{ml}$ & $1395-8588 \mathrm{pg} / \mathrm{ml}$ \\
\hline III & $5610 \mathrm{pg} / \mathrm{ml}$ & $2260-11001 \mathrm{pg} / \mathrm{ml}$ \\
\hline IV & $6196 \mathrm{pg} / \mathrm{ml}$ & $2757-13295 \mathrm{pg} / \mathrm{ml}$ \\
\hline
\end{tabular}




\section{Effect of Left Ventricular Ejection Fraction}

Of the 720 subjects in ICON with acute HF, $655(91 \%)$ had available left ventricular ejection fraction data. The relationship between left ventricular ejection fraction and NT-proBNP among subjects with acute HF in ICON is demonstrated in Figure 3; among these subjects a modest, but significant relationship existed between ventricular function and natriuretic peptide concentrations $(r=-0.289, p<0.001)$.

Figure 3: Linear regression relationship between systolic and NT-proBNP concentrations in the 655 subjects with acute heart failure and available left ventricular ejection fraction data.

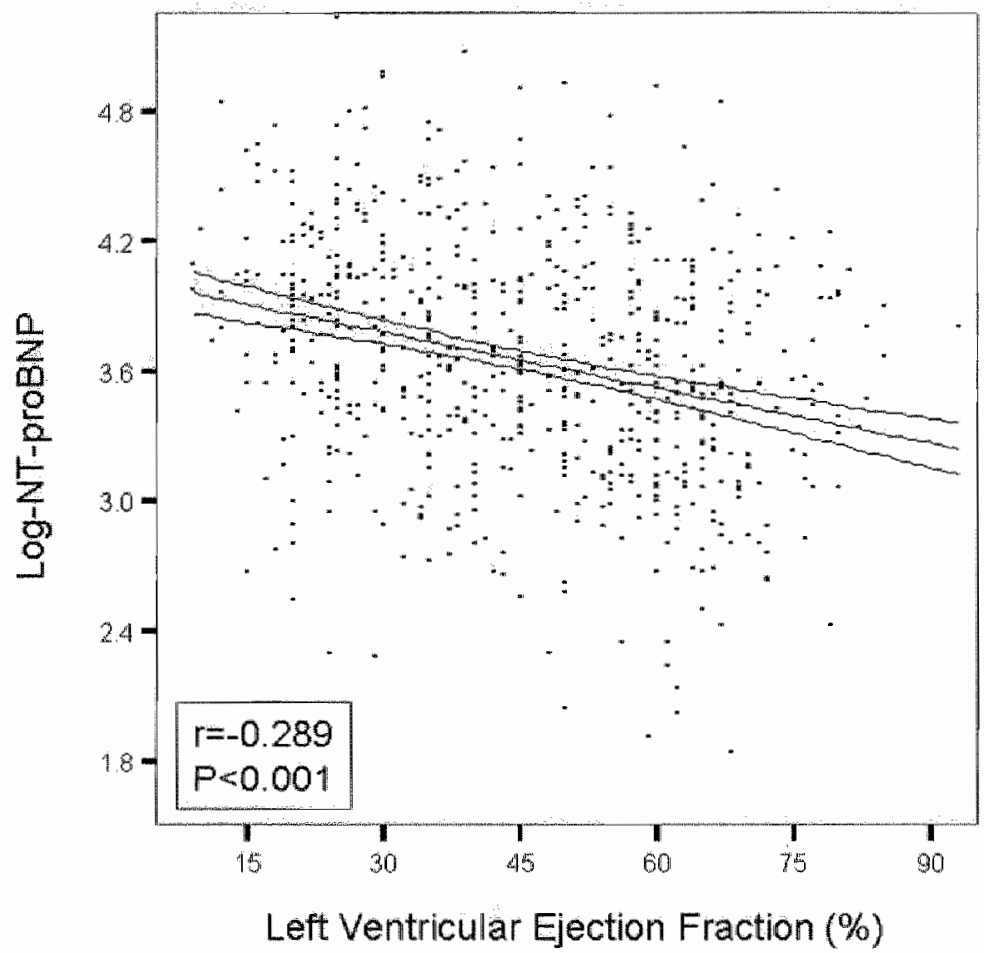

Of those with available ejection fraction data, when categorized using a left ventricular ejection fraction of $50 \%, 293(45 \%)$ subjects had preserved systolic function, while the balance had acute HF with impaired systolic function. Those subjects with acute HF but preserved left systolic function had lower NT-proBNP concentrations $(3070 \mathrm{pg} / \mathrm{ml}$, $\mathrm{IQR}=1344-7974 \mathrm{pg} / \mathrm{ml}$ ) when compared to those with impaired systolic function (6536 $\mathrm{pg} / \mathrm{ml}, \mathrm{lQR}=2777-13407 \mathrm{pg} / \mathrm{ml}, \mathrm{p}<0.001$ for difference). The overall sensitivity of NTproBNP in subjects with preserved systolic function was $84 \%$, compared to $92 \%$ in those with impaired systolic function. Of the subjects with non-systolic HF below the threshold for diagnosis, $7(2.4 \%)$ had NT-proBNP concentrations below $300 \mathrm{pg} / \mathrm{ml}$. 


\section{Cut-point Analysis: Identification of Acute HF}

Following bootstrapping methodology with a goal of optimal diagnostic accuracy across the wide age range in ICON, we selected cut-points emphasizing strong sensitivity for younger subjects, strong specificity for older subjects, and a balance of both for subjects at intermediate age ranges. In order to optimally confirm the diagnosis of HF, we found that dividing patients into 3 age groups (of $<50$ years, $50-75$ years, and $>75$ years) yielded the optimal diagnostic accuracy, balanced with ease of use. Bootstrapping methods demonstrated that this 'triple cut point' strategy was superior to using a single, age-independent cut point (of $1243 \mathrm{pg} / \mathrm{ml}$ ).

Notably, while female gender was associated with a trend towards higher median NTproBNP levels among patients without acute HF (190 vs $160 \mathrm{pg} / \mathrm{ml}, \mathrm{p}=0.12)$, the median and inter-quartile ranges (IQR) of NT-proBNP concentration in female patients with acute $\mathrm{HF}(\mathrm{n}=350 ; 5801 \mathrm{pg} / \mathrm{ml}, \mathrm{IQR}=2300-12149 \mathrm{pg} / \mathrm{ml})$ were not significantly higher than those in male patients with acute HF ( $\mathrm{n}=370 ; 5645 \mathrm{pg} / \mathrm{ml}, \mathrm{IQR}=2411-11215$ $\mathrm{pg} / \mathrm{ml} ; \mathrm{p}=0.66$ ), and there was no further advantage in sensitivity by adding gender stratification to age.

Example ROC curves derived from the proposed "age-alone" diagnostic strategy are depicted in Figure 4. Among those patients $<50$ years $(n=184), 50-75$ years $(n=537)$ and $>75$ years of age $(n=535)$, NT-proBNP had an area under the ROC curve of $0.99,0.93$, and 0.86 for the diagnosis of acute $H F$ (all $p<0.0001$ ).

Figure 4: Receiver operating characteristic (ROC) curves for NT-proBNP based diagnosis of acute heart failure across three age groups. As depicled, NT-proBNP had high area under the curve (AUC) in each age group.

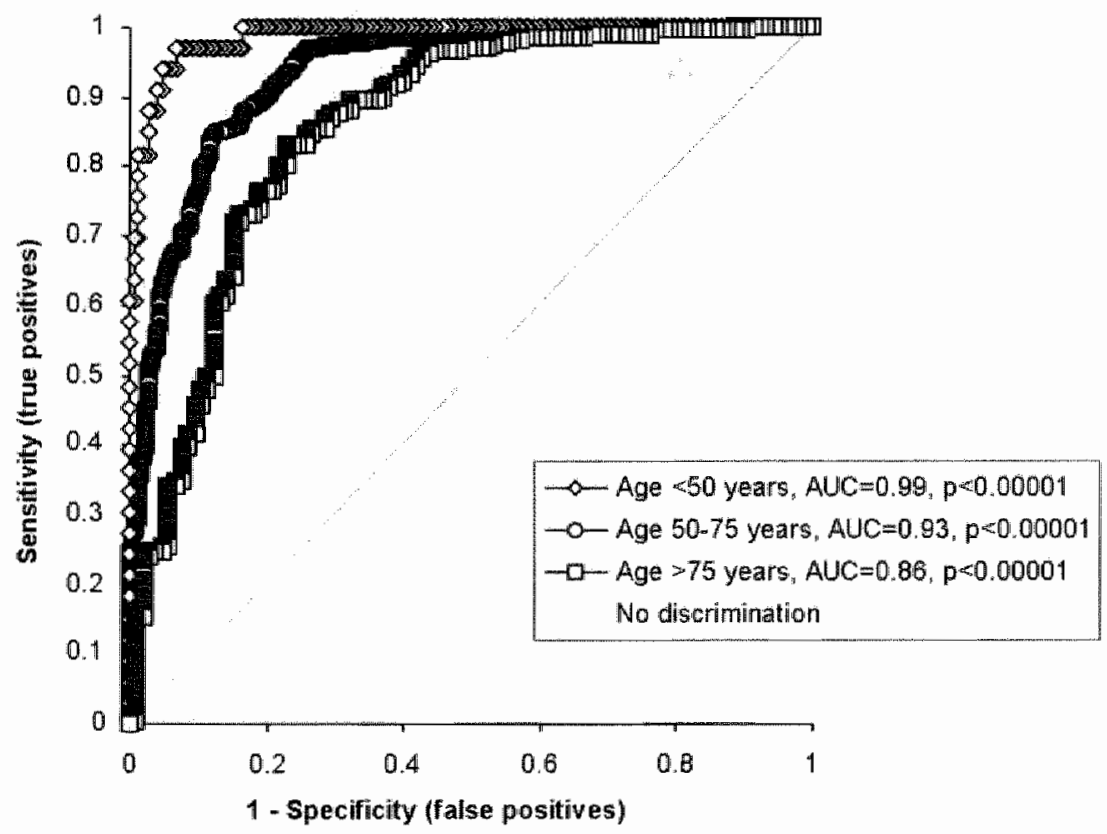


The bootstrap-validated optimal cut-points (with $95 \%$ Cl) were estimated to be 450 $\mathrm{pg} / \mathrm{ml}(145,1463 \mathrm{pg} / \mathrm{ml}), 900 \mathrm{pg} / \mathrm{ml}(676,1244 \mathrm{pg} / \mathrm{ml})$, and $1800 \mathrm{pg} / \mathrm{ml}(1281,2641$ $\mathrm{pg} / \mathrm{ml}$ ) for the identification of acute HF in subjects aged $<50,50-75$, and $>75$ years. The diagnostic sensitivities, specificities, positive and negative predictive values (PPV, MPV), and accuracies for these age-alone confirmatory cut points are depicted in Table 2. Overall, this confirmatory strategy was associated with a sensitivity of $87 \%$, a specificity of $83 \%$, and a PPV of $86 \%$. The accuracy for confirming acute HF using this strategy was $85 \%$.

Table 2: Optimal NT-proBNP cut-points for the diagnosis or exclusion of acule HF among dyspneic patients

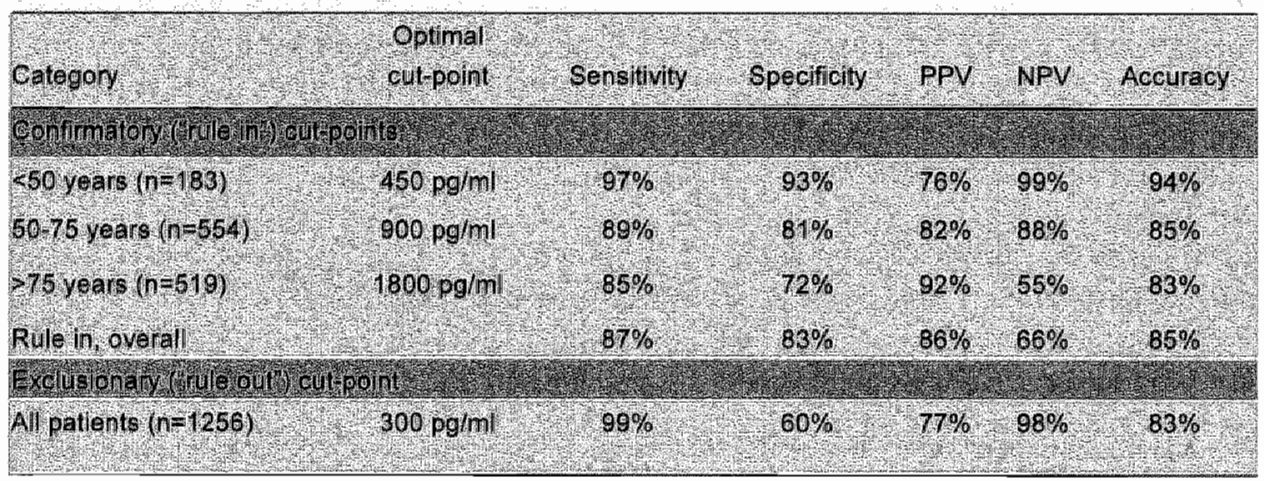

\section{Cut-point Analysis: Exclusion of Acute HF}

In recognition of the value of NT-proBNP for the exclusion of acute $\mathrm{HF}$, we examined the manufacturer's recommended cut-points of $125 \mathrm{pg} / \mathrm{m}$.l for patients $<75$ years of age and $450 \mathrm{pg} / \mathrm{ml}$ for those $\geq 75$ years of age, and found them to have an overall NPV of 95\%. After examining numerous age-telated cut-point strategies, we found that using an age-independent approach for "ruling out" acute $\mathrm{HF}$ in our cohort was superior, with a single cut-point of $300 \mathrm{pg} / \mathrm{ml}(95 \% \mathrm{Cl}=241,369)$ demonstrating a sensitivity of $99 \%$, specificity of $60 \%$, and a NPV of $98 \%$ (also Table 2).

\section{Prognostic Implications of NT-proBNP}

Among the 1256 subjects in the present analysis, $109(8.6 \%)$ died within 76 days of presentation. Of these, $89(81.7 \%)$ had acute HF. Among these patients with acute $\mathrm{HF}$, the median NT-proBNP levels were higher in those patients dying by 76 days of followup $(10426 \mathrm{pg} / \mathrm{ml}, \mathrm{IQR}=5611-23818 \mathrm{pg} / \mathrm{ml}$ ) compared to those surviving ( $4873 \mathrm{pg} / \mathrm{ml}$, $\mathrm{IQR}=2204-10897 \mathrm{pg} / \mathrm{ml} ; \mathrm{p}<0.001$ for difference). 
ROC analyses were performed in an effort to identify optimal NT-proBNP cut-points for prediction of short-term mortality in acute HF. Among those patients with acute $\mathrm{HF}$ $(\mathrm{n}=720)$, ROC analysis of NT-proBNP to predict short-term mortality had an AUC of $0.76(\mathrm{p}<0.0001)$; the optimal NT-proBNP cut-point for predicting 76 day mortality in patients with acute HF was $5180 \mathrm{pg} / \mathrm{ml}$, which was $68 \%$ sensitive, and $72 \%$ specific for predicting short-term death, with a PPV of $19 \%$ and a NPV of $96 \%$.

\section{Multivariable Analysis: Mortality}

Top candidates predictive of mortality in acute HF based on bootstrap replications are detailed in Table 3, and included results from testing of cTnT, NT-proBNP, hemoglobin, and renal function, as well as age. These candidates were then entered into multivariable logistic regression analyses to determine their significance for predicting mortality in acute HF. Though significant in multivariable analyses, both age ( $\mathrm{OR}=1.03$, $95 \% \quad \mathrm{Cl}=1.0-1.05, \mathrm{p}=0.02)$ and serum creatinine $(\mathrm{OR}=1.35,95 \% \mathrm{Cl}=1.02-1.81$, $\mathrm{p}=0.036$ ) were rejected on the basis of the strict Bonferroni criterion of tail $\mathrm{p} \leq 0.01$. Accordingly, the final independent predictors of 76-day mortality in acute HF are detailed in Table 4; for patients with acute $\mathrm{HF}(\mathrm{n}=720)$, the independent predictors of death by 76 days were hemoglobin $(\mathrm{OR}=0.92,95 \% \mathrm{Cl}=0.87-0.97), \mathrm{cTnT}>0.03 \mathrm{ng} / \mathrm{ml}$ $(\mathrm{OR}=3.4,95 \% \mathrm{Cl}=1.6-5.2)$, and NT-proBNP $>5180 \mathrm{pg} / \mathrm{ml}(\mathrm{OR}=5.2,95 \% \mathrm{Cl}=2.2-8.1)$.

Table 3: Top five candidate predictors of mortality in subjects. with acute HF, based on 100 bootstrap replications. As cTnT values were missing in $48(6.7 \%)$ subjects, bootstrap replications were first performed without cTnT results (and are displayed, A), followed by the subsequent analysis in the presence of $c T n T$ values $(B)$.

A

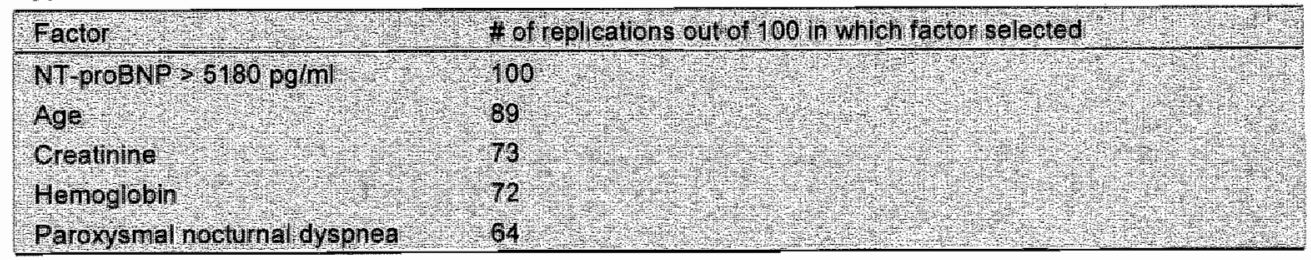

\section{B}

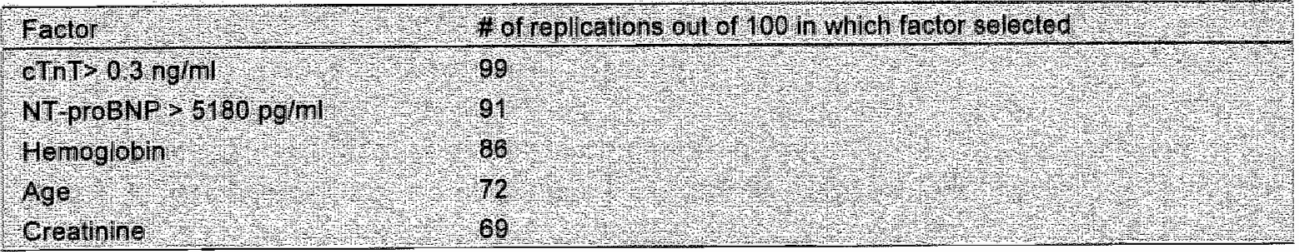


Table 4: Independent predictors of 76 day mortality among those with acule HF. Neither age, nor New York Heart Association classification were independent predictors of short-term death in the presence of NT-proBNP results.

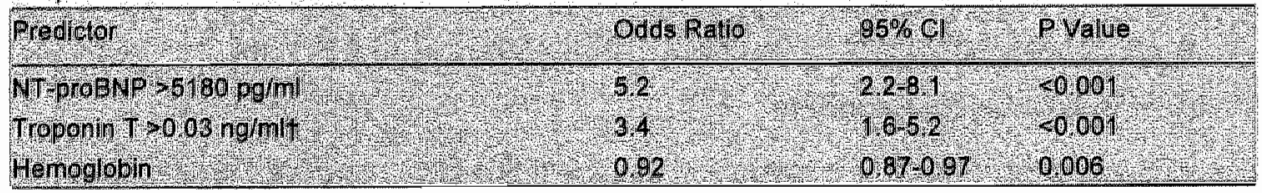

tTroponin T results missing in $48(6.7 \%)$ subjects

Kaplan-Meier curves depicting the differences in 76-day mortality rates between those patients with acute $\mathrm{HF}$ above and below the threshold of $5180 \mathrm{pg} / \mathrm{ml}$ are demonstrated in Figure 5. By 76 days, a significant difference in survival existed between the two groups ( $\log$ rank $\mathrm{p}<0.00001$ ), the curves for which diverged early and continued to separate by the end of the 76 day period.

Figure 5: Kaplan-Meier curves demonstrating survival rates of patients with acute heart faillure $(\mathbb{N}=720)$ during the first 76 days following presentation, expressed as a function of NT-proBNP concentration (log rank test $0 \times 0.001$ ).

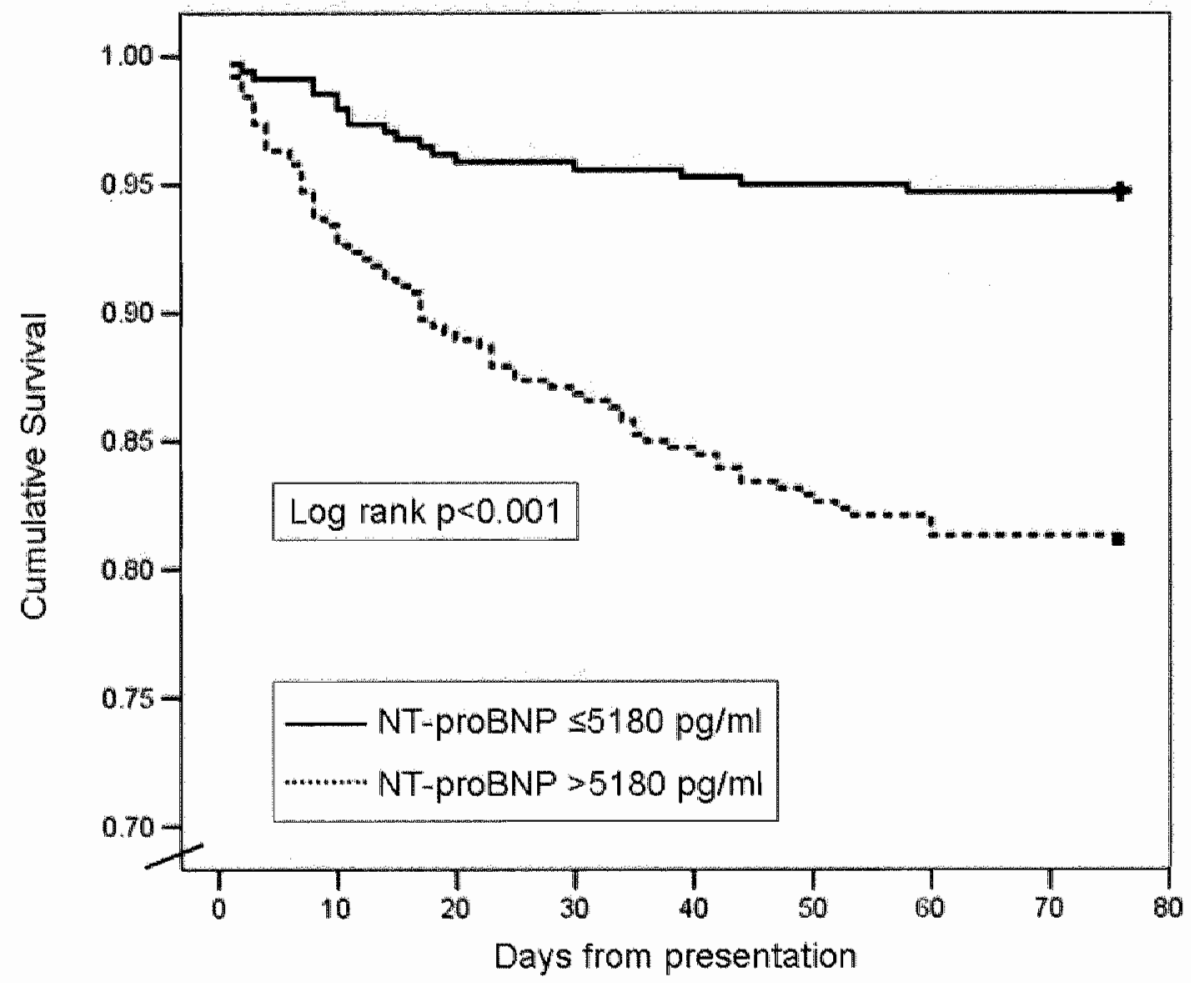




\section{DISCUSSION}

Our results demonstrate the importance of NT-proBNP for the diagnosis and exclusion of acute HF in dyspneic patients, and offer guidance regarding the importance of agestratification for improving diagnostic sensitivity for younger patients, while preserving the specilicity of the test for older patients with dyspnea and suspected acute HF. Also, in our dataset, the presenting NT-proBNP was not only useful for diagnosis, but also strongly predicted likelihood for short-term mortality in subjects with acute $\mathrm{HF}$, with a more than five-fold increase in risk for death by 76 days among those with marked elevation in NT-proBNP concentrations.

The importance of age stratification to improve the accuracy of natriuretic peptide testing to confirm the diagnosis of acute HF is supported by the observation of a direct relationship between age and levels of both NT-proBNP and BNP. ${ }^{11-13}$ This relationship between age and natriuretic peptide levels is likelly consequent to age-related changes in left ventricular compliance, ${ }^{1.4}$ as well as decreasing GFR. ${ }^{15}$ Notably, while age stratification improves the ability of NT-proBNP to identify a high likelihood for acute $\mathrm{HF}$, we found no need for age stratification to exclude the diagnosis. The confirmation and exclusion cut-points for NT-proBNP will help clinicians more confidently utilize the marker in the evaluation of the dyspneic patient, preserving sensitivity for younger patients with suspected HF, while optimizing specificity for elderly patients. While agestratification for identifying acute HF might be expected to potentially increase the risk for a higher proportion of older subjects falling below the cut-points identifying acute HF, but above the cut point excluding the diagnosis (a phenomenon referred to as the 'gray zone' for natriuretic peptides), our data demonstrates that in fact the overall incidence of a 'gray zone' diagnosis was only $16 \%$, actually less than the $26 \%$ incidence reported for BNP, using a single cut-point. ${ }^{16}$ In the situation of a 'gray zone' diagnosis, clinical judgment is often necessary to ascertain the correct diagnosis, ${ }^{1,3}$ including consideration of situations in acute HF with lower than expected NT-proBNP concentrations, such as non-systolic $\mathrm{HF}^{17}$ and obesity. ${ }^{18}$ Indeed, in our analysis, those subjects with non-systolic HF had significantly lower NT-proBNP concentrations, with reduced sensitivity for confirming acute $\mathrm{HF}$. Notably, among those with non-\$ystolic HF below the threshold for acute $H F$, $>97 \%$ had an NT-proBNP value above the "rule out' cut-point of $300 \mathrm{pg} / \mathrm{ml}$.

The large number of patients in our study both with and without acute HF afforded us the opportunity to further examine the relationship between gender and NT-proBNP levels. It is well-known that among healthy subjects NT-proBNP levels ate higher in older female subjects compared to age-matched male subjects, ${ }^{12,19}$ possibly due to at higher prevalence of diastolic abnormalities or more significant age-related reductions in GFR in women. No significant gender-related differences in median or inter-quartile NT-proBNP levels were noted among our patients with or without acute $\mathrm{HF}$, and the addition of gender stratification to age added no further diagnostic value for evaluating subjects.

The admission NT-proBNP concentration was so strongly predictive of short-term mortality among our patients with acute $\mathrm{HF}$ that its presence in multivariable models overwhelmed the prognostic impact of other traditional risk factors for mortality such as age or NYHA classification. The importance of NT-proBNP testing for prognosis 
among outpatients with chronic HF was recently described, ${ }^{20-22}$ however the role of NTproBNP testing for risk stratification for patients with an acute exacerbation of heart failure remained incompletely understood. Most prior analyses examined the risk associated with persistent post-treatment elevation of NT-proBNP, ${ }^{23,24}$ and were restricted to a relatively small number of subjects. In one study, baseline NT-proBNP levels did not appear to predict short-term hazard. ${ }^{24}$ In contrast, our study is more powered for such an analysis, and demonstrates the importance of NT-proBNP concentration at presentation: although NT-proBNP was nearly universally elevated among patients with acute HF, among all factors analyzed, marked elevation of NTproBNP (essentially just above the median NT-proBNP concentration in our HF patients) was the single strongest predictor of death by just slightly longer than 2 months from presentation. Our data thus establish the importance of NT-proBNP at presentation not only for diagnosis, but also simultaneous short-term risk assessment in acute HF.

With data now supportive of the utility of NT-proBNP in a wide variety of cardiovascular states the importance of this marker is established. While comparative studies are limited in number, ${ }^{8,25,26}$ both NT-proBNP and BNP appear to deliver important diagnostic and prognostic information in a wide variety of patient types; the choice of which marker to use should be based on the differences in analytical performance, the needs of the institution utilizing the assays, and individual clinician comfort with the results from the assays.

Limitations of our study include the fact as a pooled analysis it lacks predefined endpoints, despite the similar designs and goals of the respective data sources. In this setting, the possibility of chance observations may be increased. ${ }^{27}$ In addition, nearly half of the subjects were derived from a single study, ${ }^{\prime}$ with attendant effects on demographics and results of the pooled analysis. While every patient in the ICON study was dyspneic, further stratification of subjects using the NYHA classification represents a subjective measure, influenced by numerous factors, including the opinion of the caregiver evaluating the subject. Indeed, the inadequacy of physician-estimated measures of disease severity in acute $\mathrm{HF}$ are well-described, ${ }^{28}$ and may explain, in part, the significant overlap of NT-proBNP concentrations between NYHA classifications in ICON. Lastly, the cut-points proposed by the present study for identifying or excluding acute $\mathrm{HF}$ are similar to those from the PRIDE study, ${ }^{\prime}$ with the exception of the addition of $1800 \mathrm{pg} / \mathrm{ml}$ for those $>75$ years. Notably, however, the addition of this cut-point is relevant, as the age-related effects on NT-proBNP results are significant, and the average age of patients with acute $\mathrm{HF}$ is rising.

In conclusion, in the first large-scale international analysis of NT-proBNP testing for evaluating patients with suspected acute HF, we demonstrate the utility of NT-proBNP testing for both diagnosis and exclusion of acute HF. As well, we demonstrate the value of NT-proBNP for the short-term estimation of risk for mortality in acute HF.

\section{Acknowledgements}

The authors wish to thank John Newell for expert statistical assistance, as well as the co-investigators and staff at their respective institutions. The ICON Study was supported in part by an unrestricted grant from Roche Diagnostics, Inc. 


\section{REFERENCES}

1. Januzzi, J.L., C.A. Camargo, S. Anwarwddin, A.L. Baggish, A. Chen, D. Krauser, R. Tumg, R, Camerom, I.T. Nagurney, D.M. Lloyd-Jones, C.U. Chae, S.F. Melanson, P. SIuss, E.L. Lewandrowsk, and K. D. Lewandrowski, The N-teminal ProBNP Investigation of Dyspnea in the Emergenoy Deparment (PRIDE) Sudy. Am J Cardioll, 2005;95948-54.

2. Maisel, A.S., P. Krishnaswany, R.M. Nowak, J. MaCord, I.E. Hollander P. Duc, T. Oniand, A.B. Storrow, W.T. Abraham, A.H. Wu, P. Clopton, P.G. Steg, A. Westheim, C.W. Kmulsen, A. Perez, R. Kazanegra, H.C. Hermann., and P.A. McCullough, Rapid measunement of B-type natriuretio peptide in the emergency diagnosis of heart lailure. N Engl J Med, 2002;347:161-7.

3. McCullough, P.A., R.M. Nowak, J. McCord, J.E. Hollander, H.C. Herman, P.G. Sitg, P. Dine, A. Westheim, T. Omland, C.W. Knudsem, A.B. Stomow, W.T. Atbraham, S. Lamba. A.H. Whi, A. Perez, P* Clopton, P. Krishraswamy, R. Kazanegra, and A.S. Maisel, B-type natriuretic peptide and clinical judgment in emergency diagnosis of heart failure: analysis from Breathing Not Properly (BNP) Multingtional Siudy. Circulation, 2002; 106:416-22.

4. Christenson, R., F. Apple, C. Cannon, G. Francis, R. Jesse, D. Mortow, L.K.R. Newby, J. A. Storrow, H.W. Tang, and A. Wu, National Assocation of Clinical Biochenisuy Laboratory Medicine Practice Guidelines: Biomamers of Acue Coronary Syndrome and Heat fallume. int htip:/Www nacb.org/lmpg/card_biomarkers_LMPG_draft_PDF.stu. 2004.

5. Liu, P., J.M. Arnold, I. Belenkie, C. Demers, P. Dorian, N. Gianeti, H. Haddad, I. Howlett, A. Ignazewski, P. Jong, R, Mckelwie, G. Moe, J.D. Parker, V. Rao, J.L. Rouleau, K. Teo, Kx, Tsuyuki, M. White, V. Huckel, D. Issac, D. Johnstone, M.H. LeBlanc, H. Lee, G. Newton, J. Niznick, H. Ross, S. Roth, D. Roy, S. Smith, B. Sussex, and S. Yusul, The 2002/3 Canadian Cardiovascular Society consensus guideline update for the diagnosis and managenent of heart hilure. Can $f$ Cardiol, $2003 ; 19: 347-56$

6. Remme, W. A. and K. Swedberg, Guidelines for the diagnosis and treatment of chronic heart failure. Etur Heart J, 2001;22:1527-60.

7. Bayes-Genis, A., M. Santalo-Bel, E. Zapico-Muniz, L. Lopez, C. Cotes, J. Bellido, R. Leta "P. Casan, and 1. Ordonez-Llanos, $\mathrm{N}$-terminal probrain natriuretic peptide (NT-proBNP) in the emergency diagnosis and in-hospital monitoring of patients with dyspnoea and ventricular dystunction. Eur I Heat Fail, $2004: 6: 301-8$.

8. Lainchbury, J.G., E. Campbell, C.M. Frampton, T.G. Yandle, M.G. Nicholls, and A.M. Richerds, Brain natriuretic peptide and n-terminal brain natruretic peptide in the diagnosis of heart Gilure in palients with acute shortness of breath. If Am Coll Cardial, 2003;42:728-35.

9. Levey, A.S., J.P. Bosch, J.B. Lewis, T. Greene, N. Rogers, and D. Roth. A more arechrate method to estimate glomerulan filtation rate from serum creatinine: new prediction equation. Modifucat ion of biel in Renal Disease Study Group. Ann Intern Med, 1999;130:461-70.

10. Endin, M., C. Passino, S. Del Ry, C. Prontera, F. Galet an, and A. Clorico, lnfuence of gender on circulating cardiac natrituretic homones in patients with heart failue. Clin Chem Lab Med, 2003; 41 : $686-92$

11. Raymond, I. B.A. Groennung, P.R. Hidebrandi, J.C. Nilsson, M. Baumanm, J. Trawinsthi, wnd F" Pedersen. The influence of age, sex and other variables on the plasmatevel of N-terninal pro brain matriuretic peptide in a large sample of the general population. Heart, 2003; 89:745-51.

12. Redfield, M.M., R.J. Rodeherfer, S.J. Jacobsen. D.W. Mahoney, K.R. Bailey, and J,C. Bument, Jr. Plasma brain natriuretic peptide concentration: impact of age and gender, I Am Coll Cardiol, 2002 , $40.976-82$

13. Ray, P., M. Arthad, Y. Lefort. S. Birolleat, C. Beigellman, and B. Riou, Usefuhess of B-Hpe natriuretic peptide in elderly patients with acute dyspnea. Intensive Care Med, 2004;30:2230-6

14. Arbab-Zadeh, A.. E. Dijk, A. Prasad, Q. Fu, P. Torres, R. Zhang, J.D. Thomas, D. Pstmot. and B.D. Levine, Effect of aging and physical activity on lef vatricula complance. Circulation, 2004; 110: $1799-805$.

15. McCullough, P.A., P. Duc, T. Omland, J. McCord, R. M. Nowak, I.E. Hollander, H.C. Herrmann, P.G. Steg, A. Westheim, C.W. Knudsen, A.B. Storrow, W.T. Abrathan, S. Uamba, A.H. Wu, A. Petez, P. Clopton, P. Krishnaswamy, R. Kazanegra, and A.S. Maisel. B-type natritretic peplide and renal function 
in the diagnosis of heart failore: an analysis from the Breathing Not Properly Mulinational Study. Am J Kidney Dis, 2003:41:571-9.

16. Knudsen, C.W., P. Cloplon, A. Westhem, T.O. Ktemsdal, AH. Wu. P. Due, J. McCord, R.M. Nowak, J.E. Hollander, A.B. Storow, W. T. Abraham, P.A. MoCullough, A.s. Massel, and T. Onuand, Predictors of elevated B-ype ndrurethe peptide concentrations in dyspne patients withoui heart fallure: an analysig from the breathing not properly multinational study. Ann Emerg Med, $2005,45,573 \times 80$.

17. O'Donoghue, M. A. Chen, A.C. Baggist, 5. Anwaruddin, D. G. Krauser, R. Tung, and J.L. Januzzi, The Effects of Ejection foration on N-Terminal ProBNP and BNP Levels in Pationts with Acute CHF: Anallysis Trom the ProBNP Investigation of Dyspnea in the Emergency Department (PRIDE) Study. I Card Pail $2005: 1 \|$ (5 Suppl) $9-14$.

18. Kraiser, D.G, D.M. Lloyd-Jones, C.U. Chae, R. Cameron, S. Anwaruddin, A.l Baggish, A. Chen, R. Tung, and J.L. Januzzi, Effect of body mass index on natruretic peptide levels in patients with acute congestive heart failure: A ProBNP Unvestigation of Dyspnea in the Emergency Deparment (PRIDE) substudy. Am Heart J,2005;149:744-50.

19. Mclonagh, T.A., S. Holmetr, I. Raymond, A. Luchner, P. Hildebrant, and H.J. Dargie, NT-proBNP and the diagnosis of heart fallure: a pooled analysis of thee Buropean epidemiological situdies. Eur J Heart Fail, $2004,6: 269-73$.

20. Hartmarn, F., M. Packer, A.J. Cosits, M.B. Fowler, H. Krum, P. Mohacsi, JL. Rouleau, M. Tendera, A. Castaigne, SD. Anker, 1. Amann-Zalan, S. Hoersch, and H.A. Katus, Prognostic impact of plasma Nterminal pro-brain natruretic peptide in severe chronic congestive hear fallure: a substudy of the Carvedilol Prospective Randonized Cumulative Survival (COPERNICUS) trial, Circulation, $2004 ; 110: 1780-6$.

21. Groenning, B.A., I. Raymone, P.R. Hildebrandt, J.C. Milsson, M. Baumann, and F. Pedersen, Diagnostic and prognostic evaluation of left ventricular systolic heart failure by plasma $N$-terminal pro-brain natrituretic peptide concentrations in a large sample of the general population. Heart, 2004; 90:297-303.

22. Gardner, R.S., F. Ozall D. A.J. Murday, S.D. Robb, and T“.A. McDonagh, N-terminal pro-brain natriuretic peptide. A new gold standard in predicting mottality in patients with advanced heart failure. Eur Heart 1 , $2003 ; 24: 1735-43$.

23. Bettencourt, P. A. Azevedo, J. Pimenta, F. Frioes, S. Ferreira, and A. Ferreira, N-terminal-pro-brain matriuretic peptide predicts outcome after hospital discharge in heart failure patients. Circulation, 2004; $110: 2168-74$

24. O'Brien, R.J., I.B. Squire, B. Denme, J.E. Davies, and L.L. Ng, Pre-discharge, but not admission, tevels ol NT"-proBNP predict adverse prognosis following acute LVF. Eur J Heart Fail, 2003;5:499-506.

25. Mucller, "T., A. Gegenhuber, W. Poelz, and M. Haltmayer, Head-to-head comparison of the diagnostic utility of $\mathrm{BNP}$ and $\mathrm{NT}^{\mathrm{T}}$ proBNP in symptomatic and asymptomatic struetural heart disease. Clin Chim Acta, 2004:341:41-8.

26. Yea, K.T", A.H. Wu, F.S. Apple, M.H. Kroll, R.H. Christenson, K.B. Lewandrowski, F.A. Sedor, and A.W. Butch, Multicenter evaluation of the Roche NT-proBNP assay and comparison to the Biosite Triage BNP assay. Clin Chim Acla, 2003;338:107-15.

27. Broply, JM., G.R. Dagenais, F. MoSherry, W. Williford, and S. Yusuf, A mulivariate model for predicting mortality in patients. with hear failute and systolic dyshuction. Am 』 Med, 2004;116:300-4.

28. Maisel, A., J.E. Hollander, D. Guss, P. McCullough, R. Nowak, G. Green, M. Saltzberg, S.R. Ellison, M.A. Bhalla, V. Bhalla, D. Clopton, and R. Jesse, Primary results of the Rapid Emergency Department Hoat Cafure Oupatient Trial (REDHOT). A multicenter study of B-type natrinatic peptide levels, omergency department decision making, and outcomes in patients presenting with shortmess of breath. I An Coll Cardiol, 2004:44:1328-33. 
Dyspnea with Intermediate Amino-terminal pro-Brain Natriuretic Peptide concentrations: A Comprehensive Analysis

R van Kimmenade", Y Pinto", A Bayes-Genis", J Lainchbury", A Richards", James L Januzzi Jill

*University Hospital Maastricht, Maastricht, The Netherlands

†ospital de la Santa Creu i Sant Pau-ICCC, Barcelona, Spain.

FChristchurch School of Medicine and Health Science, Christchurch, New Zealand

Massachusetts General Hospital, Boston, USA

American Journat of Cardiology 2006; in press 


\section{ABSTRACT}

Aims: Age-stratified cut-points for amino-terminal pro-brain natriuretic peptide (NT-proBNP) concentrations are diagnostic in $83 \%$ of all subjects with acute dypnea. We analyzed the subjects with NT-proBNP concentrations between the 'rule-out' and 'rule-in' cut-points, the so-called 'grey zone'.

Methods: We studied NT-proBNP concentrations, clinical characteristics and 60-day mortality in 1,256 acutely dyspneic patients from an international multi-center study.

Results: Of all subjects, 215 had 'grey zone' NT-proBNP concentrations, of which $₫ 16$ subjects $(54 \%)$ were diagnosed with heart failure(HF). Among these subjects, HF patients were more likely to be older, to have a history of $\mathrm{HF}$, to be in atrial fibrillation and to have elevated troponin T concentrations, when compared with those without HF. In multivariate analysis, the use of loop diuretic on presentation $(O R=3.99$; $95 \% \mathrm{CI}=1.58-10.1, \mathrm{p}=0.003)$, paroxysmal nocturnal dyspnea, $(\mathrm{OR}=4.50 ; 95 \% \mathrm{CI}=1.31$ $15.4, \mathrm{p}=0.02)$, jugular venous distention $(\mathrm{OR}=3.05 ; 95 \% \mathrm{CI}=1.06-8.79, \mathrm{p}=0.04)$ and the absence of cough $(\mathrm{OR}=0.18 ; 95 \% \mathrm{Cl}=0.06-0.52, \mathrm{p}=0.001)$ were associated with a diagnosis of acute HF among 'grey zone'patients. Subjects with HF and diagnostic NT-proBNP concentrations had the highest mortality rates, subjects without HF and NT-proBNP below $300 \mathrm{pg} / \mathrm{ml}$ had the lowest mortality rates; subjects with 'grey zone' NT-proBNP had intermediate outcomes, irrespective of their final diagnosis.

Conclusions: Adding specific clinical information to NT-proBNP improves diagnostic accuracy among subjects with intermediate NT-proBNP concentrations. Mortality rates in subjects with intermediate NT-proBNP concentrations are lower than those with NT-proBNP concentrations diagnostic for HF, but are higher than in subjects with NT-proBNP concentrations below the 'grey zone'.

Keywords: Natriuretic peptides, Heart failure, diagnosis, prognosis 


\section{INTRODUCTION}

Heart Failure (HF) is a syndrome with increasing prevalence and consequently rising costs for modern western society. ${ }^{1}$ Despite this high prevalence, it may be exceptionally difficult for clinicians to properly diagnose HF in acute dyspneic patients, since history and physical examination may lack sensitivity and specificity. Recently, the serum markers brain natriuretic peptide (BNP) and its amino-terminal pro-peptide (NT-proBNP) were shown to be useful for the diagnostic evaluation of patients with acute dyspnea; ${ }^{2,3}$ results of testing for both peptides proved to be better diagnostic tools than any single clinical parameter, ${ }^{4}$ or clinical judgment without natriuretic peptide testing. ${ }^{3.5}$

Despite the strength of natriuretic peptide testing, one weakness of these useful biomarkers is the fact that a significant percentage of patients with breathlessness may fall above the cut-points associated with a lower likelihood for HF (i.e. above the rule out' threshold), and below those with higher likelihood for diagnosis of the disease (i.e. below the 'rule in' threshold). This situation of intermediate natriuretic peptide elevation, at times referred to as the 'grey zone', has been reported to occur in almost one third of the patients tested with BNP, ${ }^{6}$ and to an extent, relates to the severity of HF, the prevalence of non-systolic $\mathrm{HF}^{\gamma}{ }^{\gamma}$ as well as prevalence of other diagnoses such as acute coronary syndromes (ACS) that are associated with more modest elevations in natriuretic peptide concentrations compared to acute HF. Irrespective of the mechanism, less is understood about the optimal approach to the dyspneic patient with such intermediate elevations of natriuretic peptides.

In a recent report, we published NT-proBNP cut-off values for both the diagnosis or exclusion of acute HF in patients presenting with acute dyspnea, based on our analyses in the International Collaborative Of NT-proBNP (ICON) study. ${ }^{8}$ One reason to ageadjust the diagnostic thresholds was to reduce the risk of a 'false positive' diagnosis of acute HF in an older patient, in whom higher values of NT-proBNP might be expected. This age-stratification might be associated with a higher probability for a patient with an intermediate NT-proBNP concentration, particularly in older subjects. Therefore, in order to better understand the clinical characteristics of those patients with intermediate NT-proBNP concentrations, as well as to better understand the differences between those patients in the 'grey zone' with and without acute HF, we performed the present analysis.

\section{METHODS}

\section{Patients}

The ICON study has been previously published. ${ }^{9}$ Briefly, the study population consists of 1256 patients from three previously reported prospective clinical studies of natriuretic peptide testing for the evaluation of dyspneic subjects, from Christchurch, New Zealand, ${ }^{10}$ Barcelona, Spain, ${ }^{11}$ and Boston, USA, ${ }^{3}$ combined with a registry of consecutively admitted HF patients at the University Hospital of Maastricht, The Netherlands. 
All data sources had compatible inclusion/exclusion criteria, and obtained similar clinical information, including standard demographics, past medical history, drug therapy, presenting symptoms and signs, physical examination, results of laboratory testing, chest $X$-ray information and electrocardiography results. From this study population, using bootstrapping statistical techniques, a strategy of age-dependent cutpoints (i.e. $450 \mathrm{pg} / \mathrm{ml}$ for subjects $<50$ years, $900 \mathrm{pg} / \mathrm{ml}$ for subjects between 50 and 75 years, and $1800 \mathrm{pg} / \mathrm{ml}$ for subjects above 75 years) was optimal to diagnose HF, while an age-independent cut-point of $300 \mathrm{pg} / \mathrm{ml}$ was most useful for excluding the diagnosis of acute HF.

For the purposes of this study, we considered those subjects between $300 \mathrm{pg} / \mathrm{ml}$ and their age-adjusted cut-point to identify acute $\mathrm{HF}$ as being in the 'grey zone'. In this study, we refer to such a situation as an 'intermediate' NT-proBNP' concentration, and use this term interchangeably with 'grey zone'.

\section{Laboratory Analyses}

NT-proBNP levels were determined by an immuno-electrochemilumenescence method (Elecsys ${ }^{\circledR}$, Roche Diagnostics, Switzerland). Creatinine and hemoglobin concentrations were determined by the use of routine tests available in each hospital. Glomerular Filtration Rate (GFR) was calculated with the use of the simplified Modification of Diet in Renal Disease equation. ${ }^{12}$

\section{Statistical Analyses}

Data are presented as medians with intra-quartile ranges (IQR) for non-normally distributed variables and means \pm standard deviations (SD) for all other continuous variables. Differences in baseline variables between two groups were analyzed using the Wilcoxon rank-sum or Mann-Whitney $U$ test for continuous variables and nonparametric $\chi^{2}$ testing for categorical variables.

Univariate screening of baseline variables was used to identify candidate independent predictors of HF. Following, multivariable analysis was performed using forward stepwise logistic regression, including all candidate variables with p-values $\leq 0.10$ in univariable analysis. Goodness of fit was evaluated using the Hosmer-Lemeshow test. Results are presented as odds ratios (OR) with 95 percent confidence intervals (CI).

Survival curves were computed with the Kaplan-Meier curves, and differences between the curves were evaluated with the log-rank statistic. All statistic analyses were performed using SPSS software (Chicago, Ill., USA). P values were considered significant when $<0.05$.

\section{RESULTS}

Of the 1256 overall subjects included in the ICON study, $720(57 \%)$ were diagnosed with acute HF at presentation. Of these acute HF subjects, $604(84 \%)$ had an NT-proBNP concentration that fulfilled their age dependent rule-in criterion. Thus, 116 patients had acute HF and an 'intermediate' NT-proBNP concentration. 
As well, 99 patients with acute dyspnea but without acute $H F$ also had an "intermediate" NT-proBNP concentration. Of the 536 subjects without HF in the ICON study, $437(82 \%)$ had a NT-proBNP concentration below $300 \mathrm{pg} / \mathrm{ml}$.

\section{Identifying Acute HF in Subjects with Intermediate NT-proBNP Concentrations}

Baseline characteristics of the subjects with intermediate NT-proBNP concentrations are shown in Table 1. In total, 215 of 1256 patients (17\%) in the ICON study had an intermediate NT-proBNP concentration in the "grey zone". As mentioned above, 116 patients $(54 \%)$ of these 215 patients were diagnosed with acute HF. Among subjects with intermediate NT-proBNP concentrations, HF patients were more likely to be older and to have a prior history of $\mathrm{HF}$, as well as histories and physical examination findings referable to $\mathrm{HF}$, compared to those without acute $\mathrm{HF}$. Those with acute $\mathrm{HF}$ ' in the "grey zone" were more likely to be in atrial fibrillation than non-HF subjects in the "grey zone', to have chest radiography results consistent with $\mathrm{HF}$, and were more likely to have an elevated troponin T concentration. In contrast non-HF 'grey zone' patients were more likely to have histories, symptorns, and signs consistent with either prior or acute obstructive airway diseases or airway infections. The diagnoses of the grey zone patients who did not suffer from HF as the cause of their acute dyspnea are depicted in Table 2.

Following, in a multivariate analysis that included factors significant in univariate analysis, several factors independently associated with a diagnosis of acute HF among grey zone patients were identified, including the use of loop diuretic on presentation, $(\mathrm{OR}=3.99 ; 1.58-10.1 \quad 95 \% \mathrm{Cl}, \quad \mathrm{p}=0.003)$, complaints of paroxysmal noctumal dyspnea, $(\mathrm{OR}=4.50 ; 1.31-\mathbb{5 . 4} 95 \% \mathrm{CI}, \mathrm{p}=0.02)$, jugular venous distention (OR $=3.05 ; 1.06-8.7995 \% \mathrm{Cl}, \mathrm{p}=0.04$ ) and the absence of a cough (OR=0.18;0.06-0.52 $95 \% \mathrm{Cl}, \mathrm{p}=0.001$ ) (Table 3 ). Notably, in this group of subjects with intermediate NT-proBNP results, none of the radiological signs significant in univariable analysis were significant predictors of $\mathrm{HF}$ in multivariable analysis. 
Table 1: Differences in basidine characteristics of patients with a grey zone NT-proBNP concentration. with or without acule heart fallure.

\begin{tabular}{|c|c|c|c|}
\hline characteristif & $\begin{array}{l}\text { llot Acute he grey zone } \\
(n=99)\end{array}$ & $\begin{array}{l}\text { Acute } 4 F \text { grey rone } \\
(\mathrm{A}=116)\end{array}$ & p-value \\
\hline Male gender & $51 \%$ & 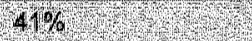 & 019 \\
\hline Age. years (mean 4 sD) & $71(12.4)$ & $77(10.5)$ & 50001 \\
\hline Body Mass index. kglim $^{2}$ (neean + so) & $27(66)$ & $28(62)$ & 0.67 \\
\hline Past medical history & & & \\
\hline Hyperiension. & $49 \%$ & $64 \%$ & 0.32 \\
\hline Goronay Arery Diseasa & $34 \%$ & $51 \%$ & 0.20 \\
\hline Myocardial Infarginon & $16 \%$ & $39 \%$ & 021 \\
\hline pror He & $14 \%$ & $50 \%$ & 001 \\
\hline GopD/asthma & $56 \%$ & $39 \%$ & 0.01 \\
\hline Use of loopdluretic on presentetion & $23 \%$ & $65 \%$ & 0,001 \\
\hline Symptems on presentation & & & \\
\hline Paroxysinal Nocturnal Dyspnea & $0 \%$ & $35 \%$ & $<0.001$ \\
\hline Orthopnea & $22 \%$ & $48 \%$ & 80001 \\
\hline Cough & $53 \%$ & $28 \%$ & 60.001 \\
\hline Fever & $46 \%$ & $5 \%$ & 0.10 \\
\hline NHA Aclass & 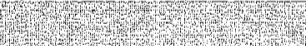 & The & 0.51 \\
\hline & $31 \%$ & $12 \%$ & \\
\hline IIII & $27 \%$ & $48 \%$ & \\
\hline $\mathrm{N}$ & $39 \%$ & $40 \%$ & \\
\hline Signs on presentation & 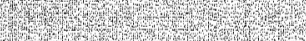 & (2) & \\
\hline JGgular venous distention & $11 \%$ & $47 \%$ & 80,00 \\
\hline Ss Gallop & W\%. & $12 \%$ & 010 \\
\hline Edema. & $23 \%$ & $63 \%$ & 0.01 \\
\hline Rales & $30 \%$ & $64 \%$ & 001 \\
\hline Whegzing & $34 \%$ & 210 & 0.10 \\
\hline Pulse beals perminute (man $\mathrm{s}$ SD & $90(235)$ & $97(23)$ & 0.22 \\
\hline Atrial Eibrillation on Eec & $12 \%$ & $35 \%$ & 50.001 \\
\hline Chest $X$ Ray Findings & & & 2y) \\
\hline Triersilial Edema & $0 \%$ & $32 \%$ & 80.001 \\
\hline Pleural sffision. & $11 \%$ & $24 \%$ & 0.04 \\
\hline Cephalization of vessels & $4 \%$ & $25 \%$ & 0.01 \\
\hline Cardionnegaly & $10 \%$ & $41 \%$ & 0.06 \\
\hline Laboratory rosults & & & \\
\hline Hemeglobin g/dL (mean + sD) & $126(2,15)$ & $125(2.68)$ & 053 \\
\hline Troponin T nglin L (minesh $4 \mathrm{SO})$ & $005(0,243)$ & $018(139)$ & 001 \\
\hline Creatinine muld (mean $4 \mathrm{sq}$ ) & $102(0.356)$ & $0.4(0.43)$ & 088 \\
\hline NT proBNP, pginl (imedian IQR) & $494(386829)$ & $860(6391307)$ & 80001 \\
\hline GFP ninin/ $73 m^{2}($ mean 1 SD) & $76(278)$ & $72(27.6)$ & 089 \\
\hline
\end{tabular}


Table 2: Diagnoses of the patients with an intermediate NT-proBNP concentration but without acute heart failure as cause of their dyspnea. In addition, among those subjects without acute $\mathrm{HF}$ and an intermediate NT-proBNP concentration; prior HF was present in $14 \%$.

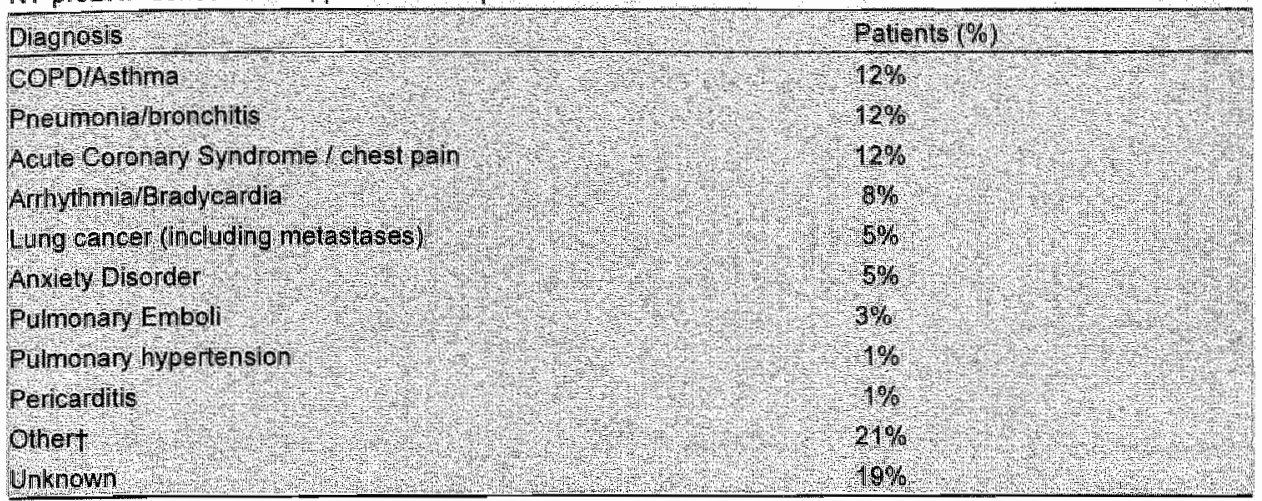

thncludes: anemia, cancer, gastrointestinal pathologies, sleep apnea, septic shock

Table 3: Multivariate analysis shows the factors independently associated with a diagnosis of acute HF among grey zone patients, using fonward step-wise logistic regression.

\begin{tabular}{|c|c|c|c|}
\hline Gharaeteristic & OR & $95 \% \mathrm{Cl}$ & Devalue \\
\hline Cougl & 0.18 & 0.06 .0 .52 & 0.001 \\
\hline Use of loop diuretio on presentation & 3.99 & 158.10 & 0.003 \\
\hline Paroxysmal nocturnal dyspnea & 450 & 132154 & 0.02 \\
\hline Jugular vein distention & 305 & $106-879$ & 0.94 \\
\hline Pror HF & 2.63 & 102680 & 0.06 \\
\hline lower extrenity edema & 206 & $0.94-9.3$ & 106 \\
\hline S3 Gallop & 10.4 & $002-1307$ & 0.07 \\
\hline Pror COPDjesthina & 0.48 & 0201,19 & 0.11 \\
\hline Orthoprea & 206 & 0736.83 & 917 \\
\hline Wheszing & 081 & 029222 & 917 \\
\hline Fever & 134 & 027662 & 072 \\
\hline NYHA class U on admission & 121 & $0,433.42$ & 072 \\
\hline Age & 100 & 100.07 & 092 \\
\hline Edema & Tog & 0.34316 & 096 \\
\hline Arial Fibrillation: & 0,98 & $0,31-308$ & 098 \\
\hline Ghest $x$-ray Findings & & & \\
\hline Intersitial edema & 188 & 060602 & 029 \\
\hline Infltrate, & 0.57 & 0.12264 & 0.7 \\
\hline Pleural effusion. & 168 & $0,48 \cdot 6.65$ & 042 \\
\hline Gephalization of vessels & 2.24 & $0.44-115$ & 0.34 \\
\hline Cardionegaly & 1.53 & $047-506$ & 0.46 \\
\hline
\end{tabular}




\section{Clinical Characteristics of HF Subjects with Intermediate versus Diagnostic NT-proBNP Concentrations}

Baseline characteristics of HF patients as a function of "intermediate' versus diagnostic NT-proBNP concentrations are shown in Table 4. Patients who had diagnostic NT-proBNP concentrations were more likely to be younger and to have a worse renal function, as represented by both higher serum creatinine concentrations and lower GFR. 'Grey zone' patients did not differ significantly from other HF patients in numerous other clinical characteristics. Notably, however, among those subjects with HF and available left ventricular ejection fraction data $(n=655)$, those subjects with 'intermediate' NT-proBNP concentrations had higher left ventricular ejection fractions $(53 \pm 17 \%)$ compared to those with NT-proBNP concentrations diagnostic of HF $(44 \pm 18 \% ; \mathbb{p}<0.001$ for difference between groups).

Table 4: Differences in baseline characteristics between HF patients with a grey zone NT-proBNP concentration, and HF patients with an NT-proBNP concentration that meets their rule-in criterium.

\begin{tabular}{|c|c|c|c|}
\hline Gharacteristio & $\begin{array}{l}\text { HF grey zone } \\
(n=(16)\end{array}$ & $\begin{array}{l}\text { Hf diagnos } \\
(n=604)\end{array}$ & pratise \\
\hline Male gender & $41 \%$ ? & $53 \%$ & 066 \\
\hline Agevears (meant so) & $77(105)$ & $(74(1,7)$ & 0,001 \\
\hline Body miass index, $\mathrm{kg} / \mathrm{m}^{2}$ (mean $+\mathrm{SD}$ ) & $28(62)$ & $27(5,8)$ & 0.46 \\
\hline Past medical history & & 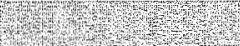 & \\
\hline Mypertension & $64 \%$ & $60 \%$ & 016 \\
\hline Coronary aitey diseaso & $51 \%$ & $63 \%$ & 099 \\
\hline Myogardial infarction & $33 \%$ & $35 \%$ & 046 \\
\hline 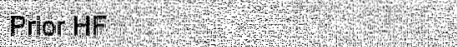 & $50 \%$ & $52 \%$ & 078 \\
\hline Coporastina & $39 \%$ & $27 \%$ & 0.27 \\
\hline Use of loge diliretic on presentation & $65 \%$ & $50 \%$ & 0.34 \\
\hline Symptoms on presentation & & & \\
\hline Papoxysmal nooturnal Dy spriet & $35 \%$ & 310 & 055 \\
\hline Ontheprove & $48 \%$ & 516 & 060 \\
\hline Congil) & $28 \%$ & 327 & 020 \\
\hline Fover. & $5 \%$ & $5 \%$ & 030 \\
\hline NYlA cless & & Pry & 084 \\
\hline 1) & $12 \%$ & $7 \%$ & \\
\hline 11. & $48 \%$ & $48 \%$ & \\
\hline 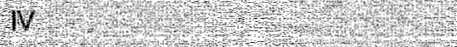 & $40 \%$ & $45 \%$ & \\
\hline Sghs on presentation & & r. & 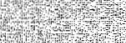 \\
\hline Wiguar venous distention & $47 \%$ & $51 \%$ & 0.50 \\
\hline S3 Gallop & $12 \%$ & $6 \%$ & 0.18 \\
\hline Edema & $63 \%$ & $56 \%$ & 0.10 \\
\hline Rales & $64 \%$ & $69 \%$ & 0.63 \\
\hline Wherzing & $21 \%$ & $15 \%$ & 0.40 \\
\hline Puise beals per minute $($ mean $\pm \mathrm{sD}$ ) & $87(23.8)$ & $95(26.5)$ & 0.68 \\
\hline Eco Characteristics & & & \\
\hline Atrial Fibrillation & $35 \%$ & $35 \%$ & 0.99 \\
\hline
\end{tabular}


Table 4: continued

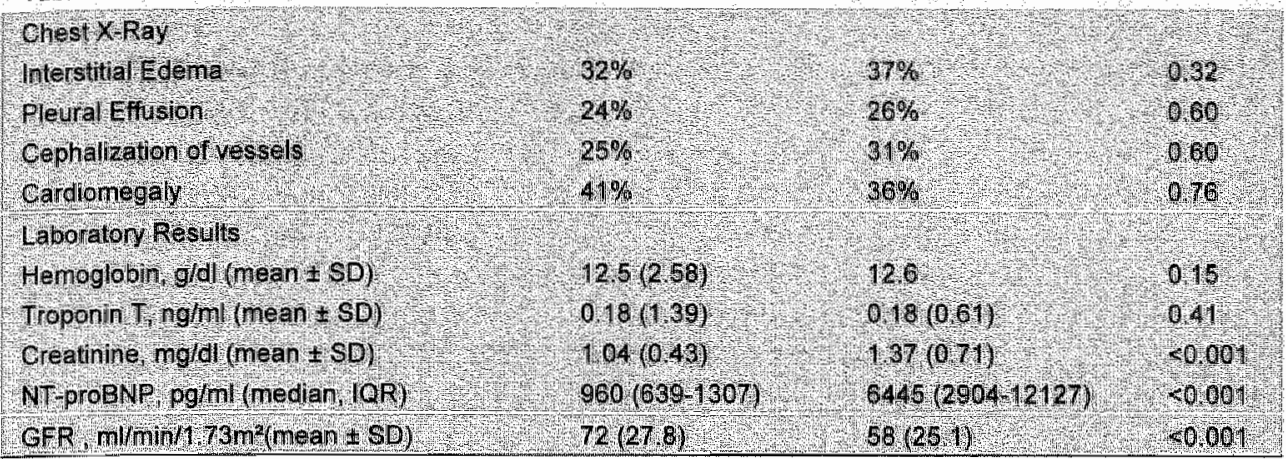

\section{Short-term Mortality Rate in all ICON subjects}

Kaplan-Meier curves for 60 days mortality (Figure 1), show that patients with acute HF and diagnostic NT-proBNP concentrations had the highest rates of death, while patients without $\mathrm{HF}$ and $<300 \mathrm{pg} / \mathrm{ml}$ had the lowest rates of death. Interestingly, patients in the 'grey zone', irrespective of their diagnosis, the rates of mortality were higher than those $<300 \mathrm{pg} / \mathrm{ml}$, lower than those below a diagnostically elevated NT-proBNP, but did not differ as a function of the presence or absence of a diagnosis of HF.

Figure 1: Kaplan-Meier curves demonstrating survival rates of all subjects. "Intermediate NT-proBNP" should be interpreted as in between rule-in and rule-out concentrations. "Diagnostic NT-proBNP" should be interpreted as $<300 \mathrm{pg} / \mathrm{ml}$ in those without HF and as above the rule-in cut point for those with $\mathrm{HF}$.

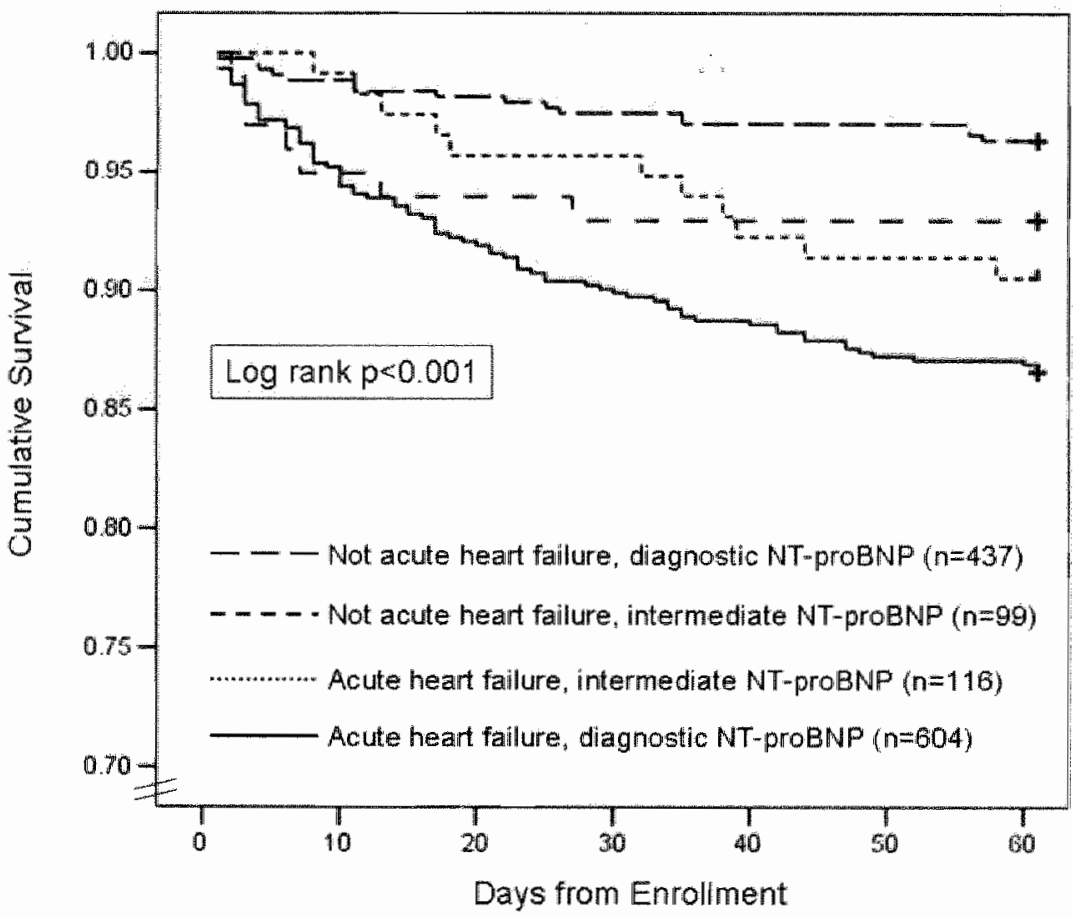




\section{DISCUSSION}

In the primary results of the ICON study, we described a strategy of age-adjusted cutpoints for NT-proBNP to optimize sensitivity and specificity for identifying acute $\mathrm{HF}$, while also identifying an age-independent cut point for excluding acute HF in acutely dyspneic patients. In this further analysis from the ICON study, we describe more in detail the subset of patients with an intermediate NT-proBNP concentration in between the cut-points for excluding or identifying the diagnosis of acute HF, the so-called "grey zone". In $84 \%$ of the patients suffering from acute HF in the ICON study, the $\mathbb{N T}$-proBNP concentration met the previously described cut-points for diagnosing $\mathrm{HF}$. Secondly, $82 \%$ of the patients with acute dyspnea not caused by acutely destabilized HF had an NT-proBNP concentration below the cut-point for excluding the diagnosis. Of the remaining 215 subjects (17\% overall) in the 'grey zone' there was a more or less equal amount of HF ( $54 \%$ ) and non-HF patients (46\%), which allowed for the present analysis, performed in an effort to better understand the differences between those subjects between the exclusion and confirmatory NT-proBNP cut-points for acute HF. We demonstrate that in these subjects, clinical factors such as history and physical examination are useful to identify those subjects with and without acute HF in this limited but nonetheless important 'grey zone'. We also demonstrate that even in a situation of diagnostic uncertainty, those subjects with a "grey zone" NT"proBNP value had higher rates of short term mortality than those below $300 \mathrm{pg} / \mathrm{ml}$, a cut-point previlously shown to have good NPV for excluding acute HF. We previously demonstrated the importance of NT-proBNP testing for the diagnosis or exclusion of acute $\mathrm{HF}_{\text {; }}$ these results will further aid clinicians in making the proper diagnosis when NT-proBNP concentrations are not as clearly useful.

Recently, the characteristics of patients with a BNP concentration in the 'grey zone' in the Breathing Not Properly Multinational Study were also described. ${ }^{6}$ In this manuscript, Knudsen and colleagues focused on the characteristics of the patients with a BNP concentration in the grey zone but without $\mathrm{HF}_{\text {, }}$ and showed that atrial fibrillation, decreased hemoglobin concentration, decreased body mass index, increased age and radiographic cardionegaly were independent predictors of elevated natriuretic peptide levels in such patients without acute HF. While useful, the findings of Knudsen and colleagues offer less guidance to the clinician in understanding the differences between "grey zone' subjects without and with acute HF, as our analysis does; negotiating this distinction is what is most often encountered in clinical practice. We emphasize the importance of interpreting natriuretic peptide results in the context of clinical factors, in onder to assist in their interpretation, particularly for those subjects with non-diagnostic, internediate results.

A common misconception regarding natriuretic peptide values is that a non-diagnostic or intermediate result offers neutral results with respect to diagnosis or prognosis. In addition to deriving a better understanding of how to secure correct diagnosis using a 'grey zone' NT-proBNP value, we also found that patients with a NT-proBNP concentration within the grey zone had similar rates of death regardless whether they suffered from acute HF or not, rates of mortality which were typically higher than those below the "rule out" threshold of $300 \mathrm{pg} / \mathrm{ml}$. This result is not necessarily surprising, as natriuretic peptide concentrations are best considered as a continuous variable, rather 
than as being superficially cut above or below a threshold value, and as such, the mortality risk of dyspneic patients with internediate values of NT-proBNP (thougli below the threshold for a diagnosis of acute HF) is likely higher than those with lower concentrations. Additionally, that the risk of subjeots without acute $\mathrm{HF}$ but with intermediate NT-proBNP concentrations was similar to those with acute $\mathrm{HF}$ in this category is not surprising either, and in line with prior reports. ${ }^{13-15}$ that show that NT-proBNP is a powerful predictor of survival in all subjects whether it involves $\mathrm{HF}$ patients, patients with ACS or even subjects without any evident acute pathology. Accordingly, a "grey zone" diagnosis should not be mis-interpreted as a "false positive" or 'false negative". It identifies a subgroup of breathless patients at intermediate risk for short-term mortality, in whom the use of clinical factors in the history and physical examination may be utilized to more accurately secure a clinical diagnosis, with appropriate treatment measures thereafter. Based on the results from our study and others, we propose the concept of 'dyspnea and intermediate natriuretic peptide concentrations" as an important diagnostic sub-group of patients, in whom prognosis is also intermediate between those with lower and higher natriuretic peptide levels.

In conclusion, based on the population from the ICON study, we have delineated the characteristics of the dyspneic patients with an intermediate NT-proBNP concentration (defined as being between cut-points with high negative predictive and positive predictive values). Previously referred to as the "grey zone" this situation is not uncommon, and influenced greatly by clinical factors such as cardiac structure and function, as well as other syndromes with known effects on NT-proBNP concentrations such as ACS or pulmonary embolism. Among such subjects with 'dyspnea and intermediate natriuretic peptide concentrations', we demonstrate that adding information from history and physical examination to NT-proBNP concentrations would be expected to further improve the abillity to make a correct clinical diagnosis in these patients. As the rate of short term death in dyspneic subjects with intermediately elevated NT-proBNP concentrations appeared to be higher than in subjects with lower NT-proBNP (ie $<300 \mathrm{pg} / \mathrm{ml}$ ) in our study, we argue such patients should be taken seriously, with efforts toward securing a correct diagnosis, careful triage, and diseasespecific therapy, in order to potentially improve the impaired prognosis in such patients.

\section{REFERENCES}

1. Jessup M, Brozena $S_{\times}$Heart failure. N Engl J Med 2003; 348:2007-18.

2. Maisel AS, Kushnaswamy P. Nowak RM, et al. Rapid measurement of B-iype natriutetic peptide in the emeryency diagnosis of hear failure. N Engl J Med 2002; 347:161-7.

3. Januzzi J1., Jr., Camargo CA, Anwaruddin S, et at. The N-Leminat Pro-BNP Investigation of Dyspnest in the Emergency department (PRIDE) study. Am I Cardiol 2005; 95:948-54.

4. Morrison LK, Harrison A, Krishnaswamy P, Kazanegra R, Clopton P, Mainel A. Uility of a rapid Bnatriuretic peptide assay in differentiating congestive heart failure from lung disease in pationts presenting with dyspnea. J Am Coll Cardiol 2002; 39:202-9.

5. MeCullough PA, Nowak RM, MoCord J, et al. B-type natriuretic peptide and clinical judgment in energency diagnosis of heart failure: analysis from Breathing Not Properly (BNP) Mulinational Study. Circulation 2002; 106:416-22. 
6. Knidsen CW, Clopton P, Westheirn A, at al Predictors of devated B-type natruretic peptide concentrations in dyspreic patients without heart failure: an analysis from the breathing not properly multinational study. Ann Emerg Med 2005; 45:573-80.

7. Malsel AS, McCord $\mathbb{J}_{\text {, Nowak }} \mathrm{RM}_{4}$ et al. Bedside B-Type natriuretic peptide in the emergency diagnosis of heart failure with reduced or preserved ejection fraction. Results from the Breathing Not Properly Multinational Study I Am Coll Cardiol 2003; 41:2010-7.

8. Anwaruddin $\$$, Lloyd-Iones DM, Baggish $\mathrm{AL}$, et al. Renal function, Congestive Heart Failure and NT wroBMP Measurement: Results from the ProBNP Investigation of Dyspnea in the Emergency Department (PR IDE) Study. I Am Coll Cardiol 2006; 47:91-7.

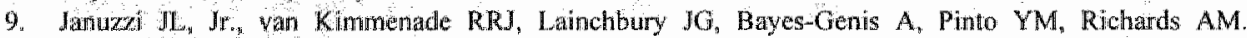
NT-proBNP Testing for Diagnosis and Short-Term Prognosis in Acute Congestive Heart Failure: An Interritional Pooled Analysis of 1256 Patients. The International Collaborative of NT-proBNP (ICON) Study. Eur Heart 12006; 27:330-337.

10. Lainchbury $J_{\mathrm{G}}$, Camplbell E, Franpton $\mathrm{CM}$, Yandle TG, Nicholls MG, Richards AM. Brain natriuretic peptide and nuterminal brain natrituretic peptide in the diagnosis of heart failure in patients with acnte shortness of breath. J Am Coll Cardiol 2003; 42:728-35.

11. Bayes-Genis A, Santalo-Bel M, Zapico-Muniz E, et al. N-terminal probrain natriuretic peptide (NT-proBNS) in the emergency diagnosis and in-hospital monitoring of patients with dyspnoex and ventricular dysfunction. Eur J Heart Fail 2004; 6:301-8.

12. Levey AS, Bosch $\mathrm{P}$, J.ewis JB, Greene T, Rogers N, Roth D. A More Accurate Method To Estimate Glomerular Pidtration Rate from Serum Creatinine: A New Prediction Equation. Ann Intem Med 1999; $130: 461-470$.

13. Kistorp C, Raymond I, Pedersen F, Gustafsson F, Faber J, Hildebrandt P. N-terminal pro-brain natriuretic peptide, C-reactive protein, and urinary albumin levels as predictors of mortallity and cardiovascular events in older adults. Jama 2005; 293:1609-16.

14. Kragelund $C$, Gronning B, Kober L, Hildebrand: $P$, Steffensen $R$. N-terminal pro-B-type natriuretic peptide and long-term mortality in stable coronary heart disease. N Engl J Med 2005; 352:666-75.

15. Bettencourt $\mathbb{P}$, Azevedo A, Pimenta J, Frioes F, Ferreira $S$, Ferreira A. N-Terminal-Pro-Brain Natriuretic Peptide Predicts Outcome After Hospital Discharge in Heart Failure Patients. Circulation 2004; 110:2168-2174. 


\title{
Amino-terminal Pro-Brain Natriuretic Peptide, Renal Function and Outcomes in Acute Heart Failure
}

\author{
Re-defining the Cardio-Renal Interaction?
}

R wan Kimmenade", J Januzzi $\mathrm{Jr}^{*}$, A Baggish", J Lainchbury", A BayesGenis", M Richards*", Y Pinto*

"University Hospital Maastricht, Maastricht, The Netherlands

"Massachusetts General Hospital, Boston, USA

"Christchurch School of Medicine and Health Science, Christchurch, New Zealand

"Hospital de la Santa Creu i Sant Pau, Barcelona, Spain

Submitted

Drs. van Kimmenade and Januzzi contributed equally to this manuscript. 


\section{ABSTRACT}

Aims: To study the individual and integrative role of NT-proBNP and parameters of renal function for prognosis in heart failure.

Methods: 720 subjects presenting with acute HF from 4 university-affiliated medical centers were dichotomised according to NT-proBNP concentration and baseline glomerular filtration rate. In addition, patients were divided according to changes in renal function. The primary endpoint was 60 days mortality.

Results: The combination of a GFR $<60 \mathrm{ml} / \mathrm{min} / 1.73 \mathrm{~m}^{2}$ with a NT-proBNP $>4647 \mathrm{pg} / \mathrm{ml}$ was the best predictor of 60 days mortality (OR 3.46;2.13-5.63 95\% CI). Among subjects with an NT-proBNP above the median, those with a GFR $<60 \mathrm{~m} 1 / \mathrm{min} / 1.73 \mathrm{~m}^{2}$ or a creatinine rise $\geq 0.3 \mathrm{mg} / \mathrm{dL}$ had the worst prognosis while in subjects with a NTproBNP below the median, prognosis was not influenced by either impaired renal function at presentation or the development of renal impairment during admission.

Conclusions: The combination of NT-proBNP with measures of renal function better predicts short-term outcome in acute HF than either parameter alone. Among HF patients, the objective parameter of NT-proBNP seems more useful to delineate the 'cardio-renal syndrome' than the previous criteria of a clinical diagnosis of HF.

Keywords: Natriuretic Peptides, Heart Failure, Kidney, Prognosis 


\section{INTRODUCTION}

In the setting of heart failure (HF) impaired renal function is common, and strongly predicts adverse outcome. ${ }^{1-3}$ This intersection of cardiac and renal insufficiency has been referred to as the "cardio-renal syndrome", particularly when acute destabilization of HF is paralleled by a drop in renal function. ${ }^{4,5}$ The relationship between cardiac and renal insufficiency may reflect common risk factors for both morbidities (such as diabetes, hypertension, and atherosclerosis) or impaired renal blood flow related to $\mathrm{HF}$, with resultant progressive deterioration of renal function. Whatever the mechanism, renal insufficiency in a patient with HF is an established marker of risk, which to date has been considered independent of other risk factors in $\mathrm{HF}$, such as advanced age or left ventricular function.

Both B-type natriuretic peptide (BNP) and its cleavage equivalent, amino-terminal proBNP (NT-proBNP) are rapidly released from cardiomyocytes after stretch and are established diagnostic and prognostic markers in chronic as well as acute $\mathrm{HF}^{7-9}$ Notably, a significant inverse relationship exists between renal function and these cardiac peptides, with higher levels of both BNP and NT-proBNP observed in patients with impairment in renal function, either with or without clinical $\mathrm{HF}^{10-12}$ Despite earlier suggestions that such elevations in BNP and NT-proBNP were merely reflective of passive accumulation due to reduced clearance in the setting of renal insufficiency and thus impairing their use in HF patients with renal impairment, ${ }^{13}$ more recent data suggest concentrations of natriuretic peptides in patients with renal insufficiency may parallel the presence and severity of cardiac abnormalities in such patients, and may offer powerful prognostic information as well.. ${ }^{12}{ }^{14}$ Hence, the relationship between NTproBNP, structural heart disease, and renal function remains incompletely understood. Accordingly, in an effort to better understand the interplay between measures of cardiac and renal insufficiencies, we analyzed the relationship between NT-proBNP concentrations, renal function, and outcomes in subjects with acute HF.

\section{MATERIAL AND METHODS}

\section{Patients}

The ICON study has been previously published. ${ }^{8}$ Briefly, the study population consists of patients from three previously reported prospective clinical studies of natriuretic peptide testing for the evaluation of dyspneic subjects, from Christchurch, New Zealand, ${ }^{15}$ Barcelona, Spain ${ }^{16}$ and Boston, USA ${ }^{8}$ combined with a registry of consecutively admitted HF patients at the University Hospital of Maastricht, The Netherlands. Of the total of 1256 subjects, 720 subjects had acute destabilized HF, while the remainder had dyspnea without acute HF. 
All data sources had compatible inclusion/exclusion criteria, and obtained similar clinical information, including standard demographics, past medical history, drug therapy, presenting symptoms and signs, physical examination, results of laboratory testing, chest $\mathrm{X}$-ray information and electrocardiography results.

\section{Laboratory results}

In all patients, blood samples were drawn on the moment of presentation, before any therapy was given. From this baseline creatinine, dynamic changes in creatinine concentration were evaluated. NT-proBNP levels were determined by an immunoelectrochemiluminisence method (Elecsys ${ }^{\text {B }}$, Roche Diagnostics, Switzerland). NTproBNP levels are expressed in $\mathrm{pg} / \mathrm{mL}$. For conversion, $1.0 \mathrm{pg} / \mathrm{mL}$ equals $1.0 \mathrm{ng} / \mathrm{L}$. Creatinine levels were determined by standard laboratory testing at each individual hospital. Glomerular Filtration Rate (GFR) was calculated based on the creatinine levels on admission using the simplified Modified Diet in Renal Disease (MDRD) formula. ${ }^{17}$ In an effort to examine the influence of dynamic changes in serum creatinine in the setting of HF, each subject's record was reviewed for serial serum creatinine levels following presentation. An increase or decrease in creatinine was defined by any increase or decrease $\geq 0.3 \mathrm{mg} / \mathrm{dL}$ during admission.

\section{Statistical analyses}

Data are presented as medians with intra-quartile ranges (IQR) for non-normally distributed variables and means \pm standard deviations (SD) for all other continuous variables. For NT-proBNP analyses, HF patients were dichotomised to above/below median NT-proBNP levels. For analyses of renal function, patients were dichotomised to GFR above/below $60 \mathrm{ml} / \mathrm{min} / 1.73 \mathrm{~m}^{2}$, both the mean value for the population as well as reflecting a cut-off value based on the standards of the National Kidney Foundation. ${ }^{2}$, ${ }^{4}{ }^{4}$ " Secondly, in order to investigate dynamic aspects in renal function, we divided our population according to previously published criteria for the cardio-renal syndrome, ${ }^{19}$ namely an increase in creatinine level during hospital admission $\geq 0.3 \mathrm{mg} / \mathrm{dL}$. As well, we also identified subjects with a decrease in creatinine level $\geq 0.3 \mathrm{mg} / \mathrm{dL}$ and those with at stable creatinine level.

Differences in baseline variables between survivors and non-survivors were analyzed using the Wilcoxon rank-sum test for continuous variables and Pearson's $\chi^{2}$ testing for categorical variables. Survival curves were computed with the Kaplan-Meier curves, and differences between the curves were evaluated with the log-rank statistic. 
Univariate screening of baseline variables was used to identify candidate independent predictors of 60-day mortality. Multivariable analysis with forward step-wise logistic regression, including all candidate variables with p-values $\leq 0.10$ or of predetermined clinical interest, was performed to identify independent predictors of 60-day mortality. Goodness of fit was evaluated with the Hosmer-Lemeshow test. All independent variables were evaluated in pairs for first-order interactions, and none were found. Results are presented as odds ratios (OR) with 95 percent confidence intervals (Cl).

\section{RESULTS}

Of the 1256 overall patients included in the ICON study, 720 patients $(57 \%)$ were diagnosed with acute $\mathrm{HF}$ at presentation. Among these 720 subjects with acute HF, the median NT-proBNP concentration was $4647 \mathrm{pg} / \mathrm{ml}$. The mean serum creatinine was $1.3 \pm 0.68 \mathrm{mg} / \mathrm{dl}$, with a corresponding mean GFR of $60.5 \pm 26.0 \mathrm{ml} / \mathrm{min} / 1.73 \mathrm{~m}^{2}$; accordingly, 373 subjects $\left(51.8 \%\right.$ ) had a GFR below $60 \mathrm{ml} / \mathrm{min} / 1.73 \mathrm{~m}^{2}$.

NT-proBNP was negatively related to GFR $(r=-0.34 ; p<0.001)$. Subjects with a GFR $<60 \mathrm{ml} / \mathrm{min} / 1.73 \mathrm{~m}^{2}(\mathrm{n}=373)$ had higher median NT-proBNP concentrations than those $(\mathrm{n}=347)$ with $\mathrm{GFR} \geq 60 \mathrm{ml} / \mathrm{min} / 1.73 \mathrm{~m}^{2} \quad(7214 \mathrm{pg} / \mathrm{ml}, \mathrm{IQR}=2757-16160$ versus 3054 $\mathrm{pg} / \mathrm{ml}, \mathrm{IQR}=1345-7620 \mathrm{pg} / \mathrm{ml}, \mathrm{p}<0.001$ for difference).

\section{Mortality analysis}

Eighty nine (12.4\%) patients with acute HF died within 60 days. Patient characteristics as a function of survival are shown in Table1. Subjects dying within 60 days were more likely to be older, more likely to have a history of prior $\mathrm{CAD}$ and left bundle branch block on ECG, and were more likely to present with fever or the absence of paroxysmal nocturnal dyspnea than survivors. As well, decedents were also more likely to have worse renal function, to be anemic, to have higher cTnT concentrations, and typically had more elevated NT-proBNP concentrations.

In multivariate analyses that included age, prior $\mathrm{HF}$, prior $\mathrm{MI}$, severity of dyspnea (NYHA classification), hemoglobin levels, cTnT results, GFR $<60 \mathrm{ml} / \mathrm{min} / 1.73 \mathrm{~m}^{2}$ and NT-proBNP level above the median value, both GFR $<60 \mathrm{ml} / \mathrm{min} / 1.73 \mathrm{~m}^{2}$ (OR 2.03; 95 $\% \mathrm{CI} 1.18-3.49$ ) or NT-proBNP concentrations above the median (OR $2.67 ; 95 \% \mathrm{CI}$ 1.58-4.51) strongly predicted 60 day mortality in an independent fashion (Table 2A). Notably, in a secondary analysis, the combination of both GFR $<60 \mathrm{ml} / \mathrm{min} / 1.73 \mathrm{~m}^{2}$ and NT-proBNP level above the median was an even stronger predictor of mortality than either measure alone (OR $3.46 ; 95 \%$ CI 2.13-5.63) (Table 2B). 
Table 1: Comparisons of patients with acute HF based on the 60-day survival

\begin{tabular}{|c|c|c|c|}
\hline Charpactertic & $\begin{array}{l}\text { (ne at day } 60 \\
(n=606)\end{array}$ & $\begin{array}{l}\text { Deceast doy day } 60 \\
(1-84)\end{array}$ & Pralue \\
\hline Age (meanustandard devibion) & $744=117$ & $185 \pm 166$ & 0002 \\
\hline Male Gender & $512 \%$ & $524 \%$ & 0.033 \\
\hline $\mathrm{Bbek} \mathrm{radst}$ & $25 \%$ & $0 \%$ & 0237 \\
\hline Prst miedical hilstory & & & \\
\hline Wyertersion & $62 \% 6$ & $512 \%$ & 0.056 \\
\hline CGororary antry disease & $507 \%$ & $1655 \%$ & 0017 \\
\hline Prior acute nyocandial iniarction & $33.7 \%$ & $42.2 \%$ & 0112 \\
\hline Prior headt fallure & $517 \%$ & $648 \%$ & 0593 \\
\hline Phlor obstivucive a lwovs disease & $29.3 \%$ & $26.2 \%$ & 0561 \\
\hline Siroking (past or present) & $51,9 \%$ & $52.4 \%$ & 0985 \\
\hline Syinpromsisighs & & & \\
\hline Parovesmal hoetumal dyspisa & $332 \%$ & $190 \%$ & 0009 \\
\hline Phopnea (1) & $516 \%$ & $48.4 \%$ & 0635 \\
\hline Lewer extremily edema & $46.5 \%$ & $46 \%$ & 0823 \\
\hline Chest pain & $335 \%$ & $325 \%$ & 0.861 \\
\hline Tough & $328 \%$ & $274 \%$ & 0361 \\
\hline Fever & $4,1 \%$ & $107 \%$ & 0.009 \\
\hline Increasedsputun & $18.3 \%$ & $167 \%$ & 0713 \\
\hline NYMA Glass 4 & $442 \%$ & $50.0 \%$ & 0.319 \\
\hline Physical Exanination. & & & (1) \\
\hline Pliss rate (meantsi) & $928 \pm 258$ & $95.5+260$ & 0381 \\
\hline Wugular Venolis d dstehslon & $48,8 \%$ & $56.0 \%$ & 1222 \\
\hline sagallop. & 8996 & $83 \%$ & 0639 \\
\hline Lowerextremity odema & $563 \%$ & $52.4 \%$ & 0,501 \\
\hline Reles & $66.7 \%$ & $67.9 \%$ & 0.882 \\
\hline Wherng & $169 \%$ & $107 \%$ & 0.151 \\
\hline EcG indings & & & t) \\
\hline 6ris poythin & $59.6 \%$ & $64.3 \%$ & 0.408 \\
\hline Avilatib/fuitior & $34.6 \%$ & $42,1 \%$ & 0671 \\
\hline Ceft ventrutur hypertrophy & $10.7 \%$ & $6.3 \%$ & 0.409 \\
\hline Lefl bundlo branch b/ok & $150 \%$ & $250 \%$ & 0.02 \\
\hline Chest X ray frndings & & & \\
\hline hiersitial edema & $376 \%$ & $298 \%$ & 0161 \\
\hline inflicate & $117 \%$ & $167 \%$ & 9196 \\
\hline Plevial offusion. & $26.6 \%$ & $226 \%$ & 0440 \\
\hline Cepiralization of vessels & $204 \%$ & $357 \%$ & 0.235 \\
\hline Cardonegaly & $37.0 \%$ & $39.3 \%$ & 0.680 \\
\hline Laboratory findings & & 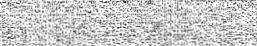 & \\
\hline Creatinine, ingld (median lap) & $1.12(087,1.50)$ & $1,41,1022,101$ & $<0.001$ \\
\hline GFR (niminls, $73 \mathrm{~m}^{2}$ (nedan loR) & $607(42.907922)$ & $439(30.926403)$ & $<0.001$ \\
\hline Troponn T $\geq 001 \mathrm{ng} / \mathrm{ml}$ & $475 \%$ & $773 \%$ & $<0001$ \\
\hline Herroglobin, gld, (meantsD) & 1271206 & $120+1,97$ & 0063 \\
\hline NTpprobNf pg/mi (nedian, lor) & $4077(1740.9989)$ & $0448(3805-22179)$ & 50.001 \\
\hline
\end{tabular}


Table 2: Multivariate analysis utilizing A) individual and B) combined measures of cardiac and renal insufficiency for the prediction of death by 60 days following presentation with acute HF.

A

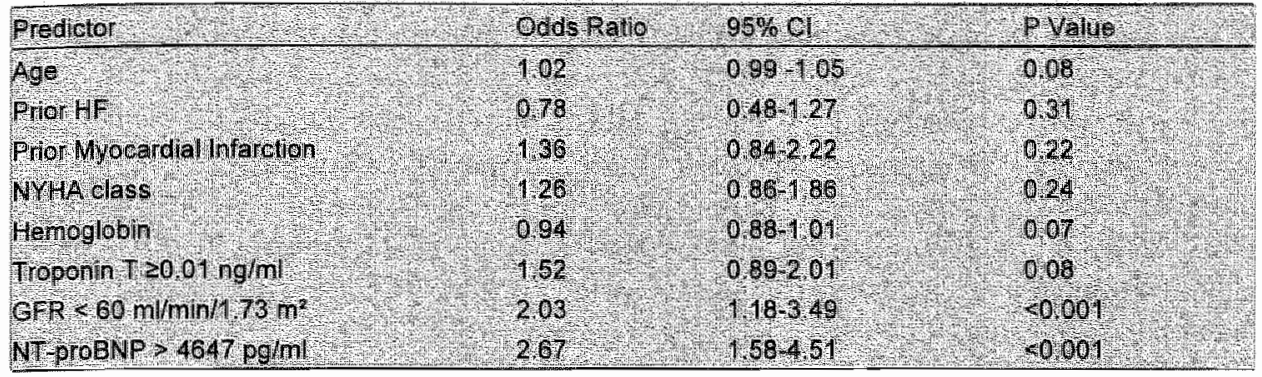

$\mathrm{B}$

\begin{tabular}{|c|c|c|c|}
\hline Predicter & Odds Ratio & $65 \% \mathrm{cl}$ & P Valus \\
\hline Age & 102 & $099+105$ & 006 \\
\hline Pror If & 078 & $0.48-127$ & 0,4 \\
\hline Prior Myecardias intaretion & 137 & 6.642 .24 & 020 \\
\hline NMA class & 124 & 0184.183 & 028 \\
\hline Wenoglobin & 194 & 0060104 & 007 \\
\hline Tropolis T $\geq 0.01$ ng/mi & 132 & C.83.206 & 0110 \\
\hline $\mathrm{GFP} / 50 \mathrm{mu} / \mathrm{minh} 17 \mathrm{~s} \mathrm{\textrm {m } ^ { 2 }} \mathrm{8}$ & 346 & $213-5.63$ & 600 \\
\hline NT proBNP $>4647 \mathrm{pg} / \mathrm{ml}$ & & & \\
\hline
\end{tabular}

Kaplan-Meier survival curves depicting mortality rates as a function of NT-proBNP concentration and GFR (Figure 1) demonstrate that the majority of fatal events in the first 60 days from presentation occurred in subjects with an NT-proBNP level above the median plus a GFR $<60 \mathrm{ml} / \mathrm{min} / 1.73 \mathrm{~m}^{2}$, with low rates of mortality (and no statistical difference) in the other categories, including HF with a GFR $<60 \mathrm{ml} / \mathrm{min} / 1.73^{2}$ but with an NT-proBNP below the median.

\section{Cardio-renal Syndrome and 60-day Survival}

In an effort to better understand the relationship between renal function and HF outcomes, we examined the relationship between dynamic changes in serum creatinine in the setting of acute HF, and outcomes. ${ }^{5}$ This group of subjects $(n=627)$ with available data was similar to the group as a whole in terms of baseline demographics, including a similar NT-proBNP median of $4694 \mathrm{pg} / \mathrm{ml}$, and was dichotomised with respect to NTproBNP concentrations above or below the median, and analyzed as a function of serum creatinine changes. In recognition of previous definitions of "cardio-renal syndrome, ${ }^{4,5.19}$ the outcomes of those subjects with an in-hospital rise of serum creatinine $\geq 0.3 \mathrm{mg} / \mathrm{dL}$ were compared to those without a rise in creatinine. 
In addition, we also examined the outcomes of subjects whose creatinine fell by $\geq 0.3$ $\mathrm{mg} / \mathrm{dL}$ during their hospitalization as well. This left three diagnostic categories within NT-proBNP groups: those with 1) an increase in serum creatinine $\geq$ than $0.3 \mathrm{mg} / \mathrm{dL}, 2$ ) those with change in serum creatinime $<0.3 \mathrm{mg} / \mathrm{dL}$ during hospitalization, and 3) those with a decrease in serum creatinine $\geq$ than $0.3 \mathrm{mg} / \mathrm{dL}$ following presentation.

The outcomes of subjects as a function of NT-proBNP concentration and dynamic changes in serum creatinine are shown in Figure 2. Among the HF patients with an NTproBNP level above the median, those with a rise in serum creatinine $(n=173)$ had the worst overall 60-day prognosis; those subjects with high NT-proBNP but with no change in creatinine $(\mathrm{n}=110$ ) had intermediate outcomes, and those with a fall in serum creatinine $\geq 0.3 \mathrm{mg} / \mathrm{dL} \quad(\mathrm{n}=28)$ had the most benign outcomes (but which were nonetheless worse than those with an NT-proBNP below the median). Notably, in those patients with NT-proBNP levels below the median, we found no graded relationship between dynamic changes in creatinine and rates of mortality.

Figure 1: Survival curves of HF subjects in ICON as a function of GFR and NT-proBNP concentration on admission (log-rank $p<0.001)$.

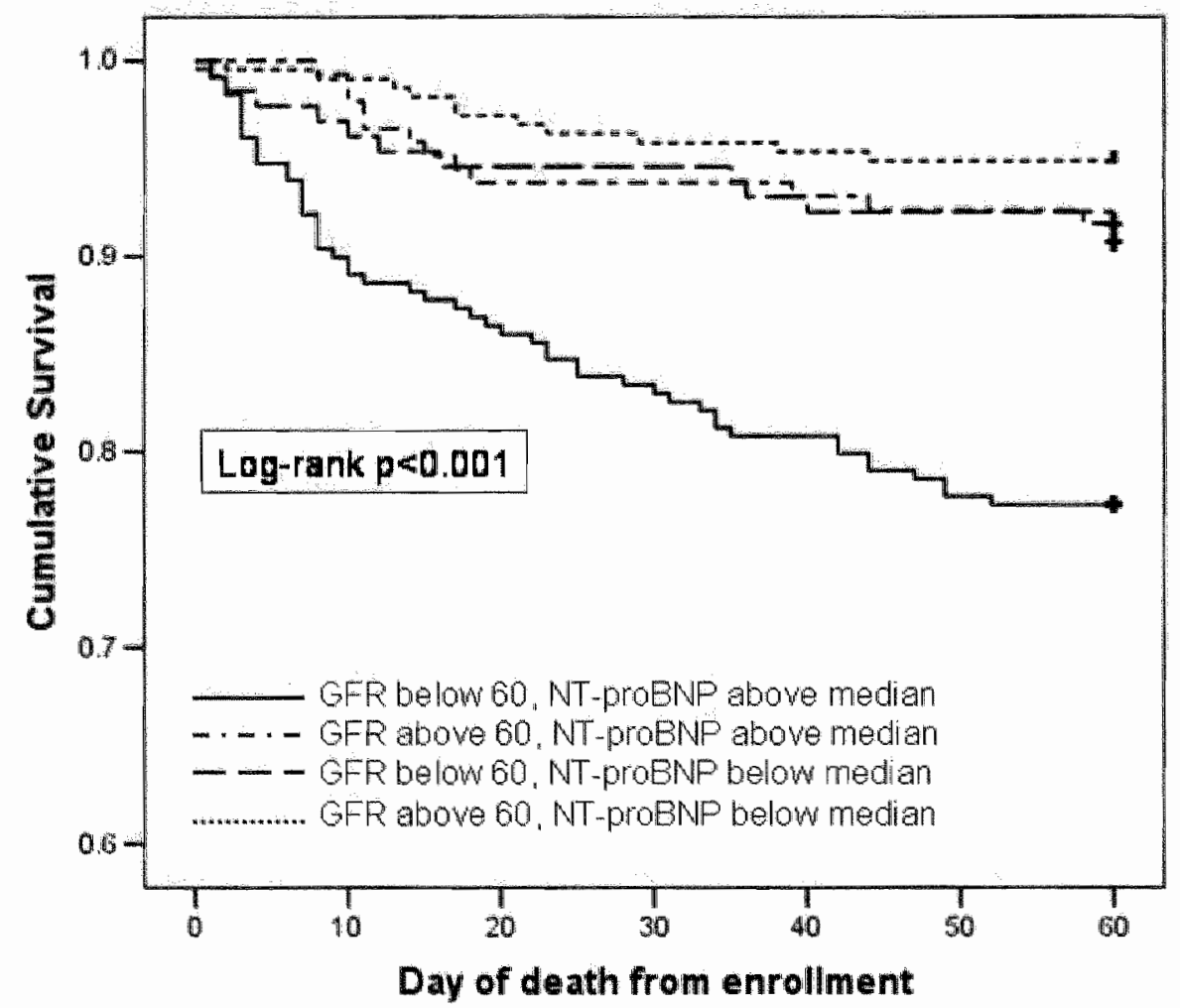


Figure 2: Survival curves of $H F$ subjects in $I C O N$ as a function of NT-proBNP concentration on admission and dynamic changes in renal function following presentation (log rank $p<0,001)$.

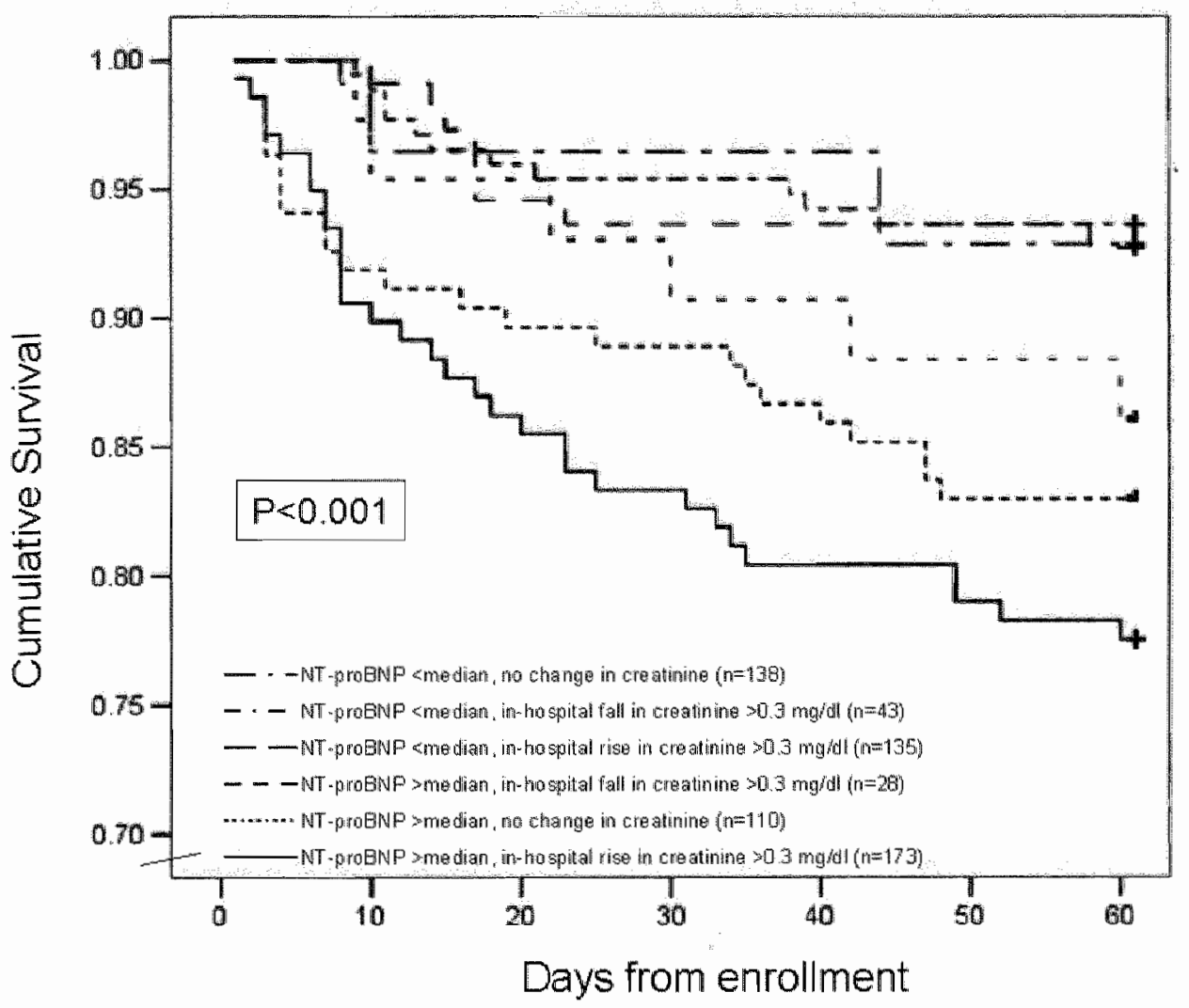

\section{DISCUSSION}

The complex interaction between heart and kidneys remains an area poorly understood and one of great focus in modern medicine. Using data from the ICON study, we demonstrate the dynamic interaction between $\mathrm{HF}$, renal function and outcomes, emphasizing the value of the addition of an objective measure of HF severity (NTproBNP) to an objective measurement of renal function (GFR or serum creatinine) to better stratify risk in acute $\mathrm{HF}$.

Besides sharing strong commonality with respect to risk factors for their development, cardiac and renal impairment are strongly connected on a neurohormonal basis via the renin-angiotensin-aldosterone system and its antagonists (BNP and nitric oxide), the sympathetic nervous system as well as inflammatory pathways. ${ }^{20}$ The chronic activation of each of these pathways may aggravate the progression of both cardiac and renal insufficiencies. Indeed, cardiac abnormalities are present in the large majority of 
patients with end stage renall disease (ESRD). ${ }^{21}$ Furthermore, in the setting of acute destabilization of heart failure, the dynamic relationship between the heart and kidneys may be accentuated: cardiac output reduces, which may be counteracted by systemic and other responses such as a decrease in renal blood flow in order to retain circulating fluid. and restore cardiac output. ${ }^{3,22}$ In addition, the uremic milieu itself may further affect cardiac contractility, with promotion of myocyte fibrosis and death. ${ }^{23 .}{ }^{24}$ It is thus not at all surprising that measures of cardiac insufficiency, such as natriuretic peptides, are strongly influenced by the presence and severity of renal insufficiency.

This combination of acute cardiac and renal insufficiency-at times termed 'cardiorenal syndrome $e^{4,5}$-is a marker of particularly high risk for adverse outcome in the setting of acute $\mathrm{HF}$, with up to a $67 \%$ increment in the risk of death observed within 6 months after discharge when compared to HF patients withour renal complications. ${ }^{25}$

In our analysis of NT-proBNP and renal function in subjects with acute HF, we report several important findings with potentially useful clinical implications. Firstly, consistent with all other studies, ${ }^{9}{ }^{26-30}$ we show NT-proBNP as a most powerful predictor of mortality in acute HF, remaining so in the presence of normal or impaired renal function. However, in none of all previous published studies ${ }^{96-30}$ was GFR taken into account in the multivariate analyses. Notably, while NT-proBNP and GFR were both significantly related to mortality, the novel approach of combining the two measures led to our finding that the combination of the two was a superior tool for identifying patients with HF at highest risk for short-term death, while also demonstrating that in our study, many HF subjects with moderate or worse renal insufficiency but lower NT-proBNP concentrations had 60-day outcomes comparable to those without significant renal insufficiency. In addition, while analyzing the concept of dynamic changes in 'cardio-renal' insufficiency, we demonstrate the utility of NTproBNP to stratify the subjects to a wide range of risks within various categories of renal function. Importantly, though a rise in creatinine indeed identified subjects at higher risk for mortality following presentation (the classic definition of the cardio-renal syndrome), this risk was only present in those with elevated NT-proBNP concentrations. Those subjects with creatinine rise during admission but without a markedly elevated NT-proBNP level demonstrated a relatively low 60-day mortality rate similar to subjects with a low NT-proBNP level, regardless of their evolution in creatinine. Our data suggest that defining the 'cardio-renal syndrome' simply as the development of worsened renal function in a patient with HF may require reconsideration. Indeed, the heterogeneity of cardio-renal insufficiency was recently emphasized by Forman et al., who demonstrated that HF patients with deterioration in renal function are not simply those with the poorest ventricular function, lowest cardiac output, or the lowest blood pressure, but included patients with preserved systolic function, less complaints of low output (such as fatigue), as well as high blood pressures. $^{31}$ 
While most prior analyses of cardiorenal interaction have focused on those subjects with HF and a rise in serum creatinine, the outcomes of those subjects with an improvement in renal function (accounting for more than $11 \%$ of our study population) consequent to treatment for HF remains less well-described. We describe a novel group of patients with elevated NT-proBNP, in whom serum creatinine fell following presentation. In the cohort of subjects with markedly elevated NT-proBNP, a falling creatinine was associated with a statistically significantly lower of death compared to those with an elevated NT-proBNP and either a rise or no change in renal measurements. Notably, however, the outcomes of subjects in ICON with a high NT-proBNP and improvement in serum creatinine were still worse than those with low NT-proBNP.

Although it is generally accepted that renal impaiment correlates with poor outcome in patients with $\mathrm{HF}^{1-3}$, ${ }^{1-3}$ ere is still some debate whether a rise in serum creatinine is the best expression of renal impairment in $\mathrm{HF}$, or if relative increase in serum creatinine, or a high serum creatinine on admission ${ }^{31.33}$ better rellect 'cardio-renal' risk. While our data suggest that both GFR or dynamic changes in renal function offer relatively comparable prognostic data, in the setting of a high presenting NT-proBNP, a GFR $<60$ $\mathrm{ml} / \mathrm{min} / 1.73 \mathrm{~m}^{2}$ on admission provides these prognostic data riglt at presentation, rather than requiring serial measurements of creatinine.

Limitations of our study include the fact that GFR estimation was performed utilizing the MDRD equation, rather than directly measuring renal function. The MDRD equation is accepted to be a generally accurate measure of renal function, and in our study provided robust results regarding prognosis. Secondly, only a small number of Afro-Americans were included in this trial and our findings should therefore carefully be extrapolated to this population. Lastly, as in all studies discussing the Cardio-Renal. Syndrome, the measurement of serum creatinine for assessment of dynamic changes in renal function was performed at variable time intervals in our study.

In conclusion, the combined use of objective parameters of cardiac (NT-proBNP) and renal (GFR) function allowed identification of those HF patients at highest risk for short-term death, and argues that elevations of NT-proBNP in the setting of renal insufficiency are not, in fact, spurious. Moreover, analyses of the rates of mortality based on dynamic changes in renal function suggest a graded risk for death among those with highest concentrations of NT-proBNP. This latter finding lends support to the consideration that therapies aimed specifically at the cardio-renal syndrome, ${ }^{34}$ may improve survival in these patients. 'Lastly, our data may support a reconsideration of the definition of 'cardio-renal' syndrome to include a natriuretic peptide standard rather than the clinical diagnosis of HF to define the cardiovascular element to this complex syndrome of combined cardiac and renal insufficiencies.

\section{Acknowledgements}

The ICON study was supported in part by an unrestricted grant from Roche Diagnostics, Inc. 


\section{REFERENCES}

1. McAlister FA, Ezckowitz J, Tonelli M, Amstrong PW. Renal Insufficiency and Heart Faalure: Prognostic and Therapautic Implications From a Prospective Cahort Study. Circulation 2004; 109:10041009.

2. Mathon NG, Blackstone EH, Francis GS, Starling RC, 3rd, Young JB, Lauer MS. The prognostic vallue of estimaled creatinine clearance alongside functional capacity in ambulatory patients with chronic congestive heert faillure. I Am Coll Cardiol 2002; 40:1 106-13.

3. McCletlan WM, Flanders WD, Langston RD, Jurkovitz $C$. Presley R. Anemia and renal insufficiency are independent risk factors for death among patients with congestive heart failure adrnitted to community hospitals; a population-based study. I Am Soc Nephrol 2002; 13:1928-36.

4. Shlipalk MO, Massie BM. The Clinical Challenge of Cardiorenal Syndrome. Circulation 2004; 110:15141517.

5. Stewenson LW, Nohria A, Mielniczuk L. Torrent or Torment From the Tubules? Challenge of the Cardiorenal Connections. J Am Coll Cardiol 2005; 45:2004-2007.

6. Bruneau BO, Piaza LA, de Bold AJ. BNP gene expression is specifically modulated by stretch and ET-1 in a new model of isolated rat atria. Am I Physiol 1997; 273:H2678-86.

7. Maisel AS, Krishaswamy P, Nowak RM, et al. Rapid measurement of B-type natriuretic peptide in the emergency diagnosis of heart failure. $N$ lengl I Med $2002 ; 347: 161-7$.

8. Januzzi JL, Jr, Camargo CA, Ariwaruddin S, et at. The N-terminal Pro-BNP Investigation of Dyspnea in the Energency department (PRIDE) study. Am J Cardiol 2005; 95:948-54.

9. Hartmann F, Packer M, Coats ASS, et al. Prognostic Impact of Plasma N-Terminal Pro-Brain Natriuretic Peptide in Severe Chronic Congestive Heart Failure: A Substudy of the Carvedilal Prospective Randonized Cumulative Survival (COPERNICUS) Trial. Circulation 2004; 1 10:1780-1786.

10. Luchner A, Hengstenberg $C$, Lowel H, et al. N-Terminal Pro-Brain Natriuretic Peptide After Myocardial Inferction: A Marker of Cardio-Renal Function. Hypertension 2002; 39:99-104.

11. McCuilough PA, Duc P, Onaland T, et al. B-type natriuretic peptide and renal function in the diagnosis of heart failure: an analysis from the Breathing Not Properly Multinational Study. Am J Kidney Dis 2003; $41: 571-9$.

12. Anwaruddin \$, Lloyd-Jones DM, Baggish AL, et al. Renal function, Congestiwe Heart Failure and NT:proBNP Measurement: Results from the ProBNP Investigation of Dyspnea in the Emergency Department (PRIDE) Study. I Am Coll Cardiol 2006; 47:91-7.

13. McCullough PA, Sandberg KR. Sorting out the evidence on natriuretic peptidles. Rev Cardiovase Med 2003; 4 Suppl 4:S13-9.

14. Defilippi CR, Fink JC, Nass CM, Chen H, Christenson R. N-terminal pro-B-type natriuretic peptide for predicting coronary disease and left wentricular hypertrophy in asymptomatic CKD not requiring dialysis. An J Kidney Dis 2005; $46: 35$-44.

15. Lainchhury JG. Camphell E, Frampton $\mathrm{CM}_{n}$ Yandle $\mathrm{TG}$, Nicholls $\mathrm{MG}$, Richards AM. Brain natriuretic peptide and n-terminal brain natriuretic peptide in the diagnosis of heart failure in patients with acute shortuess of breath. I Am Coll Cardiol 2003; 42:728-35.

16. Bayes-Genis $A$, Santalo-Bel $M$, Zapico-Muniz E, ei al. N-terminal probrain natriuretic peptide (NTproBNP) in the emergency diagnosis and in-hospital monitoring of patients with dyspnoea and vertricular dysfunction. Eur J Heart Fail 2004; 6:301-8.

17. Levey AS, Bosch JP. Lewis JB, Greene T, Rogers N, Roth D. A More Accurate Method To Estirnate Glomerular Filtration Rate from Serum Creatinine: A New Prediction Equation. Ann Intern Med 1999; $130: 461-470$.

18. Dries DL, Exner DW, Domanski MI, Greenberg B, Stevenson LW. The prognostic implications of renal insufficiency in asymptomatic and symptomatic patients with left ventricular systolic dysfunction. I Am Coll Cardiol 2000; 35:681-9.

19. Pit B. Segal R, Martinez PA, et al. Randomised trial of losartan versus captopril in patients over 65 with heart laiture (Evaluation of Losartan in the Elderly Study, ELLTE). Lancet 1997; 349:747 ×52.

20. Bongart LG, Cramer M., Doevendans PA, Joles IA, Braam B. The severe cardiorenal syndrome: 'Guyton revisited'. Eur Heart J 2005; 26:11-7. 
21. Parfrey PS, Foley RN, Harnett JD, Kent GM, Murray DC, Barre PE. Outconne and risk factors for let ventricular disorders in chronic uraemia. Nephrol Dial Transplant 1996; 1.1:1274.85.

22. Braunwald $\mathrm{E}$. The Denolin lecture. Congestive heart failure: a thall century perspective. Eur Heart / 2001; 22:825-36.

23. Mall $G$, Huther $W$, Schneider $J$, Lundin $P$. Ritz $E$. Dituse intermyocardiocytic fibrosis in uanemic patients. Nephrol Dial Transplant 1990; 5:39-44.

24. Amann $\mathrm{K}_{*}$ Breitbach M, Ritz E, Mall G. Myocyte/capillary mismatch in the heart of uremic patients. Am Soc Nephrol 1998; 9:1018.22.

25. Smith GL, Vaccarino $\mathrm{V}$, Kosiborod $\mathrm{M}$, ef al. Worsening renal function: what is a clinically meaningful change in creatinine during hospitalization with heart failure? I Card Fail 2003; 9:13-25.

26. Bettencourt $\mathbb{P}$, Azevedo A. Pimenta J, Frioes F, Ferrein S, Ferreira A. N-Terminal-Pro-Brain Natriuretio Peptide Predicts Outcome After Hospital Discharge in Heart Failture Patients. Circulation 2004; 110:2168-2174.

27. Gustafsson F, Steensgaard-Hansen F, Badskjaer J, Poulsen AH, Corell P, Hildebrandt P. Diagnostic and Prognostic Performance of N-Terminal ProBNP in Primary Care Patients With Suspected Heart Failure. J Card Fail 2005: 11:15-20.

28. Taniguchi $R$, Sato $Y, Y$ amada $T$, et al. Combined meastrements of cardiac troponin $T$ and $N$-terninal pro-brain natriuretic peptide in patients with heart failure. Circ I 2004; 68:1160-4.

29. Rothenburger $M$, Wichter $T$, Schmid $C$, et al. Aminoterminal pro type $B$ natriuretic peptide as a predicive and prognostic marker in patients with chronic heart failure. J Heart Lang Transplant 2004; 23:1189-97.

30. Richards $A M$, Doughty $R$, Nicholls $M G$, et al. Plasma N-terminal pro-brain natriuretic peptide and adrenomedullin: prognostic utility and prediction of benefit from carvedilol in chronic ischemic left ventricular dysfunction. Australia-New Zealand Heart Failure Group. J Am Coll Cardiol 2001; 37:17817.

31. Forman DE, Butler J, Wang $Y$, et al. Incidence, predictors at admission, and impact of worsening renat function among patients hospitalized with heart failure. J Am Coll Cardiol 2004; 43:61-7.

32. Weinfeld MS, Chertow GM, Stevenson LW. Aggravated renal dysfunction during intensive therapy for adwanced chronic heart failure. Am Heart J 1999; 138:285-90.

33. Leithe ME, Margonien RD, Hermiller JB, Unverferth DV, Leier CV. Relationship between central hemodynamics and regional blood flow in normal subjects and in patients with congestive heart failure. Circulation 1984; 69:57-64.

34. Patema $S$, Di Pasquale $P$, Parrineilo $G$, el al. Changes in brain natriuretic peptide levels and bioelectrical impedance measurements after treatment with high-dose furosemide and hypertonic saline solution versus high-dose furosemide alone in refractory congestive heart failure: a double-blind study. J Am Coll Cardiol 2005; 45:1997-2003. 
Renal Handling of BNP and NT-proBNP in Hypertensive Subjects

R van Kimmenade", J Bakker", A Houben ${ }^{*}$, A Kroon", R Rennenberg", H Crijns", M van Dieijen-Visser ${ }^{\dagger}$, P de Leeuw ${ }^{\prime \prime}, Y$ Pinto"

* Department of Cardiology, University Hospital Maastricht

${ }^{t}$ Department of Clinical Chemistry, University Hospital Maastricht

* Department of Intemal Medicine, University Hospital Maastricht

submitted 


\section{ABSTRACT}

Background: Plasma concentrations of BNP and NT-proBNP, both established cardiac biomarkers, are inversely related to renall function. This relation has been interpreted to indicate an accumulation of these peptides with declining glomerular filtration rate.

However, renal impairment and cardiovascular disease often coincide and it remains possible that elevated natriuretic peptides in subjects with renal impairment truly reflect cardiac involvement rather than decreased clearance.

Methods and Results: In order to study this issue, we measured concentrations of BNP, NT-proBNP and Cystatin-C in the renal arteries and veins of 178 hypertensive patients undergoing renal arteriography and combined these findings with invasive renal blood flow measurements. These data enabled us to investigate the renal handling of BNP, NT-proBNP and Cystatin-C. Fractional extractions of BNP and NT-proBNP correlated with the fractional extraction of Cystatin- $\mathrm{C}(\mathrm{r}=0.39 ; \mathrm{p}<0.001$ and $\mathrm{r}=$ $0.50 ; p<0.001$ respectively). In patients with renal impairment and elevated levels of natriuretic peptides, e/a ratio -as an echocardiographic measure of diastolic functionwas significantly lower $(1.01 \pm 0.39$ versus $0.79 \pm 0.22, \mathrm{p}<0.001)$.

Conclusions: Our study confirms that patients with renal impairment have elevated levels of natriuretic peptides but also typical echocardiographic abnormalities compatible with diastolic dysfunction. We found that the renal clearance of BNP and NT-proBNP parallels the renal clearance of Cystatin-C. Our findings surmise that in mild renal impairment, (i.e. GFR $>30-40 \mathrm{ml} / \mathrm{min} / 1.73 \mathrm{~m}^{2}$ ) natriuretic peptide serum concentrations are minimally influenced by decreased clearance. However, combining measurements of (NT-pro)BNP with Cystatin-C might distinguish changes related to modifications in renal function from changes in cardiac production, which often coincides.

Keywords: natriuretic peptides, kidney, heart failure 


\section{INTRODUCTION}

B-type Natriuretic Peptide (BNP) and its cleavage equivalent aminoterminal pro-BNP (NT-proBNP) are well-established biochemical markers in clinical cardiology. The diagnostic accuracy and prognostic value of both peptides has been clearly established in patients suspected for cardiowascular diseases. ${ }^{-4}$ Furthermore, a pilot-study has suggested that NT-proBNP guided treatment of heart failure may be even superior to therapy based on clinical judgement alone.

However, in daily clinical practice, it is still a matter of debate how to interpret levels of natriuretic peptides in relation to renal function. Since plasma concentrations of NTproBNP and BNP both are inversely related to creatinine clearance, ${ }^{6-8}$ it has been proposed that both peptides accumulate with declining GFR. ${ }^{7}$

On the other hand, alternative explanations are equally plausible. McAlister et al. showed that in a large population of patients with heart failure, renal function is often impaired. Vice versa, cardiac function is often impaired in patients suffering from renal failure, 10 illustrating the intricate relationship between the two. Therefore, it has also been surmised that elevated serum levels of natriuretic peptides in patients with impaired renal function may very well reflect increased cardiac production in patients where renal impairment is accompanied by increased wall stress. ${ }^{11.12}$

Based on their molecular weight, both BNP and NT-proBNP (3.5 kDa and 8.5 kDa, respectively) are by definition members of the group of Small Molecular Weight Proteins (SMWP), which include all proteins with a molecular weight ranging from 1 to $50 \mathrm{kDa} .{ }^{13-15}$ These proteins are freely filtered by the glomeruli and catabolized by the tubular epithelial cells, without any other renal processing like tubular secretion as for instance in creatinine $(0.1 \mathrm{kDa})$ or active reabsortion as for instance in albumin $(69$ $\mathrm{kDa})$. Cystatin-C (13 kDa), another SMWP, combines all these characteristics with a steady production, making it a promising new marker for renal function, especially since in contrast to creatinine, its production seems not to be influenced by other: parameters such as body composition. ${ }^{16.17}$

In order to study the influence of renal function on serum levels of BNP and NT. proBNP and since the production of Cystatin-C is also independent of myocardial function, we investigated the differences in renal handling of $B N P$, NT-proBNP and Cystatin-C in hypertensive patients undergoing renal arteriography for suspected renal artery stenosis.

\section{PATIENTS AND METHODS}

\section{Patients}

This study was performed in 178 hypertensive patients in whom renal artery stenosis was suspected on the basis of one or more of the following criteria: treatment-resistant hypertension despite the use of at least two adequately dosed antihypertensive agents, overt peripheral vascular disease, the presence of an abdominal bruit, or an increase in serum creatinine during $\mathrm{ACE}$ inhibitor treatment. 
Written informed consent was obtained from all patients and the Medical Ethical Committe of the Maastricht University Hospital had approved the study protocol. All antihypertensive medications were stopped 21 days prior to the investigation.

\section{Technical Investigations}

Routine echocardiography was performed according to standard clinical protocol within a four months period surrounding the angiography. After selective catheterisation of both renal arteries and veins and before administration of any contrast agent, blood samples were drawn simultaneously from the renal arteries and veins for determination of BNP, NT-proBNP, albumin, Cystatin-C and creatinine levels. Subsequently, mean renal blood flow (RBF) per $100 \mathrm{~g}$ renal tissue was measured selectively in both kidneys by the ${ }^{133}$ Xenon washout technique, as described before. ${ }^{18-20}$ Briefly, after subtraction of background radiation, the disappearance of Xenon $(37 \mathrm{MBq})$ from the kidney, measured by an extra-corporal sodium iodide detector, is analyzed mathematically using a twophase exponential decay model. Occasionally, a monophasic decline in activity is observed and the curve is analyzed accordingly. RBF is calculated as the weighted average of the fast and the slow component, and is expressed as ml per minute per $100 \mathrm{~g}$ renal tissue. All RBF analyses were performed using Prism 3.0 software. The Xenon washout technique provides an accurate estimate of renal blood flow and in our hands, and has a coefficient of variation of $8 \%$ for repeated measurements. Since less than $1 \%$ of arterial flow becomes urine, we assume venous flow to equal arterial flow.

\section{Laboratory tests}

BNP levels were assessed by using a RIA method (Shionoria, Shionogi, Japan). NTproBNP levels were determined by an immuno-electrochemiluminisence method (Elecsys 2010, Roche Diagnostics, Switzerland), creatinine levels were assessed by a modified alkaline picrate method (Synchron LX 20, Beckman, USA). Since the arteriovenous difference is within the accuracy limits of detection, all patients with a NT-proBNP or BNP concentration $<5$ pmol/L were excluded from analyses that involve total arterial delivery and total venous efflux.

Albumin concentrations were determined by means of biochromatic digital endpoint methodology using bromcresol purple reagent (Synchron LX 20,Beckman, USA). Cystatin $\mathrm{C}$ was measured by particle enhanced immunonephelometry on a BN Prospec analyzer (Dade-Behring, Germany).

\section{Statistical Analyses and Calculations}

Renal Plasma Flow (RPF) was calculated as RBF $\times$ (1-hematocrit). Total arterial delivery of a substance was calculated as [concentration arterial $\times\left(\mathrm{RPF}_{\text {Lef }}\right.$ Kidney $+\mathrm{RPF}_{\text {Right }}$ Kidney )]. Total venous efflux of a substance was callculated as [(concentration Lef $_{\text {renal wein }} \mathrm{x}$ $\mathrm{RPF}_{\text {Leth Kidacy) }}+$ (concentration $_{\text {Right renal vein }} \mathrm{x}$ RPF Right Kidney)]. Renal uptake (in $\mathrm{mol} /$ minute/ $100 \mathrm{~g}$ renal tissue) by each kidney was computed as RPF $\mathrm{x}$ (arterial concentration--venous concentration). Total renal uptake was calculated as the sum of uptake by the right and left kidney. Fractional extraction of BNP or NT-proBNP was 
calculated as (total arterial delivery total venous effux) $\mathrm{x}$ (total anterial delivery) $\mathrm{x}$ $100 \%$ in patients with an NT-proBNP or BNP within the limit of detection. Glomerular filtration rate was calculated using the MDRD formula. ${ }^{21}$ NT-proBNP levels are expressed in pmol/1, to convert pmol/ to $\mathrm{pg} / \mathrm{ml}$, multiply by 8.47 . BNP levels are expressed in $\mathrm{pmol} / \mathrm{l}$, to convert pmol/l to $\mathrm{pg} / \mathrm{ml}$, multiply by 3.49 .

For statistical analyses SPSS 11.5 (SPSS Inc., Chicago, Illinois, USA) software was used. Data are presented as medians with inter-quartile ranges (IOR) for non-normally distributed variabies and means \pm standard deviations (SD) for all other continuous variables. Pearson $r$ was used to test correlations. The 2 -tailed independent student $t$-test was used in nomal distributed parameters, the Mann-Whitney $U$ test was used in nonparametric distributions, the $\chi^{2}$ test was used for categorical variables. Differences of correlations were considered significant when $\mathrm{p}<0.05$.

\section{RESULTS}

Renal angiography was successfully performed in all 178 patients. Baseline characteristics are shown in Table 1. In 39 patients it was not possible to measure flow in both kidneys due to severe renal artery stenosis, congenital single kidney, prior nephrectomy or technical problems.

Table 1: Baseline characteristics of study patients

\begin{tabular}{|c|c|}
\hline Gharacteristies & Meap(15O) \\
\hline sex (naleitemale) & $86 / 50$ \\
\hline age (years) & $56(12)$ \\
\hline length $(\mathrm{cm})$ ? & $170(11)$ \\
\hline welghl $(\mathrm{kg})$ & $79(18)$ \\
\hline body surace area $(\mathrm{m})$ & $192(0.23)$ \\
\hline hematoct $(\%)$ ) & $4016)^{2}$ \\
\hline serum creatinine (umoln) & $93(39)$ \\
\hline 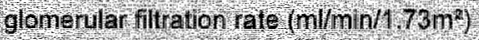 & $77(26)$ \\
\hline Meanateral bloog & $134(23)$ \\
\hline
\end{tabular}

Serum levels of BNP correlated well with serum levels of NT-proBNP $(r=0.79$, $\mathrm{p}<0.001)$. We confirmed the correlation between GFR and serum concentration of Cystatin- $C(r=0.72 ; p<0.001)$ and also the previously published correlations between GFR and serum concentrations of NT-proBNP and BNP $(r=-0.32$ and $p=<0.001$ for both) (Figure 1). 
$62 \mid$ CHAPTER

Figure $1 \mathrm{ABC}$ : Relationship between Glomerular Filtration Rate (GFR) and serum concentrations of Cystatin-C (figure 1A) MT-proBNP (figure 1B) and BNP (figure 1C)

Figure $1 \mathrm{~A}$

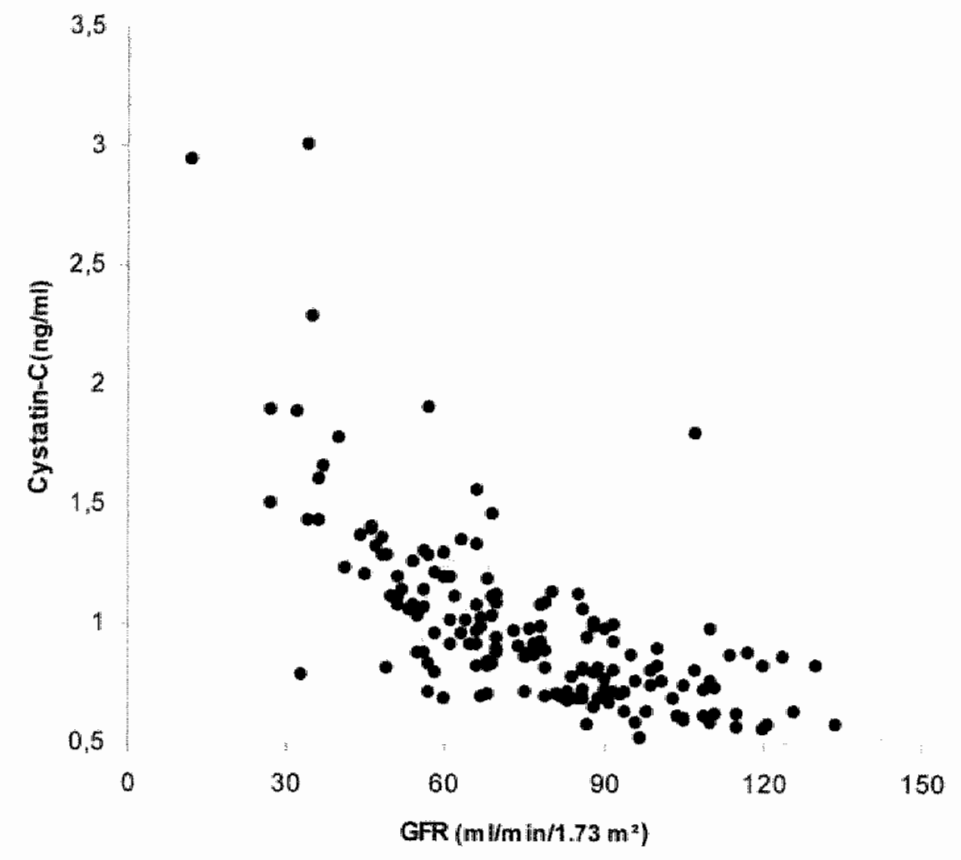

Figure $1 B$

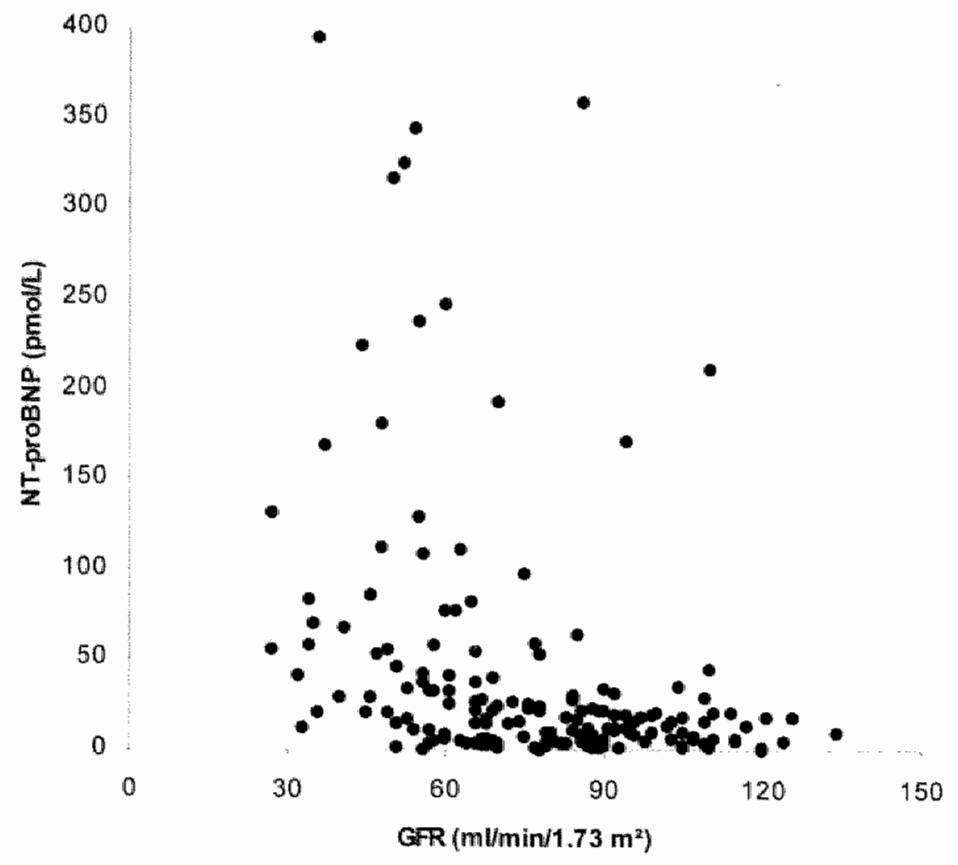


Figure $1 \mathrm{C}$

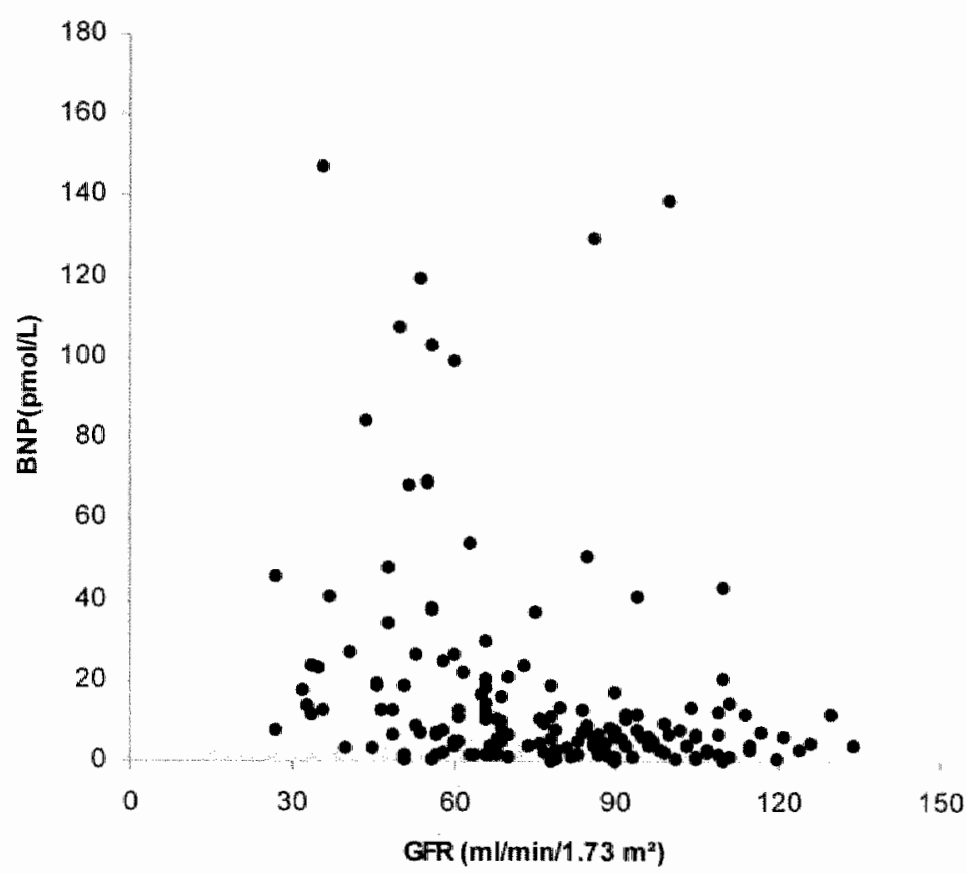

Fractional extractions of BNP and NT-proBNP correlated with the fractional extraction of Cystatin-C but not with the fractional extraction of albumin (Table 2).

Table 2: Correlations between different fractional extractions

\begin{tabular}{|c|c|c|}
\hline (1) & $\begin{array}{l}\text { Fractionat Extraction } \\
\text { Cystatinte }\end{array}$ & $\begin{array}{l}\text { Fraclonial Extrection } \\
\text { Aloumine. }\end{array}$ \\
\hline 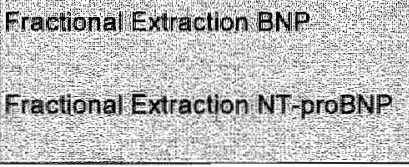 & $\begin{array}{l}p=139 \\
p+0,01 \\
P=0,50 \\
P<0,001\end{array}$ & $\begin{array}{l}P=0.03 \\
P=0.79 \\
P=0.10 \\
P=0.45\end{array}$ \\
\hline
\end{tabular}

To study possible differences in renal handling of natriuretic peptides in the presence or absence of impaired GFR, we dichotomised the study group into subjects with a GFR $>/=60 \mathrm{ml} / \mathrm{min} / 1.73 \mathrm{~m}^{2},(\mathrm{n}=129)$ versus those with a $\mathrm{GFR}<60 \mathrm{ml} / \mathrm{min} / 1.73 \mathrm{~m}^{2}(\mathrm{n}=48)$. Results are shown in Table 3. No significant differences were found between fractional extraction of either BNP, NT-proBNP or Cystatin-C in both groups. Renal plasma flow was lower in the patients with impaired GFR. Echocardiographic examination revealed that the e/a ratio was significantly lower in the patients with renal impairment $(0.79+\%$ 0.22 versus $1.01+1-0.39 ; p<0.001$ ) and that left ventricular mass index was higher in this group, although the latter value was of borderline statistical significance (see "Table 3). 
Table 3: Main characteristics of the patients with nomal ( $\left.50 \mathrm{mimin} / 1.73 \mathrm{~m}^{2}\right)$ and impaired

( $60 \mathrm{~m}$ t/min/1. $73 \mathrm{~m}$ ) renal function.

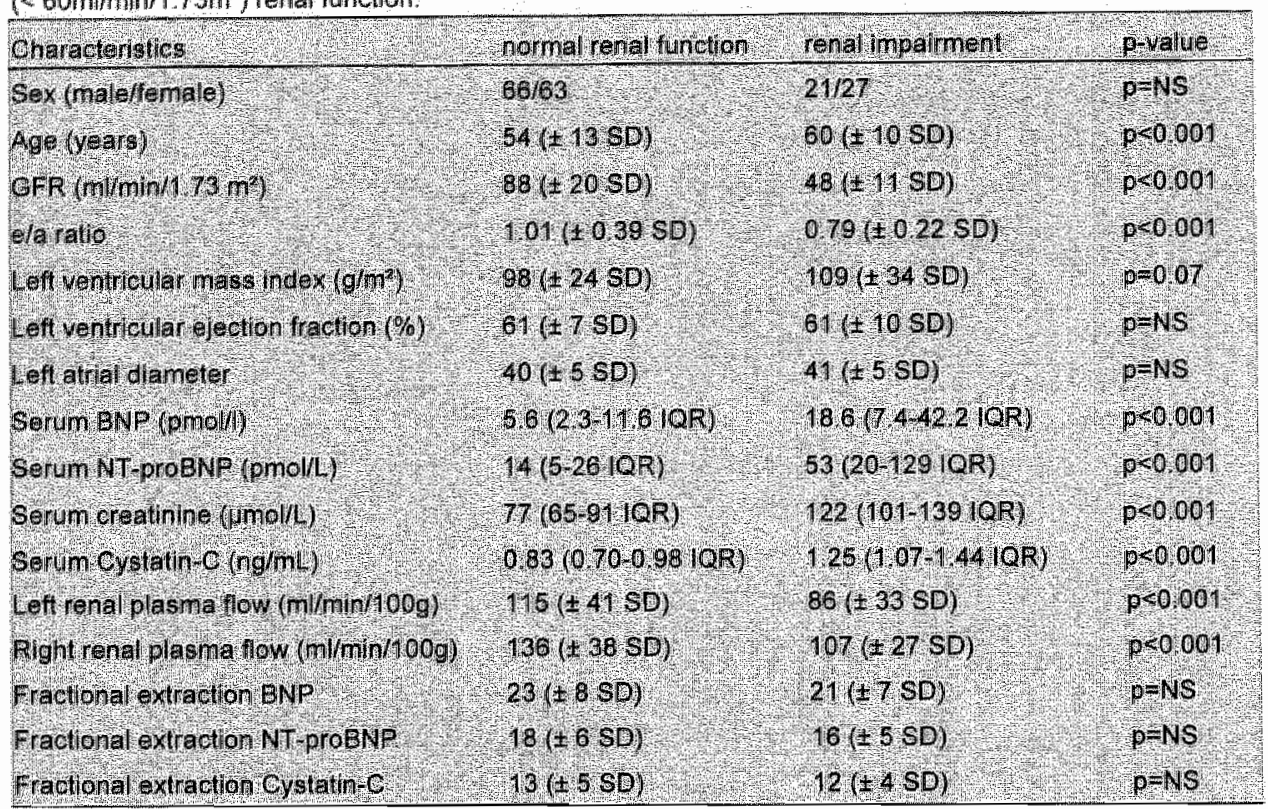

Data are given as mean $₫$ Standard Deviation(SD) for parametric parameters and as median with InterQuartile Regions (IQR) for non-parametric parameters.

\section{DISCUSSION}

We studied the human renal handling of BNP, NT-proBNP and Cystatin-C. Cystatin-C is of similar size as BNP and NT-proBNP and all are expected to pass the glomerulus freely. The main difference between the peptides is that while Cystatin-C is produced at a constant rate, production of BNP and NT-proBNP obviously varies with cardiac loading. We show here that both BNP and NT-proBNP are renally cleared in a manner similar to that seen for other Small Molecular Weight Proteins, (SMWP) indicating that there are no particular properties regarding the renal handling of both natriuretic peptides. This has important ramifications, as it shows that renal handling of both natriuretic peptides can be inferred by judging the renal handling of Cystatin-C.

We show here that serum concentrations of the steadily produced SMWP Cystatin-C relates strongly to GFR, which underlines that circulating levels of a continuously produced SMWP is importantly influenced by renal function. In contrast, variably produced SMWPs like the natriuretic peptides correlate quite poorly with GFR. This suggest that serum concentrations of such a SMWP are mainly governed by their rate of production, of course within a certain limit of GFR.

That production, rather than clearance is the major determinant in our population, is underscored by our finding that in subjects with renal impairment, echocardiographic parameters indicated diastolic dysfunction. It has been previously shown that elevated levels of BNP are related to diastolic dysfunction. ${ }^{22}$ Therefore, we believe that the fact 
that renal impairment and a diminished cardiac function are usually associated, is more important for the correlation between GFR and BNP or NT-proBNP than a simple accumulation of these proteins (as is the case for Cystatin-C). Unfortunately, echocardiography was not performed on the moment of sampling and other studies who were more specific designed to address this issue, clearly show that patients with renal impairment and elevated levels of BNP or NT-proBNP have echocardiographic abnormalities. ${ }^{23.24}$ Even in dialysis patients, BNP is independently linked to left ventricular mass and function and has shown to predict overall and cardiovascular mortality. ${ }^{25}$ This underlines that these elevated levels of pepticles cannot simply be interpreted as merely artefacts.

Although 48 patients in our study population had a GFR $<60 \mathrm{ml} / \mathrm{min} / 1.73 \mathrm{~m}^{2}$, there were only 4 patients with a GFR below $30 \mathrm{ml} / \mathrm{min} / 1.73 \mathrm{~m}^{2}$. Therefore, our conclusions should not be extrapolated to patients with end stage renal disease or undergoing dialysis. Interestingly, while we studied the renal handling of natriuretic peptides, studies investigating the cardiac production of natriuretic peptides confirm our above findings. ${ }^{26}$ This group measured BNP concentrations in the aortic root and coronary sinus of 366 heart failure patients thus enabling to assess the cardiac production of BNP. It was striking that at similar levels of production, the serum values did not increase in subjects with a GFR above $40 \mathrm{ml} / \mathrm{min}$ indicating that in this range, lowering GFR did not affect the serum levels of BNP. However, in patients with a GFR $<40 \mathrm{ml} / \mathrm{min}$, production of BNP increased, but at the same time serum level rose proportionally more. This suggest that while cardiac production is increased in subjects with more severe loss of renal function, impaired clearance only seems to play a role when GFR drops below $40 \mathrm{ml} / \mathrm{min}$.

We conclude therefore from combining this study with ours, that renal impaiment only contributes to serum concentrations of BNP and NT-proBNP when the GFR is less than $30-40 \mathrm{ml} / \mathrm{min} / 1,73 \mathrm{~m}^{2}$. However, since McAlister et al. show that $84 \%$ of the heart failure patients have a GFR $>30 \mathrm{ml} / \mathrm{min}$, BNP and NT-proBNP offer valuable information in the majority of heart failure patients. ${ }^{9}$ Still caution must be exerted when judging subjects with severely depressed renal function. Here we propose that in latter cases, concomitant measurement of Cystatin- $\mathrm{C}$ may provide a reliable estimation of the renal component in determining the levels of BNP and NT-proBNP.

It is presumed that, although steric and electrostatic factors also play a role in glomerular filtration, all molecules weighing less than 40-50 kDa pass the glomerulus freely. ${ }^{14}$ Since both BNP ( $\left.3.5 \mathrm{kDa}\right)$ and NT-proBNP $(8.5 \mathrm{kDa}$ ) weiglh significantly less, filtration in the glomeruli is not limiting the clearance of both natriuretic peptides in patients with moderate renal impairment.

In patients with heart failure, the decrease in GFR is mostly caused by a decrease in RPF rather than a decrease in filtration fraction. ${ }^{27}$ However, it is unlikely that changes in RPF (in the range that we studied) affects only the renal clearance of the natriuretic peptides and not of other peptides one could use to correct for.

This mechanistic study questions the concept that the association between lower GFR and increased natriuretic peptide levels is merely based on accumulation. Previously, other association studies have also been erroneously interpreted to indicate a lack of renal clearance, thereby causing clinicians to distegard valid diagnostic measures. For example, elevated levels of lipase $(56 \mathrm{kDa})$ in patients with renal impairment have been 
assumed to result from impaired excretion. ${ }^{2 *}$. This neglected the obvious alternative explanation that elevated lipase may signify pancreatic damage in patients with renal impaiment: Baggenstoss already described in 1948 that nearly $50 \%$ of the patients who died of chronic renal failure had histological abnormalities of the pancreas ${ }^{30}$ However, only when Seno et al. showed that the renal clearance of lipase is not hampered in patients until the creatinine clearance is less than $40 \mathrm{ml} / \mathrm{min}^{31}$ it was acknowledged that elevated lipase may signify pancreatic damage in patients with renal impairment. Indeed, after the introduction of CT and ultrasonography it was shown that the incidence of acute pancreatitis is almost a 100 -fold increased in patients with chronic renal failure. ${ }^{32}$

A difference in renal handling in patients with renal impairment cannot explain the relatively higher serum levels of NT-proBNP as compared to BNP: both peptides seem to be handled equally by the kidney. However, since the ratio NT-proBNP/BNP increases further in patients with renal impaiment, as shown by Kenperman et al., another explanation needs to be proposed.

Unlike NT-proBNP, BNP is not only cleared by filtration but also by the specific clearance receptor NPR-C and the Neutral Endopeptidase 24.11 (NEP). ${ }^{34}$ Kuhn and colleagues showed that the implantation of a left ventricular assist device in patients with severe heart failure decreases myocardial expression of the NPR-C clearance receptor, which led the authors to conclude that with worsening heart failure the NPR-C is upregulated. ${ }^{35}$ This confirms the earlier findings by Andreassi and colleagues, who also described an upregulation of the NPR-C clearance receptor in platelets of patients with heart failure. ${ }^{37}$ Speculatively, this suggests that clearance of BNP by a non-renal route via the NPR-C is upregulated in worsening heart failure, a mechanism that does not influence clearance of NT-proBNP, and could be responsible for an elevated NTproBNP/BNP ratio in renal impaiment. Yet an alternative mechanism for upregulation of non-renal clearance of BNP is suggested by Jaffe et al ${ }^{38}$ who raise the possibility that the difference in serum levels of BNP and NT-proBNP may be caused by an increase of NEP activity whose serum levels are increased in patients with end-stage renal disease. ${ }^{30}$

Secondly, our patient population consisted of hypertensive subjects rather than patients suffering from heart failure. Although our patients do have a level of renal function which is comparable to patients in heart failure," our patients naturally have a lower production of BNP and NT-proBNP than heart failure patients. Hypothetically, one can not exclude that in heart failure patients accumulation of these peptides might be more important. However, our data also indicate that therefore the production has to be increased, which corrects this possible accumulation effect.

Taken together we propose that NT-proBNP or BNP are handled by the kidney in the same manner as Cystatin-C or any other SMWP and that correcting for Cystatin-C might improve the diagnostic capacity of NT-proBNP or BNP. However, we also show that the effects of mild renal impairment is modest, so that correction for Cystatin-C does not seem to be needed in clear-cut diagnostic situations (with dramatically increased NT-proBNP or BNP levels or GFR $>40 \mathrm{ml} / \mathrm{min} / 1.73 \mathrm{~m}^{2}$ ) but may be warranted when modest changes in NT-proBNP or BNP are accompanied by a changes in GFR, so that the dynamics of GFR can be accounted for by taking Cystatin-C into account. 


\section{REFERENCES}

1. Januzzi JL, Jr., Camango CA. Aruwaruddin $\mathrm{S}$, et all. The N-terminal Pro-BNB Lmestigation of Dyspnea in the Emergency department (PRIDE) study. Am I Cardio 2005; 95:948-54.

2. Maisel AS, Krishnaswamy P, Nowatk RM, et al. Rapid measurement of B-type natrutedit peptide in the emergency diagnosis of heart faitute. N Engl J Med 2002; 347:161-7.

3. Bettencourt P, Azevedo A, Pimenta 1, Frioes F, Ferreina S, Ferreira A. N-Teminal-Pro-Brain Natriuretic Peptide Predicts Outcome After Hospital Discharge in Hewr Failure Patients. Circulation 2004: $110: 2168-2174$.

4. Maisel A, Hollander JE, Guss D, et al. Primary results of the Rapid Emergency Deparment Heart foulure Outpatient Trial (REDHOT). A multicenter study of B-type natriuretic peptide levels, energency department decision making, and outcomes in pattients presenting with shormess of breath. I Am Coll Cardiol $2004 ; 44: 1328-33$.

5. Troughton RW, Frampton CM, Yandle TC, Espiner EA, Nicholls MG, Richards AM. Treatment of heart fallure guided by plasma aminoterninal brain natrututic peptide (N-BNP) concentrations. Lancet 2000; $355: 1126-30$.

6. Luchner A, Hengstenberg C, Lowel H, al $\mathrm{N}$-Terminal Pro-Brain Natriuretic Peptide After Myocardicil Infaretion: A Marker Of Cardio-Renal Function. Hypertension 2002; 39:99-104.

7. MeCullough PA, Duc P, Omland T, et al. B-type natrunetic peptide and renal function in the diagnosis of heart failure: an analysis from the Breathing Not Properly Multinational Study. Am „K Kidtey Dis 2003; $41: 571-9$

8. Luchner A, Hengstenberg $C$, Lowel H, et al. NT-ProBNP in Outpatients After Myocatian Infarction: Interaction Between Symptoms and Left Ventricular Function and Optimized Cut-Points. J Card frat $20015 ; 11: 21-7$.

9. MeAlisten. FA, Ezekowitz 1, Tonelli M. Armstrong PW. Renal Insufficiency and Heart Failute: Prognostic and Therapentic dmplications Lrom a Prospective Conort Study. Circulation 2004; 109:1004. 1009 .

10. Parfrey PS, Foley RN, Harnet JD, Kent OM, Murray DC, Barre PE. Outcone and risk factors for lett wentricular disorders in chronic uraemia. Nephrol Dial Transplant 1996;11:1277-85.

11. MoDonagh TA, Holmer $S$, Raymond I, Luchner A, Hildebrant F*, Dargie HI. NT-proBNP and the diagnosis of heart failure: a pooled analysis of three European epidemiological studies. Buropean Joumal of Heart Fallure $2004 ; 6: 269-273$.

12. Alehagen $U$, Lindstedt $G$, Eriksson $H$, Dahlstrom U. Utility of the Amino. Teminal Fragment of ProBraill Natriuretic Peptide in Plasma for the Evaluation of Cardiac Dysfunction in Elderly Patients in Primary Health Care. Clin Chem 2003; 49:1337-1346.

13. Carone FA, Peterson DR, Oparil S, Pulman TN. Retal tubulam transport and catabolism of proteins and peptides. Kidney Int 1979; $16: 271-8$

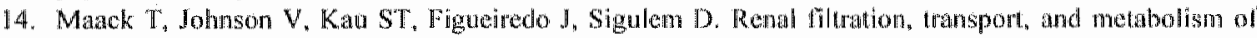
low-molecular-weight proteins: a deview. Kidney ln 1979; 16:251-70.

15. Clark WR, Gao D. Low-imolecular weight proteins in end-stage renal disease potential toxicity and dialytic removal mechanisms. IAm Soc Nephrol 2002; 13 Suppl I:S41-7.

16. Grubb AO. Cystatin C-propertics and use as diagnostim marker. Adv Clin Chem 2000; 35:63.99.

17. Shlipak MG, Sarnak MJ, Katz R, el al. Cystatin $C$ and the risk of death and candiovascular events among elderty persons. N Engl J Med 2005; 352:2049-60.

18. Wierema TK. Houben AJ, Kroon AA el al. Nitric oxide dependerne of renal blood flow in patients wilh renal artery stenosis. $1 \mathrm{Am}$ Soe Nephrol 2001; 12:1836-43.

19. Fogteloo Al, Meinders AE, Pijl H. Kroon AA. Frobich M, De Leww PW. Renal alearnce ol endogenous leptin in lypertensive humans with or without tenal atiery stenosis. Am \& Physiol bodocrinol Motab $200: ; 28:: \mathrm{E} 400-4$.

20. Ladefoged J. Measurements of the renal blood flow in man with the 133 xenon wash-out wehnique. A description of the method. Scand A Clin Lab Invest $1966 ; 18: 290.315$.

21. Levey AS, Bosch JP, Lewis JB, Greene T, Rogers N, Roth D. A More Accurato Method To Fstimate Glomerular Filtration Rate from Serum Creatimine: A New Prediction Equation. Ann Intern Med 1999; $130: 461-470$. 
22. Lubien $\mathrm{E}$, DeMaria $A$, Krishnaswamy $\mathrm{P}$, et al. Utility of B-natriuretic peptide in detecting diastolic dysfunction: comparison with Doppler velocily recordings. Circulation 2002; 105:595-601.

23. Takam $Y$, Horio $T$, Iwashma $Y$, et al. Diagnostic and prognostic walue of plasma brain aatriuretic peptide in non-dialysis-dependent CRf. Am J Kidney Dis 2004; 44:420-8.

24. Defilippi $\mathrm{CR}_{\text {a }}$ Fink JC, Nass $\mathrm{CM}_{\text {, }}$ Chen $\mathrm{H}_{3}$ Christenson R. N-terminal pro-B-type natriuretic peptide for predicting coronary disease and left ventricular hypertrophy in asymptomatic CKD not requiring dialysis. Am J Kidney Dis 2005; 46:35-44

25. Zocali $\mathrm{C}$, Mallamaci $\mathrm{F}$, Benedeto $\mathrm{FA}$, et al. Cardiac natriuretio peptides are related to left ventricular mass and function and predict mortality in dialysis patients. J Am Soc Nephrol 2001; 12:1508-15.

26. Cody $\mathrm{RJ}$, Ljungman $\mathrm{S}$, Covit $\mathrm{AB}$, et al. Regulation of glomerular filtration rate in chronic congestive heart fallure patients. Kidney Int 1988; 34:361-367.

27. Royse WL, Jensen DM, Corwin HL. Pancreatic enzymes in chronic renal failure. Arch Intern Med 1987; $147.537-9$

28. Thinery $\mathrm{FX}$, Dueymes $\mathrm{JM}$, Vernier $\mathrm{I}$, et al. Serum lipase and anylase levels in chronic renal failure: interpretation of resulis-xeffects of extrarenal purification. Nephrologie 1988:9:263-7.

29. Baggenstoss A. The pancreas in uremia: a histopathologic study. Am J Pathol 1948:24:1003-18.

30. Seno $T$, Harada $H$, Ochi $K$, et al. Serum levels of six pancreatic enzymes as related to the degree of renal dysfunction. An J Gastroenterol 1995; 90:2002-5.

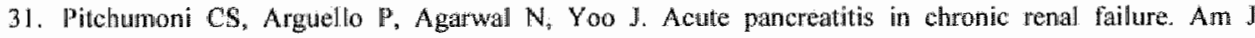
Gastroenterol 1996; $91: 2477-82$.

32. Kemperman $H$, van den Berg $M$, Kirkels $H$, de Jonge $N$. B-Type Natriuretic Peptide (BNP) and $\mathbb{N}_{\text {- }}$ Terminal proBNP in Patients with End-Stage Heart Failure Supported by a Left Ventricular Assist Dewice. Clin Chem 2004; 50:1670m1672.

33. Mukoyama M, Nakao $K$, Hosoda $K$, et al. Brain natriuretic peptide as a novel cardiac hormone in humans. Evidence for an exquisite dual natriuretic peptide system, atrial natriuretic peptide and brain natriuretic peptide. J Clin Imvest 1991; 87:1402-12.

34. Sonnenberg JI, Sakane $Y$, Jeng $A Y$, et al Identification of protease 3.4.24.11 as the mator atrial natriuretic factor degrading enzyme in the rat kidney. Peptides 1988;9:173-80.

35. Kulin M, Vols M, Mitko D, et al. Left ventricular assist device support rewerses altered cardiac expression and function of natriuretic peptides and receptors in end-stage heart failure. Candiovascular Research 2004; 64:308-314.

36. Andreassi MG, Del Ry S, Palmieri C, Clerico A, Biagini A, Giannessi D. Up-regulation of 'clearance' receptors itn patients with chronic heart failure: a possible explanation for the resistance to biological effects of cardiac natriuretic hormones. Eur J Heart Fail 2001; 3:407-14.

37. Whe $A S$, Apsie $\mathrm{BS}$, Babuti L. Why wo dont know the answer maty be more important than the specific question. Clin Chem 2004: 50:1495-7.

38. Deschodt-Lanckman M, Michaux F, De Prez E, Abranowicz D, Vanherweghem $\mathbb{J}$, Goldman $M$. Increased serum levels of endopeptidase 24.11 (enkephalinase') in patients with end-stage renal failure. Lite Sei 1989; 45:133-41.

39. Tsutamoto $T_{n}$ Wada $A_{n}$ Sakai $K$, et al. Relationship Between Renal Function and Plasma Brain Natriuretic Peptide in Patients With Heart Failure. J Am Coll Cardiol 2006; 47.582-6. 


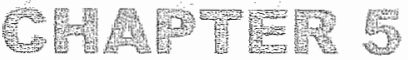

\section{Brain Natriuretic Peptide Production Is Decreased in Obese Subjects}

$R$ van Kimmenade*, $F$ van Dielen ${ }^{\dagger}, J$ Bakker", J Nijhuis", H Crijns", W Burman ", M van Dieijen-Visser", J-W Greve', Y Pinto *

* Department of Cardiology, University Hospital Maastricht

${ }^{\dagger}$ Department of General Surgery, University Hospital Maastricht

* Department of Clinical Chemistry, University Hospital Maastricht

I Department of General Surgery,Maastricht University 


\section{INTRODUCTION}

Both obesity and heart failure (HF) are highly prevalent syndromes in modern western society. Nearly $60 \%$ of the US population has a body mass index (BMI) $>25 \mathrm{~kg} / \mathrm{m}^{2}{ }^{1}$ The incidence of HF approaches 10 per 1000 among persons older than 65 years: ${ }^{2}$ Since both syndromes are highly prevalent, patients are likely to suffer from both simultaneously.

Surprisingly, obese HF patients have a better prognosis than normal weight HF patients, giving rise to the so-called "Obesity Paradox".

Brain Natriuretic Peptide (BNP) and aminoterminal proBNP (NT-proBNP), are established diagnostic markers in HF. However, it is unclear how to interpret the levels of especially BNP in overweight patients, since BNP is cleared by the Natriuretic Peptide Receptor type-C (NPR-C) which is abundantly expressed in adipocytes. Indeed, a negative correlation has been described between BNP and BMI. ${ }^{5-7}$ Interestingly, a similar correlation was recently described for NT-proBNP, which is not cleared by NPR-C. To reliably address these relationships, we investigated the effect of a decrease in $\mathrm{BMI}$ following bariatric surgery, on the concentrations of BNP and NTproBNP.

\section{METHODS \& RESULTS}

We studied 22 patients ( 5 male, 17 femalle, median age 38 years) referred to our General Surgery Department for surgical treatment of obesity. Blood samples were collected 1 day before surgery, 3 months after surgery and 6 months after surgery.

The medical history of the patients showed diabetes $(n=6)$, hypertension $(n=4)$ and myocardial infarction $(n=1)$. No patient was known with HF or was using diuretics, ACE-inhibitors, angiotensin receptor blockers, or spironolacton during the study. Four patients were using betablockers with no alternations during the study.

We conlirm the correlation between BNP and NT-proBNP vs. BMI in the combined consecutive measurements $(r=0.30, p<0.05 ; r=0.41, p<0.01$ respectively). BMI decreased drastically after 3 months $(\mathrm{p}<0.001)$ and 6 months $(\mathrm{p}<0.001)$, while BNP and NT-proBNP concentrations significantly increased after 3 months ( $p<0.01$ for both) and 6 months ( $\mathrm{p}<0.01$ for both) (Table I and Figure $1 A B C$ ). 
Table 1: Dynamic changes over time in the studied subjects

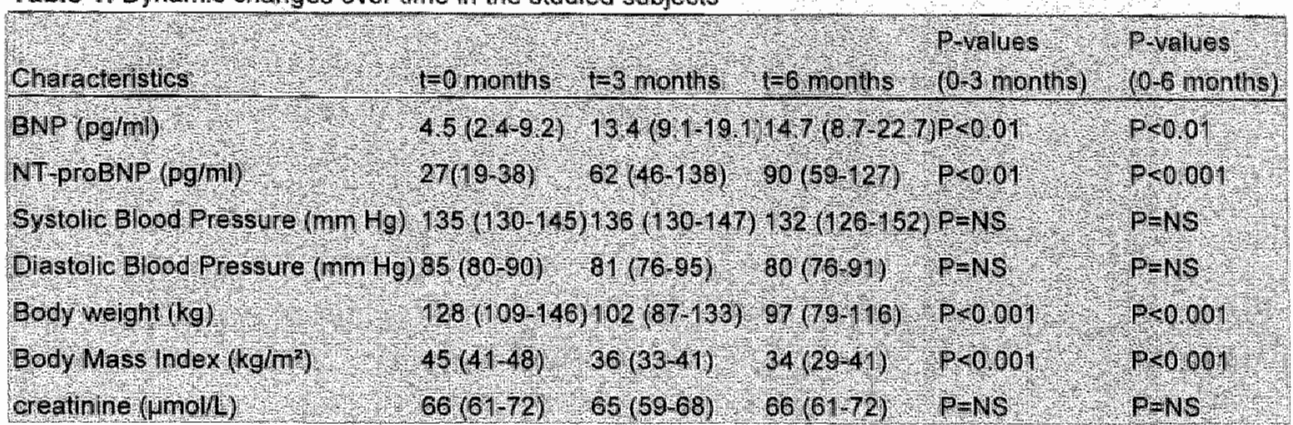

Data are provided as medians with interquartile range (IOR). The Wilcoxon signed ranks test wes used to analyze differences between preoperative and postoperative values within the patients. Spearman correlation coefficients were computed for correlation.

Figure 1: Dynamic changes in time in BMt (figure 1A), BNP concentrations (figure 1B) and NT-proBNP concentrations (figure 1C)

Figure $1 A$

\section{BMI}

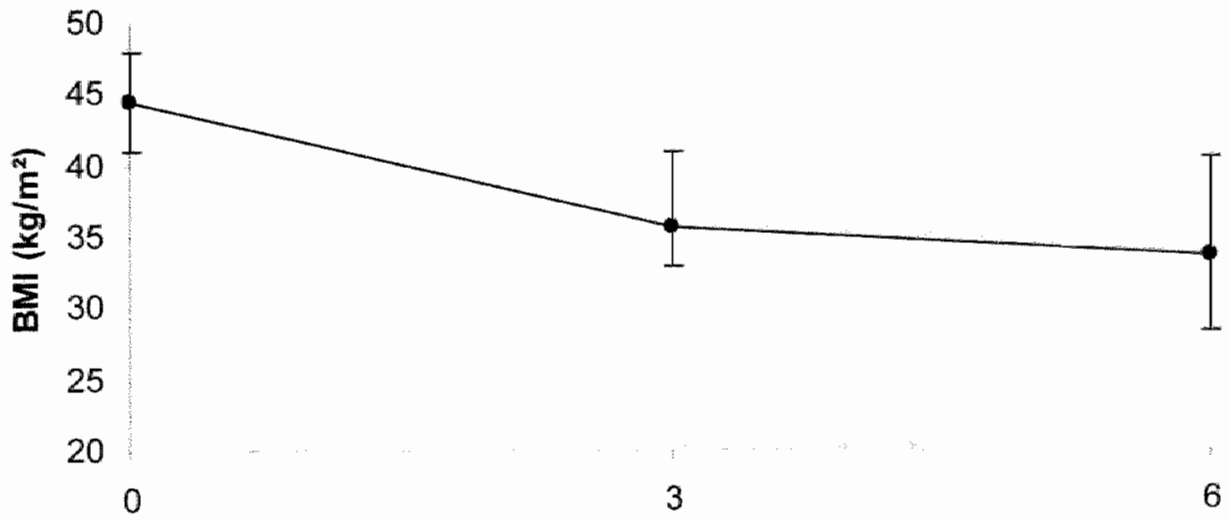

Time (months) 
${ }_{72} \mid$ OHATEE

Figura $1 B$

\section{BNP}

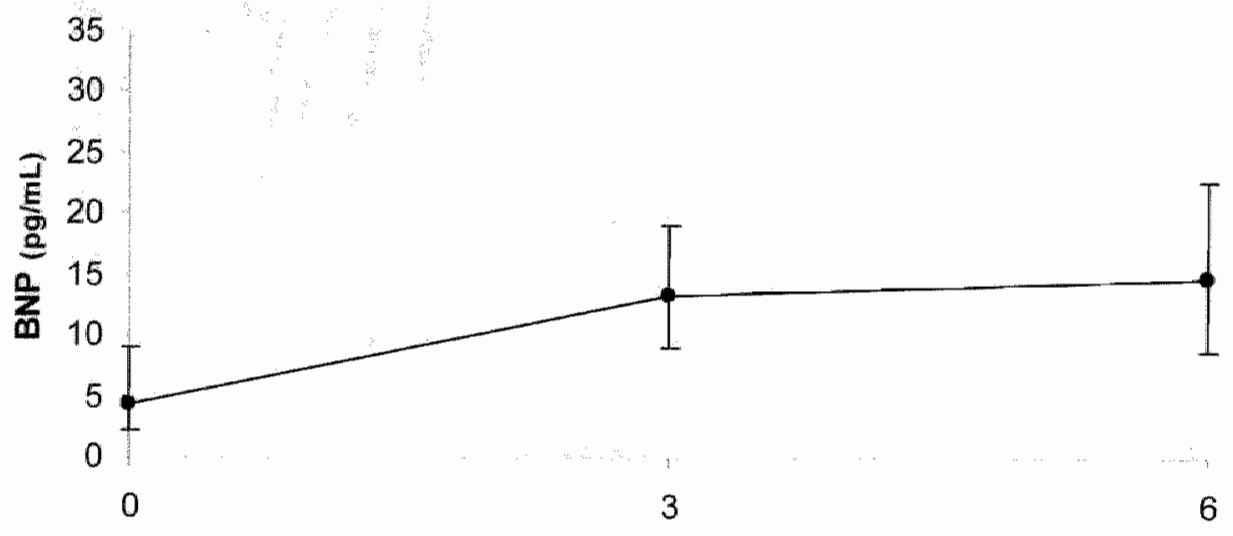

Time (months)

Figure $1 \mathrm{C}$

\section{NT-proBNP}

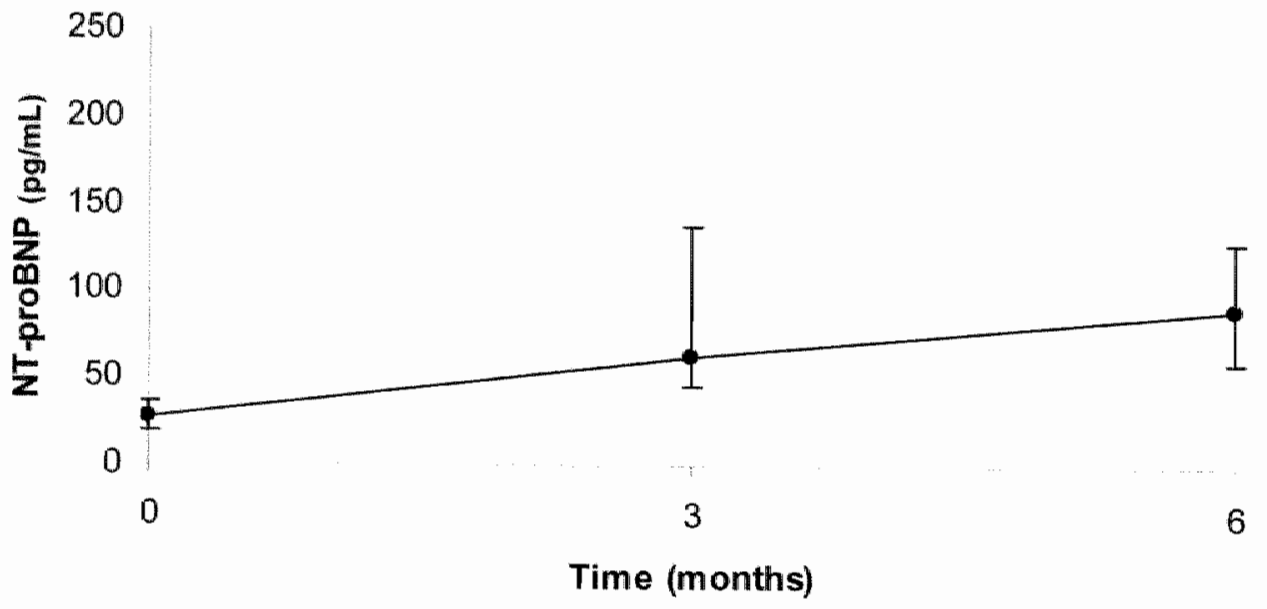




\section{DISCUSSION}

Our study rejects the hypothesis that the negative correlation between BNP and BMI is due to an upregulation of NPR-C, since the NPR-C does not clear NT-proBNP. Given the fact that both peptides derive simultaneously from the cleavage of their common predecessor proBNP, but are cleared via different mechanisms, the parallel associations between peptide concentrations and BMI suggest a relationship between adipose tissue and production.

The negative correlation between BNP and BMI was already known from large observational studies. ${ }^{5-7}$ However, these results left room for different explanations. It has for instance been hypothesized that obesity leads to an increase in NPR-C activity or that obesity causes a decrease in BNP production.9. 10

The finding that BNP and NT-proBNP increase simultaneously after weight loss, suggests that obesity suppresses their common production. This finding raises the question whether their suppression is caused either by hindered production or reflects truly lower wall stress. As both peptides are powerful predictors of outcome, "1. "the above suggest the contra-intuitive notion that lower (NT-pro)BNP concentrations herald a better prognosis for obese subjects. Mehra et al. found lower BNP levels in obese versus mon-obese $\mathrm{HF}$ patients with a non-significant tendency towards lower one-year event rate in the obese patients. ${ }^{6}$ Other studies show a significant better prognosis in obese HF patients ${ }^{3}$ suggesting that lowered (NT-pro)BNP levels indeed reflect a more advantageous cardiac status.

Our data support findings by others concerning the regulation of natriuretic peptides secretion in obesity. Morabito et al. show a decreased mRNA expression of ANP in hearts of obese rats. ${ }^{10}$ Licata and colleagues found a lack of ANP response and a reduced suppression of renine and aldosterone after saline load in obese subjects. ${ }^{9}$ We therefore speculate that neurohumoral interactions are altered and decrease natriuretic peptide production in obese subjects.

Our study is the first interventional study to show that a decrease in BMI is accompanied by an increase in not only BNP but also NT"proBNP. This inplies that there is a relationship between adipose tissue and the production of these peptides. It has been suggested that lower BNP concentrations in obese subjects are caused by an increased clearance. If this were true, we would have expected only BNP to rise after weight loss. However, NT-proBNP also rose after surgery. Taken together with the fact that both peptides derive simultaneously from their joint predecessor proBNP, the parallel increase suggests that production of BNP increases with decreasing weight.

This somewhat counter-intuitive conclusion is in line with previous studies and suggests that the previously reported negative correlation between BMI and (NT-pro)BNP cannot be explained by inappropriate inclusion of severely obese subjects as having $\mathrm{HF}$. Our data are also congruent with the notion that obese HF patients have a better prognosis, as lower BNP and NT-proBNP concentrations are powerful predictors of better outcome. $^{11.12}$ Taken together, our findings show that BNP and NT-proBNP concentrations increase with decreasing weight. This is likely to be due to dlecreased cardiac production of BNP, suggesting some yet undefined beneficial effects of obesity in HF which clearly warrants further study. 


\section{REFERENCES}

1. Must A. Spadamo J, Coakley ELF, Field AE, Coldita G, Dietz WH. The disease burden associated with overweight and obesity. JAMA $1999: 282: 1523-9$.

2. Jessup $M$, Brozena S. Heart failure. N Engl J Med 2003; 3482007-18.

3. Horwich TB, fonarow GC, Hanilton MA, MacLellan WR, Woo MA, Tillisch JH. The relationship between obesity and mortality in pattents with heart failure. I Am Coll Cardiol 2001; 38:789-95.

4. Sarani $\mathbb{R}$, Dessi-Fulgheri $\mathbb{P}$, Paci VM, Espinosa E, Rappelli A. Expression of watriuretic peptide receptors in human adipiose and other tissues. J Endocrinol invest $1996 ; 19: 581-5$.

5. Wang $\mathrm{TJ}$, Larson MG, Levy $\mathrm{D}$, et al. Jmpact of obesity on plasma natriuretic peptide levels. Circultion $2004 ; 109: 594-600$.

6. Mehra MR, Uber PA, Park MH, et al. Obesity and suppressed B-type natriuretic peptide levels in heart failure. I Am Coll Cardiol 2004; 43:1590-1595.

7. MeCord J, Mundy BJ, Hudson MP, et al. Relationship between obesity and B-type natriuretic peptide levells, Arch lntern Med 2004; 164:2247-52.

8. Krauser DG, Lloyd Jones DM, Chae CU, et al. Effect of body mass index on natriuretic peptide levels in patients with acule congestive heart failure: A ProBNP Investigation of Dyspnea in the Emergency Department (PRIDE) substudy. An Heart I 2005; 149:744-50.

9. Licala $\mathrm{G}$. Volpe $\mathrm{M}, \mathrm{Scagglione} R$, Rubattu $\mathrm{S}$. Salt-regulating homones in young normotensive obese subjects. Efrects of saline load. Hypertension 1994: 23:120-4.

10. Morabilo D, Vallotton MB, Lang U. Obesity is associated with impaired ventricular protein kinase CMAP kinase signaling and aftered ANP" mRNA expression in the heart of adult Zucker rats. IInvestig Med 2001; 49:310m8.

11. Betlencourt P, Azevedo A, Pimenta J, Frioes F, Ferreira S, Ferreira A. N-Terminal-Pro-Brain Natriuretic Peptide Predicts Outcome After Hospital Discharge in Heart Faillure Patients. Circulation 2004; 1 10:2168-2174.

12. Maisel A, Hollander JE, Guss D, et al. Primary results of the Rapid Emergency Department Heart Failure Outpatient Trial (REDHOT). A multicenter study of B-type natriuretic peptide levels, emergency department decision making, and outcomes in patients presenting with shortness of breath. I A.m Coll Cardiol 2004; 44:1328-33. 


\section{Utility of NT-proBNP, Galectin-3, and Apelin} for the Evaluation of Patients with Acute Heart Failure

$\mathrm{R}$ van Kimmenade*, J Januzzi Jrt, P Ellinort, U Sharma*, J Bakkert. A Lowt, H Crijns*, C MacRaet, P Menheeret, Y Pinto*

* Department of Cardiology, University Hosptal Maastricht. The Netherltands †Division of Cardiology, Massachusetts General Hospital, USA

†Department of Clinical Chemistry, University Hospital Maastricht, The Netherlands

I Am Coll Cardiol 2006; provisionally accepied

Drs. van Kimmenade and Januzzi contributed equally to this manuscript 


\section{ABSTRACT}

Aim: To explore the role of new biomarkers in heart failure.

Methods: Plasma levels of NT-proBNP, apelin and galectin-3 were measured in 599 patients presenting with dyspnea at the Emergency Department, of which $209(35 \%)$ had acute HF.

Results: NT-proBNP was superior to either apelin or galectin-3 for diagnosis of acute HF, although galectin-3 levels were significantly higher in subjects with HF compared to those without. Receiver operating characteristic ( $R O C$ ) analysis for mortality prediction demonstrated that, for 60 days prognosis, galectin-3 had the greatest area under the curve (AUC) at $0.74(\mathrm{p}=0.0001)$, while NT-proBNP and apelin had an AUC of $0.67(\mathrm{p}=0.009)$ and $0.54(\mathrm{p}=0.33)$. In a multivariate logistic regression analysis, an elevated level of Gal-3 was the best independent predictor of 60-day mortality (OR $10.3, \mathrm{p}<0.01$ ) or the combination of death/recurrent HF within 60 days. (OR 14.3, $\mathrm{p}<0.001)$ Kaplan-Meier analyses showed that the combination of an elevated galectin-3 with NT-proBNP was a better predictor of mortality than either of the two markers alone.

Conclusions: Our data demonstrate potential utility of Galectin-3 as a useful marker for evaluation of patients with suspected or proven acute $H F$, while apelin measurement was not useful for these indications. Moreover, the combination of galectin-3 with NTproBNP was the best predictor for prognosis in subjects with acute HF.

Keywords: Heart failure, prognosis, galectin-3, apelin, serum markers 


\section{INTRODUCTION}

It is estimated that the probability for an adult individual to develop heart failure (HF) during their lifetime is $20-30 \%,{ }^{1,2}$ with attendant financial costs for modern society. ${ }^{3}$ Additionally, despite the introduction of therapies to reduce mortality, the 30 days cumulative survival rate after incident HF exacerbation is only $86 \%,{ }^{i}$ leaving much room for improvement in the optimal evaluation and risk stratification for those so afflicted. ${ }^{3.5}$

In order to improve the short and long-term prognosis of those with HF, it would be important not only to improve the identification of those with advanced $\mathrm{HF}$, but to also be able to recognize those at highest risk for hazard. Unfortunately, even for experienced physicians, it is a complex task to properly diagnose HF and accurately assess prognosis. Accordingly, objective assessment utilizing cardiac biomarkers may be one avenue in which patients may be routinely evaluated for the presence and severity of HF. In order to optimize such a strategy, the multiple mechanisms by which heart failure leads to higher morbidity and mortality must be addressed. Thus, a single biomarker is not likely to be sufficient for a comprehensive evaluation; a multi-marker approach is therefore more likely to be of use. ${ }^{6}$

Brain Natriuretic Peptide (BNP) and its cleavage equivalent amino-terminal proBNP (NT-proBNP) are established serum markers for diagnosis and prognosis in acute or chronic HF ${ }^{7-10}$ Both peptides derive from the cleavage of proBNP, which production is rapidly up-regulated when cardiomyocytes are stretched. ${ }^{11}$ These peptides identify increased wall stress, and have proven utility for confirming the diagnosis of acute $\mathrm{HF}^{\mathrm{F}}$ in breathless subjects and predict adverse outcomes in these patients. ${ }^{7.8}$

Besides myocardial stretch, other mechanisms, such as inflammation ${ }^{12}$ or pathways regulating cardiac contractility might also play a role in $\mathrm{HF}$, while these processes might not be reflected by natriuretic peptide levels. Previous data suggest that activated cardiac macrophages produce galectin-3 (gal-3), a substance that impairs cardiac function. ${ }^{13}$ In addition, concentrations of apelin, a potent endogenous inotropic peptide have also been suggested to identify the presence of HF and to parallel risk for death. ${ }^{14}$ Despite promise of both gal-3 and apelin for the evaluation of HF, little is known about the clinical utility of either marker. Accordingly, in an effort to better understand the individual and integrative role of these novel markers of heart failure, we tested the individual and combined diagnostic and prognostic utilities of gal-3 or apelin, together with NT-proBNP, for the evaluation of subjects with suspected or proven HF.

\section{PATIENTS AND METHODS}

\section{Patients}

The institutional review board approved all investigational procedures involved in this study. The details of the PRIDE study have been published previously. ${ }^{B}$ Briefly, this study examined 599 acutely dyspneic subjects presenting to the Emergency Department of the Massachusetts General Hospital, Boston, USA. 
For each subject, a study physician assigned a final diagnosis of acute HF (from any cause) versus non-cardiac dyspnea, utilizing all hospital records pertaining to the subject, starting from the time of emergency department presentation through 60-day follow-up. These records included (when avallable) office notes, hospital discharge records, and results of all laboratory and imaging tests except for NT-proBNP levels. In addition, at 60 days an attempt was made to contact every patient and review subsequent medical course after presentation.

\section{Laboratory Measurements}

At the time of presentation, a blood sample was collected into tubes containing EDTA; the blood was immediately processed and frozen at $-80^{\circ} \mathrm{C}$ for later measurement of NTproBNP, gal-3, and apelin.

NT-proBNP analysis was performed with a commercially available immunoassay (Elecsys proBNP, Roche Diagnostics, Indianapolis, Indiana) on an Elecsys 1010 analyzer according to established methods.

Gal-3 was analysed using a commercially available ELISA kit (Bender Medsystems, Vienna, Austria) and was measured on a Victor 2 plate reader (Perkin Elmer, Turku, Finland). Calibration of the assay was according to the manufacturer's protocol. Values were normalized to a standard curve. The intra-assay and inter-assay variances for Gal-3 were $5.6 \%$ and $8.6 \%$ respectively.

Plasma apelin levels were determined using a commercially available enzyme immunoassay without extraction (Phoenix Pharmaceuticals, Belmont, CA) according to the manufacturer"s instructions. This assay employs an immunoaffinity purified rabbit antibody specific for apelin 1-12. All apelin assays were performed in duplicate with intra-experimental standards using a Victor 3 plate reader (Perkin-Elmer, Wellesley, MA). Values were nomalized to a standard curve. The intra-assay and inter-assay variances for apelin were $19 \%$ and $17 \%$ respectively. This assay employs an immunoaffinity purified rabbit antibody specific for apelin 1-12. The antibody has $100 \%$ cross reactivity to apelin $1-12,1-13$ and $1-36$; there is no cross reactivity to ADM-52, BNP-32, CNP-22, ANP (25-56), ghrelin, ET-1, or bradykinin.

\section{Statistical Analyses}

Medians of each marker in those with and without acute HF were compared utilizing non-parametric testing, while comparisons of biomarker concentrations between groups categorized by the New York Heart Association (NYHA) classification were performed using Kruskal-Wallis testing. Otherwise, concentrations of NT-proBNP, gal-3, and apelin were log-transformed to achieve normality, especially for the multivariate analyses. Comparisons of clinical characteristics between those surviving to 60 days from presentation versus those who died were performed utilizing $\chi^{2}$ tests for categorical data and the Wilcoxon rank-sum test for continuous data.

Receiver operating characteristic (ROC) curves were utilized to evaluate the utility of gal-3 and apelin compared to NT-proBNP for the diagnosis of acute HF in breathless subjects, as well as for identifying risk of death by 60 days in those with a diagnosis of acute HF. For those markers with a significant area under the ROC curves, optimal cut- 
points for identifying or excluding risk of 60-day mortality in those with acute HF were identified. ROC analyses were performed using Analyse-it software (Analyse-lt, Ltd, Leeds, UK).

Following the identification of optimal cut-points for identifying risk of mortality. Kaplan-Meier survival curves were constructed to compare 60-day mortality nates in groups divided as a function of cardiac marker categories (neither above the prognostic threshold, NT-proBNP alone above prognostic threshold, or both above the prognostic threshold), using the log-rank test to compare the rates of mortality.

\section{Multivariate Analyses}

Multivariable stepwise logistic regression was used to identify independent clinical and biochemical predictors of death or death/readmission by 60 -days in all subjects. 39 variables were considered prior to univariate analysis; only those with retention parameters $<0.05$ were considered for MV analyses. These are depicted in Table 3. Those variables considered for univariate analyses are listed in Table 1 and 2, as well as several not listed, namely race, duration of symptoms, prior medication use (including beta blocker, ACE inhibitor, etc), body-mass index, other laboratories at presentation, as well as hospital course for index hospitalization, including index diagnosis, as well as laboratory testing (including NT-proBNP and gal-3 results).

In each analysis, goodness of fit was verified using the Hosmer-Lemeshow test. For each independent predictor in multivariable analyses, odds ratios (OR) were calculated with $95 \%$ confidence intervals (CI). For all statistical analyses, all p values are twosided, with results $<0.05$ considered.

\section{RESULTS}

\section{Diagnosis of HF in Breathless Subjects}

As documented before, of the 599 subjects in the PRIDE study, $209(35 \%)$ had acute HF as a final diagnosis. In these 209 patients, 135 patients had ischemic HF as cause of their HF, while in 74 patients, there was a non-ischemic or unknown orign. Among the 390 subjects without acute HF, 150 had obstructive airways disease exacerbation, 64 had pneumonia, 31 had acute coronary syndromes, 19 had pulmonary embolism, and in 116 subjects dyspnea was attributed in $<10$ cases each to: allergic reactions, anxiety, ascites, atrial fibrillation, fever, fibrothorax, gram negative sepsis, herpes zoster, hypertension, lung carcinoma, pericarditis, supraventricular tachycardia, or unknown.

As previously described for this population, median concentrations of NT-proBNP were higher in those with acute HF versus those without (4054 versus $131 \mathrm{pg} / \mathrm{ml}, \mathrm{p}<0.001$ )." (table 1) Similarly, median concentrations of gal-3 were significantly higher in subjects with acute HF (9.2 versus $6.9 \mathrm{pg} / \mathrm{ml}, \mathrm{p}<0.001)$. Median concentrations of apelin were not different between those with and without acute HF (357 versus $360 \mathrm{pg} / \mathrm{ml}, \mathrm{p}=0.86$ ). 
Tabile 1 comparison of demographic characteristics of heart failure and non heart failure patients



With respect to HF etiology or type, there were no significant differences in median concentrations of each marker when considering ischemic versus nonischemic/unknown origin of HF (NT-proBNP: $4549 \mathrm{pg} / \mathrm{ml}$ vs. $3332 \mathrm{pg} / \mathrm{ml}, \mathrm{p}=0.61$, gal$3: 9.41 \mathrm{ng} / \mathrm{ml}$ vs $8.80 \mathrm{ng} / \mathrm{ml}, \mathrm{p}=0.35$; apelin=357.0 $\mathrm{pg} / \mathrm{ml}$ vs. $361.5 \mathrm{pg} / \mathrm{ml} ; \mathrm{p}=0.61$ ).

In contrast, considering type of $\mathrm{HF}$, median concentrations of NT-proBNP were higher in patients with systolic HF versus those with non-systolic $\mathrm{HF}(6196 \mathrm{pg} / \mathrm{ml} \mathrm{vs} .3134$ $\mathrm{pg} / \mathrm{ml}, \mathrm{p}<0.00 \mathrm{l})$. This pattern was not seen when considering gal-3 $(9.42 \mathrm{ng} / \mathrm{ml}$ vs. 8.96 $\mathrm{ng} / \mathrm{ml}, \mathrm{p}=0.97)$ or apelin (351 pg/ml vs $362 \mathrm{pg} / \mathrm{ml}, \mathrm{p}=0.66)$.

As previously described, ${ }^{8}$ ROC analysis examining NT-proBNP for diagnosis of acute HF yielded an area under the curver (AUC) for NT-proBNP of $0.94(p<0.0001)$. ROC analysis for gall-3 for the diagnosis of HF showed an AUC of 0.72 ( $p<0.0001)$, with an optimal cut-off of $6.88 \mathrm{ng} / \mathrm{ml}$ yielding a sensitivity of $80 \%$ and a specificity of $52 \%$. In contrast, the AUC for apelin for diagnosis of acute HF was $0.52(p=0.23)$. A comparison of the three ROC curves is demonstrated in Figure 1. 
Figure 1: Combined ROC curves for NT-proBNP, Gal-3 and Apelin for the dliagnosis of heart faiture in dyspneic patients. ROC analysis for NT-proBNP showed an AUC for NT-proBNP of $0.94(0<0.0001)$. ROC analysis for gal-3 showed an AUC of 0.72 ( $p<0.0001)$. The AUC for apelin for diagnosis of acute theart failure was $0.52(p=0.23)$.

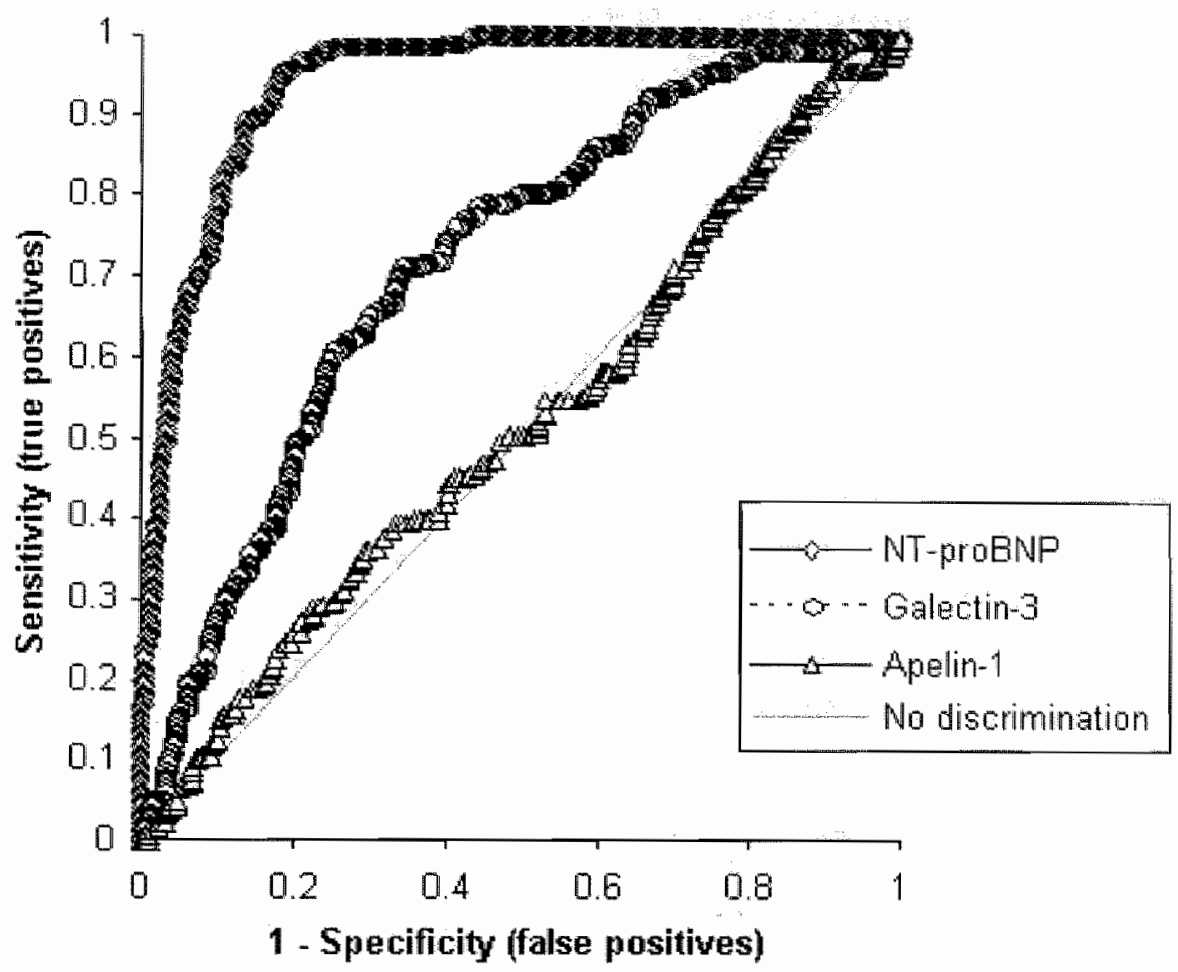

NT-proBNP had significantly greater AUC than either gal-3 or Apelin for the diagnosis of acute HF ( $<<0.0001)$; gal-3 had significantly greater AUC than Apelin ( $<<0.001$ ). Neither gal-3 nor Apelin concentrations correlated with NYHA classification.

When considering other important diagnoses in patients without acute $\mathrm{HF}$, we found no significant differences in either gal-3 or apelin concentrations in subjects with exacerbation of obstructive airway disease (median gal-3 concentration $7.38 \mathrm{ng} / \mathrm{ml}$ in patients with obstructive airway disease vs. $8.15 \mathrm{ng} / \mathrm{ml}$ in the patients without obstructive airway disease, $\mathrm{p}=0.08$; median apelin concentrations $359 \mathrm{pg} / \mathrm{ml}$ vs. 360 $\mathrm{pg} / \mathrm{ml}, \quad \mathrm{p}=0.67$ respectively) or pulmonary thromboembolism (median gal-3 concentration $7.37 \mathrm{ng} / \mathrm{ml}$ in patients with pulmonary thromboembolism vs. $7.51 \mathrm{ng} / \mathrm{ml}$ in the patients without pulmonary thromboembolism, $\mathrm{p}=0.88$; median apelin concentrations $356 \mathrm{pg} / \mathrm{ml}$ vs. $360 \mathrm{pg} / \mathrm{ml}$ respectively, $\mathrm{p}=0.45$ ) as a cause of their dyspnea. 


\section{Galectin-3, and apelin concentrations and short-term prognosis in HF}

Among the 209 subjects with acute $\mathrm{HF}, 60(29 \%)$ had recurrent $\mathrm{HF}$ within 60 days whille 17 patients $(8 \%$ ) died by 60 days of follow-up. Demographic characteristics expressed as a function of 60-day survival are shown in Table 2. Median concentrations of gal-3 were significantly higher among those subjects dying by 60 days of follow-up $(12.9 \mathrm{ng} / \mathrm{ml}$, interquartile range $[\mathrm{IQR}]=9.3-1.6 .5 \mathrm{ng} / \mathrm{ml})$ than in those surviving $(9.0$ ng/ml, $I Q R=7.3-11.6, p<0.001$ ). (Figure 2) In contrast, median apelin levels were not significantly different in decedents $(339 \mathrm{pg} / \mathrm{ml}, I Q R=250-576 \mathrm{pg} / \mathrm{ml})$ versus those surviving ( $361 \mathrm{pg} / \mathrm{ml}, 1 \mathrm{QR}=277-478 \mathrm{pg} / \mathrm{ml} ; \mathrm{p}=0.66)$.

ROC analysis for 60 days prognosis in acute HF showed an $\mathrm{AUC}$ for gall-3 of 0.74 ( $\mathrm{p}=0.0001$ ), an AUC for NT-proBNP of $0.67(\mathrm{p}=0.009)$ and an AUC for apelin of 0.54 $(\mathrm{p}=0.33)$, as depicted in fig 3 . In contrast to diagnosis of acute HF, gal-3 exhibited a significantly greater AUC than either NT-proBNP $(p=0.05)$ or Apelin $(p<0.0001)$. The optimal cut-point for gal-3 for prediction of 60-day mortality was 9.42 , which was $75 \%$ sensitive and $56 \%$ specific.

Table 2: Comparison of characteristics between patients dying during the 60 days of follow up with those surviving

\begin{tabular}{|c|c|c|c|}
\hline Gharacteristle & $\begin{array}{l}\text { Mortality } \\
(\mathrm{N}=17)\end{array}$ & $\begin{array}{l}\text { No Mortality } \\
(\mathrm{N}=192)\end{array}$ & value \\
\hline Age, years meantSDI & $60+83$ & $72+137$ & 0.06 \\
\hline Male gender & $53 \%$ & $51 \%$ & 0.47 \\
\hline Now York Heart Association elass IV & $53 \%$ & $54 \%$ & 074 \\
\hline Past medical history & & & \\
\hline Garciomyopathy & $29 \%$ & $19 \%$ & 020 \\
\hline Arial aribytimia & $41 \%$ & $31 \%$ & 0.55 \\
\hline Hypertension & $59 \%$ & $64 \%$ & 0.74 \\
\hline Biabetes melifins & $22 \%$ & $3.4 \%$ & 0.002 \\
\hline ry disoaro & 47\% & $42 \%$ & 079 \\
\hline Mrocardal & $24 \%$ & $20 \%$ & 0.71 \\
\hline Congessive healt fillu' & $65 \%$ & $53 \%$ & 0.51 \\
\hline Modications at braseilation & & & 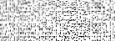 \\
\hline ieta blocker & $53 \%$ & $56 \%$ & $098^{2}$ \\
\hline Woop diuretic & $59 \%$ & $55 \%$ & 078 \\
\hline Digoxin & $20 \%$ & $22 \%$ & 088 \\
\hline Arigiolensil converting enzyma linibitor & $18 \%$ & $34 \%$ & 0.14 \\
\hline in tegeptor blocker & $12 \%$ & $7 \%$ & 0.20 \\
\hline Nitrato & $15 \%$ & $13 \%$ & 0.45 \\
\hline Pulse rate, beats per ninute (neajuse) & $02+19$ & $86+24$ & 0.09 \\
\hline Systolic blood pressure, nm Ha. (meanuso) & $123=29$ & $144 \pm 30$ & 0.39 \\
\hline Bedy rnass index rgim (meants b) & 26449 & $27+70$ & 0.86 \\
\hline SFR, nilmin/ 73 m $($ meandso $)$ & $46,3 \pm 10.5$ & 67426.0 & 00001 \\
\hline Creatinine, midl (meantsp) & $14+0.52$ & 1.00 .48 & 80001 \\
\hline Left ventriculse ejection fraction \% (meants & 475420 & $46.3+18$ & 0.88 \\
\hline Troponin t, nginil (hiedian) & 0.03 & $50.017+34$ & 0.009 \\
\hline NT proBNP poi m/ (nedian, $19 R$ & $8332(3864,157 / 7)$ & $3511(1610-954)$ & 002 \\
\hline Ga/3, nglmilmedlan, $\mathrm{QR}$ ) ? & $129(9,-16.5)$ & $90(73116)$ & 80.001 \\
\hline Apelin prima (median lar) & $339(250576)$ & $361(277-478)$ & 066 \\
\hline
\end{tabular}


Figure 2: Median Gall-3 levels among heart failure patients who died ( $n=17$ ) within 60 days and those survived $(n=192)$. Boxes, interquartile ranges; whiskers, 5 th and 95 th percentiles.

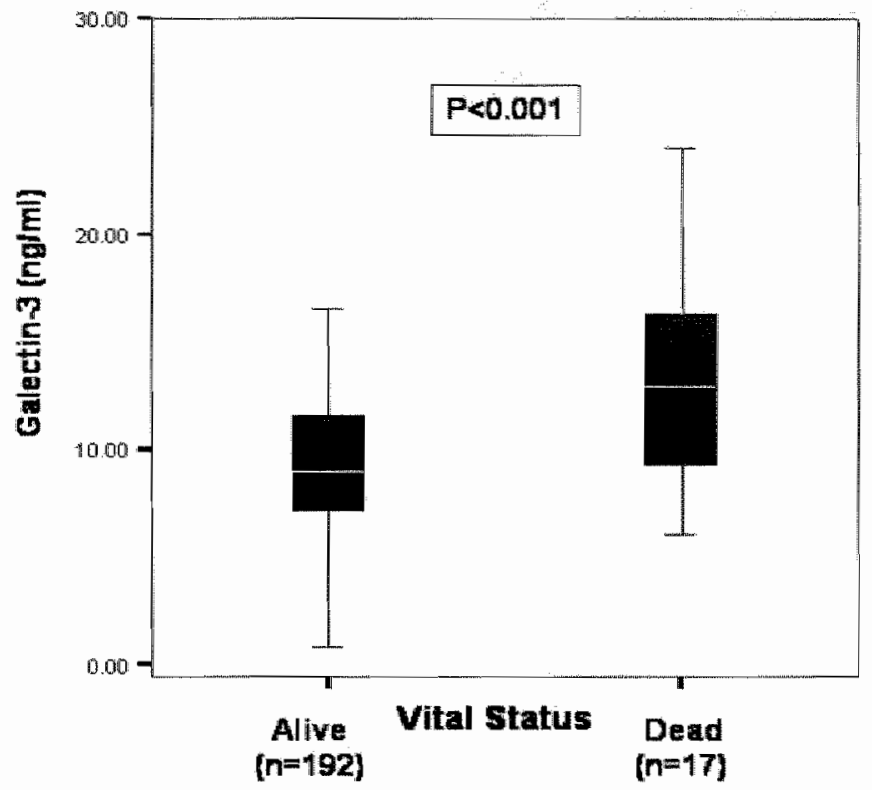

Figure 3: Combined ROC curves for NT-proBNP, Galm 3 and Apelin for 60 day mortality in heart failure. ROC analysis showed an AUC for gal-3 of $0.74(p=0.0001)$, an AUC for NT-proBNP of $0.67(p=0.009)$ and an AUC for apelin of $0.54(p=0.33)$.

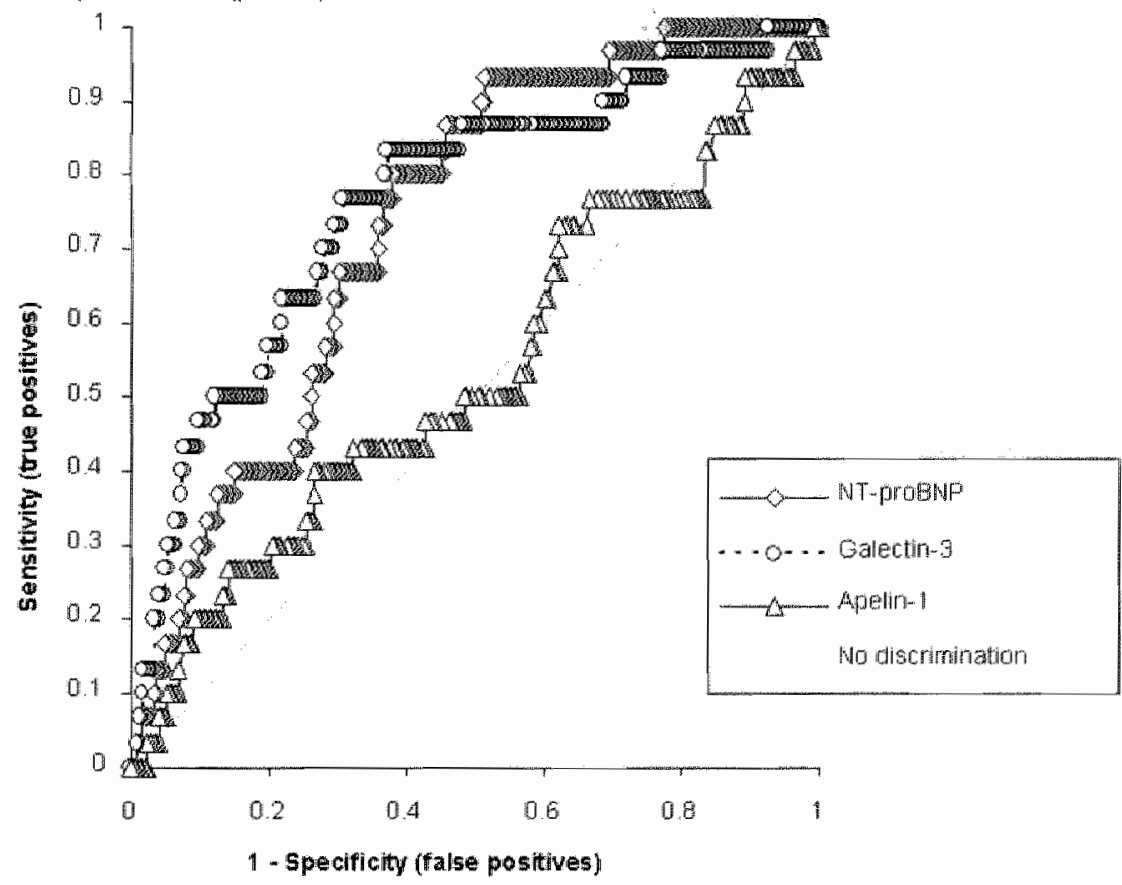


In adjusted multivariate analysis log-transformed gal-3 serum levels were the best predictor of shortenm mortality (OR 10.3, 1.6-174.1 95\% CI, p<0.01; Table 3A), superior to NT-proBNP for this purpose. However, considering the combination of NTproBNP and gal-3 for identifying those at highest risk for short-term mortality, KaplanMeier analyses showed that rates of death were highest in subjects with the combination of a gal -3 in excess of $9.42 \mathrm{ng} / \mathrm{ml}$ combined with NT-proBNP abowe $5562 \mathrm{pg} / \mathrm{ml}$ (Figure 4A).

Talbie 3A: Adjusted multivariate analysis for death within 60 days.

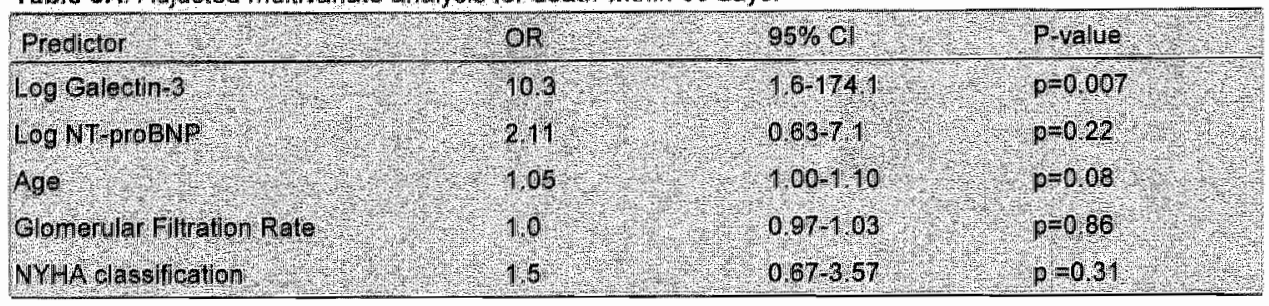

Table 3B: Adjusted multivariate analysis for the composite of death/recurtent HF within 60 days.

\begin{tabular}{|c|c|c|c|}
\hline prodetor & $O R$ & $95 \% \mathrm{Cl}$ & prave \\
\hline log Galectines & 143 & $56=45 \times$ & p <0.091 \\
\hline Log NTPRoBNP & 292 & $053-911$ & $p=0.42$ \\
\hline Age & 110 & (101/15 & $p=0,01$ \\
\hline Glomerular filtation Rate & 0198 & 0060.99 & $p=0.05$ \\
\hline NYHA classification & 156 & 078.97 & $p=020$ \\
\hline
\end{tabular}

A second adjusted multivariate analyses was performed, examining the combined endpoint of death or recurrent $\mathrm{HF}^{\mathrm{F}}$ also showed that the log-transformed gal-3 serum levels were the best predictor of events (OR 14.3 5.6-45.1 95\% CI, p < 0.001; Table $3 B$ ). Notably, the rates of death/recurrent HF were highest in subjects with elevations of both NT-proBNP and gal-3 (Figure $4 B$ ), with event rates somewhat differently affected by respective markers: elevated NT-proBNP concentrations paralleled higher rates of death (rather than recurrent HF), while gal-3 paralleled elevated rates for both death or recurrent $\mathrm{HF}$. 
Figure 4: Kaplan-Meier analyses show that in patients with acute heart failure, at presentation the: combination of a gal -3 in excess of $9.42 \mathrm{ng} / \mathrm{ml}$ combined with NT-proBNP above the optimal Gut ( $5562 \mathrm{pg} / \mathrm{ml}$ ) was assoclated with higher rates of death (Figure $4 \mathrm{~A}$ ) or mortality/recurrent heart failure (Figure $4 \mathrm{~B}$ ) than either of the two markers alone.

Figure 4A

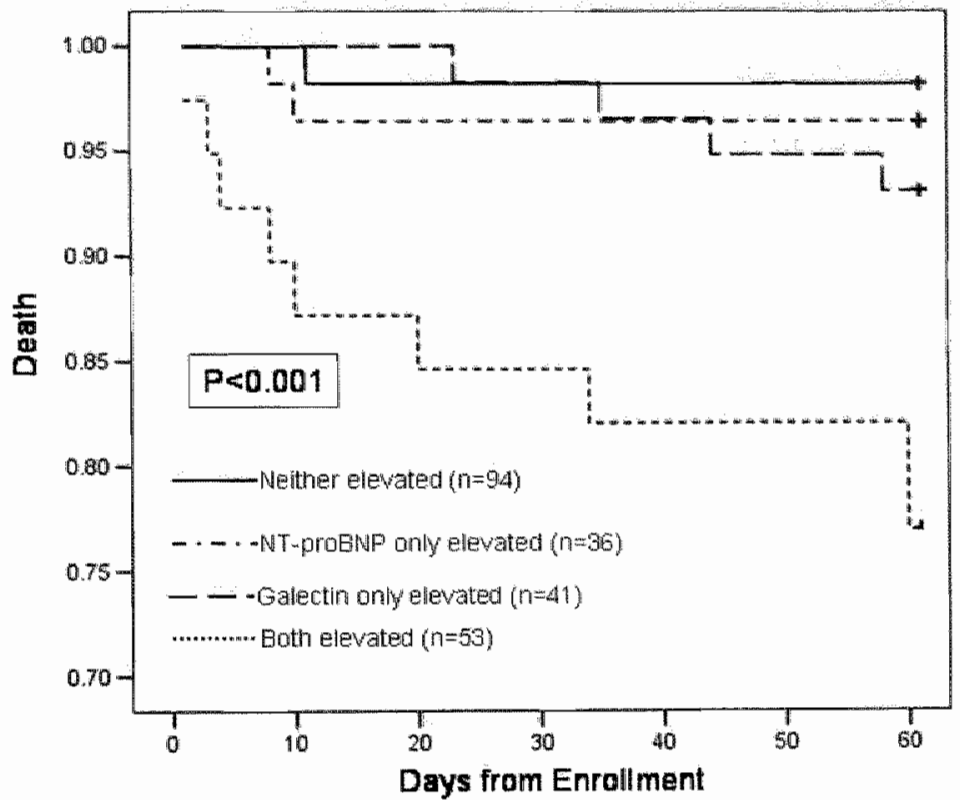

Figure $4 B$

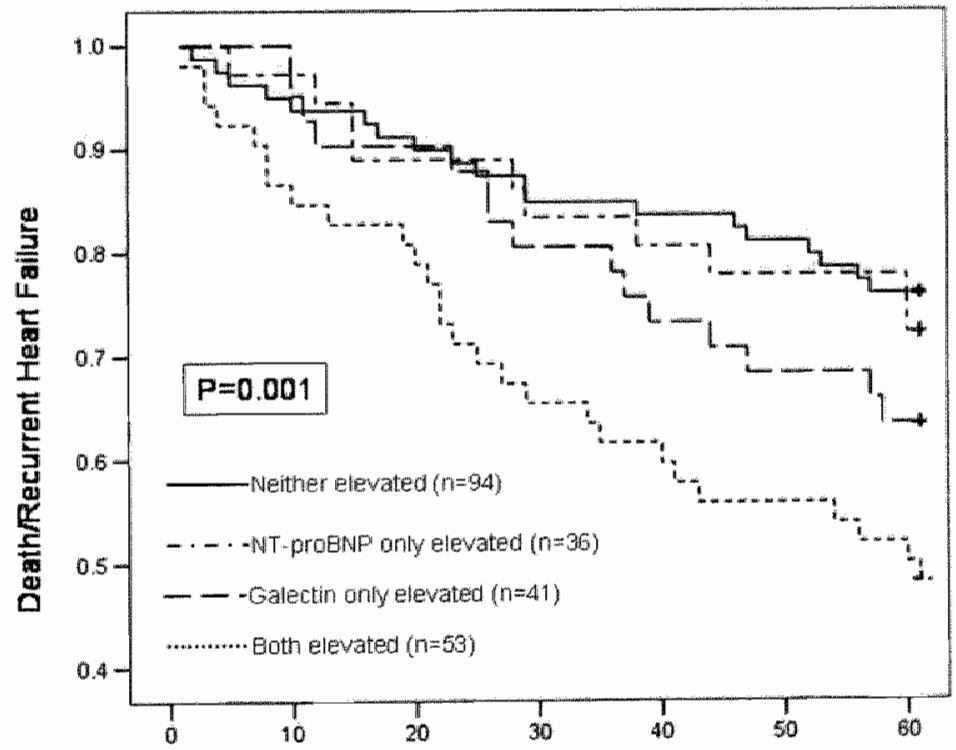

Days from Enrollment 


\section{DISCUSSION}

We have demonstrated that serum gal-3 levels are elevated in subjects with acute HF, and are prognostic of adverse outcomes over a 60-day period following presentation. In contrast, another novel marker with suggested utility in HF evaluation, apelin, did not appear to have similar utility for either diagnosis or short-term prognosis in our study. Notably, gal-3 was able to identify those HF patients at risk for short-term death or the combination of death or readmission within 60 days better than NT-proBNP; however, the combination of both markers appeared to further refine predictive utility. This finding may be of clinical importance, since the list of possible mortality-reducing interventions in HF continues to grow, ${ }^{15-18}$ although risk stratification of HF populations continues to be imperfect. This leads to considerable burden for patients, health care workers, and health care policy makers. Therefore, improving prognostication of $\mathrm{HF}$ patients by combined assessment of serum markers may help to tailor the most appropriate treatment strategy on a more individualized basis.

To date, various approaches have been proposed to prognosticate HF patients; recently the potential role of serum markers for this role has drawn considerable interest. ${ }^{6}$ While in our study NT-proBNP was superior to gal-3 for diagnosing acute HF, gal-3 was the stronger predictor of short-term mortality. Interestingly, combining gal-3 measurement with NT-proBNP allowed identification of a high-risk subgroup of acute HF subjects with a considerably higher risk of mortality compared to those with low concentrations of both NT-proBNP and gal-3. In contrast to the findings with gal-3, in this study we could not confirm a role for apelin ${ }^{14}$ as it was neither able to diagnose acute HF, nor to add prognostic information.

Since cardionyocytes represent anly one third of the myocardium, it is not surprising that cells other than myocytes are also involved in the progression of acute $\mathrm{HF}^{19}{ }^{19}$ It is also well known that in the failing human heart, immunologic and inflammatory processes play an important role. Proinflammatory cytokines modulating several cardiovascular mechanisms and activated monocytes and macrophages are all involved in the pathogenesis of not only ischemic, but all forms of HF, ${ }^{12,20-22}$ We have previously shown that cardiac macrophages are activated at an early stage in failure-prone, hypertrophied hearts and that these macrophages express gal-3. ${ }^{13}$ Intrapericardial infusion of gal-3 led to both cardiac structural changes and functional impairment in rats. ${ }^{13}$ Here we translate these experimental findings to a clinical application. Measurement of gal-3 is readily feasible and reliable in stored plasma and we here show that gal-3 levels are elevated in a discriminatory fashion in those with acute HF, with useful information regarding both diagnosis and prognosis.

Gal-3 is a $26 \mathrm{kDa}$ protein and a member of the galectin family, a group of carbohydratebinding proteins with a specific amino-acid sequence able to recognize B-galactose. ${ }^{23}$ Within this family, gal-3 is unique in structure; rather than consisting of merely one or two carbohydrate-recognition domains (CRD), gal-3 consists of tandem repeats of short amino-acid stretches fused onto the CRD. ${ }^{23-25}$ Secondly, while galectins lack a signal sequence necessary for secretion, after macrophage activation, cytosolic gal-3 shifts to the plasma membrane and integrates in vesicles extruding from the plasma membrane. ${ }^{26}$ Therefore, although gal-3 is expressed in cancerous tissue, cancer-associated stromal cells and even atherosclerotic lesions, ${ }^{23,27}$ it is not commonly significantly elevated in 
serum, other than in relatively rare clinical situations; such as in widely metastatic adenocarcinoma. ${ }^{28}$ Although theoretically this may limit the utility of gal-3 as a marker in $\mathrm{HF}$, the differentiation between disseminated cancer and HF Us usually easily done by history and physical examination.

The identification of biologically unique biomarkers offering complementary information for diagnosis (NT-proBNP), and prognosis (gall-3), as well as additive prognostic information when considered together, raises the possibility that our findings might be considered a step further towards a multimarker strategy for the evaluation of subjects with suspected or proven HF. Lee and Vasan already proposed a possible multimarker strategy and classified serum biomarkers in $\mathrm{HF}$ into 4 categories: neurohormonal markers, markers of myocyte injury, markers of matrix remodeling and inflammation related markers.". In our anallysis, we measured neurohormonal (NTproBNP, apelin) and inflammatory markers (gal-3), demonstrating the value of combining the two classes to improve prognostication. Interestingly, a marker of myocyte necrosis (cTnT) did not add independently useful information in our analysis, despite previous reports about the added value of combining cTnT with (NT-pro)BNP in $\mathrm{HF}^{29-32}$ This may merely reflect the limited power of our study.

Several other inflammation related novel biomarkers have been previously investigated in smaller numbers of HF patients, including TNF $\alpha$ receptor $1, C-C$ chemokines, soluble ST-2 receptor and apelin. ${ }^{33-35}$ Although the exact role of apelin is still not completely elucidated, it is considered to be a potent endogenous inotrope, involved in neurohumoral pathways. ${ }^{36,37}$ Since the expression pattern of apelin and the APJ receptor is similar to expression pattern of angiotensinogen and the AT I receptor, combined with the fact that A.PJ-deficient mice show an increased vasopressor response to angiotensin II, this strongly suggests that apelin plays an important role in the counterregulation of the effects of angiotensin $\mathbb{1 1} .^{14,38,39}$ Previous reports suggest apelin as a candidate marker in $\mathrm{HF}^{1 / 4}$ although the relationship between apelin and $\mathrm{HF}$ remains poorly understood. Although Foldes and colleagues demonstrated that circulating levels of apelin indeed are elevated in the early stages of $\mathrm{HF}^{\mathrm{F}}$, such levels actually decreased in more advanced stages of $\mathrm{HF}{ }^{40}$ Our findings may represent a dynamic intermediate situation between these two steady states.

Limitations of our study include the fact that gal-3 did not correlate with severity of dyspnea as categorized by the NYHA classification. Such a lack of correlation makes, according to some authors, a new diagnostic serum marker less suitable for clinical practice. However, we did not intend to investigate a new diagnostic marker, since it is already known that NT-proBNP is an excellent diagnostic marker in this population." A prognostic marker in HF actually does not necessarily correlate with NYHA classification, which is according to some authors rather subjective ${ }^{42}$ and merely a "crude estimation of a patients functional capacity". In addition, the relatively small number of subjects in our analysis, with relatively limited numbers of adverse events, may be a limitation as well. In addition, we were limited the ability to adequately explore the additional utility of a third marker with potential prognostic value in CHF such as cTnT. ${ }^{20-32}$ 
In conchusion, in contrast to negative findings with apelin, we found that gal-3 may be a novel marker for diagnosis and prognosis of acute HF. Combining clinical measurement of gal-3 and NT-proBNP may be a paradigm for the steps further towards a multimarker approach for diagnosis, prognosis and potentially optimal, more focused therapeutic management of $\mathrm{HF}$.

\section{Acknowledgements}

This study was sponsored by a grant from the Netherllands Heart Foundation.

\section{REFERENCES}

1. Bleumink $G S$, Knetsch AM, Sturkenboom $M C$, et al. Quantifying the heart fallure epidemic: prevalence, incidence rate, lifetime risk and prognosis of theart failure The Rotterdam Study. Eur Heart J2004; 25:1614-9.

2. Lloyd-Jones DM, Larson MG, Leip EP, et al. Lifetine risk for developing congestive heant failure: the Framingham Heart Study, Circulation 2002; 106:3068-72.

3. Jessup M, Brozena S. Heart failure. N Engl J Med 2003; 348:2007-18.

4. Maclntyre $K$, Capewell $S_{\text {, Stewat }} \mathrm{S}$, ot al Evidence of improving prognosis in heart failure: trends in case fatality in 66547 patients hospitalized between 1986 and 1995 . Circulation $2000 ; 102: 1126-31$.

5. Khand A, Germmel I, Clatk AL, Cleland JG. Is the prognosis of heart failure improving? J Am Coll Cardiol 2000; $36: 2284-6$.

6. Lee DS, Vasan RS, Novel narkers for heart fatlure diagnosis and prognosis. Curr Opin Cardiol 2005; $20: 201-10$.

7. Maisel AS, Krishnaswamy P, Nowak RM, et al. Rapid measurement of B-type natriuretic peptide in the emergency diagnosis of theart failure. N Engl I Med 2002; 347:161-7.

8. Januzzi IL, If, Camargo $\mathrm{CA}$, Anwantdin $\mathrm{S}$, ef all. The $\mathrm{N}$-terminal Pro-BNP Investigation of Dyspnea in the Energency department (PRIDE) study. Am J Cardiol 2005; 95:948-54.

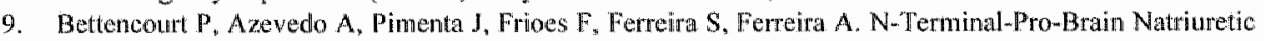
Peptide Predicts Outcome After Hospital Discharge in Heart Failure Patients. Circulation 2004; $110.2168-2174$.

10. Doust IA, Pietrak E, Dobson A, Glaseiou P. How well does B-type natrivetic peptide predict death and cardiac events in pentents with heart fallue: systematic review. BM. 2005; 330,625

1. Brunetu BO, Pazza LA, de Bold AJ. BNP gene expression is spectically modilated by stretch and ET-1 in a new model of isobled rat atriat. Am J Physiol 1997; 273:142678-86.

12. Mam DL, Youmg JB. Baste mechnisms in congestive heat failure. Recognizing the role of proinliammatory cylokines. Chest $1994 ; 105: 897-904$.

13. Sharma UC, Pokharel S, van Brakel TI, et al. Galectin-3 matks achivated macrophages in faiture-prone hypertrophiod hearts and contributes to oardiac dys function. Circulation $2004 ; 110.3121-8$.

14. Chon MM, Ash ley E.A. Deng DX, et al. Novel rote for the potent endogenous inotrope apelin in human cardiac dystumction. Circulation $2003 ; 108: 1432-9$.

15. Jessup M. Aldosterone blockade and heat fallure. N Engl J Med 2003; 348:1380-2.

16. Foody JM, Fartell MH, Krumholiz MM beta-Blocker therapy in hart faiture: scientific review. JAMA $2002 ; 287,883-9$

17. MeAlister FA, Lawson FM. Teo KK. Almstrong PW. A systematic review of randomized trials of disechse management prograns in heart faihure. Am J Med 2001: 110.378-84.

18. Moss A.J. Zareba W. Hall WJ, et al. Prophylactic implantation of a defibillator in patients with myocardial unfarction and reduced cjection fraction. N Engl J Med 2002, 346:877-83.

19. Weber KT. Cardioreparation in hypertensive heart disease. Hypertension 2001; 38:588-91. 
20. Testa M, Yeh M, Lee P, et al. Circulating levels of cytokines and their endogenous modulators in patients with mild to severe congestive heart failure due to coronary artery disease or lypentension. I An Coll Cardiol 1996; 28:964-71.

21. Devaux B, Scholz D, Hirche A, Klovekorn WP, Schaper J. Upregutation of cell adhesion molecules and the presence of low grade intlammation in thuman chromic heart falure. Eur Heart 1 1997: 18:470-9.

22. Torre-Amione G, Kapadia S, Lee J, et all. Tunor necrosis factoralphat and tumor necrosis factor receptors in the failing human heart. Circulation 1996; 93:704-11.

23. Liu FI, Rabinovich GA. Galectins as modulators of tumour progression. Nat Rev Cancer $2005 ; 5: 29-41$.

24. Cooper DN. Galectinomics: finding themes in complexity. Biochim Bioplys Acta 2002; 1572:209-31.

25. Leffer $H$, Carlsson $S$, Hedlund $M_{*}$ Qian $Y$, Poirier $F$. Introduction to galectins. Glycoconi 1 2004; $19: 433-40$.

26. Hughes RC. Secretion of the galectin family of mammalian carbohydrate-binding proteins. Biochin Biophys Acta 1999; 1473:172-85.

27. Nachtigal M. Al-Assaad 2, Mayer EP, Kim K. Monsigny $M$. Galectin-3 expression in hunzan atherosclerotic lesions. Am J Pathol 1998; 152:1199-208.

28. Iurisei I, Tinari N, Natoli $\mathrm{C}$. Angelucei D. Clanchetti $\mathrm{E}$, Lacobelli $\mathrm{S}$. Concentrations of galectin-3 in the sera of normal controls and cancer patients. Clin Cancer Res 2000; 6:1389-93.

29. Ishii I, Cui W, Kitagawa $\mathbb{F}$, et al. Prognostic value of combination of cardiac troponin IT and B-type natriuretic peptide after initiation of treatment in patients with chronic heart faiture. Clin Chem 2003; 49:2020-6.

30. Ishii $\mathrm{J}_{2}$ Nonura $\mathrm{M}$, Nakamura $Y$, et al. Risk stratification using a combination of curdiac troponin $\mathrm{T}$ and brain natrituretic peptide in patients hospitalized for worsening chronic heart failure. Am d Cardiol 2002; 89:691.-5.

31. Taniguchi $R$, Sato $\mathrm{Y}$, Yamada $\mathrm{T}$, et al. Combined measurements of cardic troponin $\mathrm{T}$ " and $\mathrm{N}$-terminal pro-brain natriuretic peptide in patients with heart failure. Circ J 2004; 68:11604.

32. Perna ER, Macin SM, Canella IP, et al. Ongoing myocardial injury in stable severe heart failure: walue of cardiac troponin T monitoring for high-risk patient identification. Circulation 2004, 110:2376-82.

33. Valgimigli $M$, Ceconi $C$, Malagutti $P$, et al. Tumor necrosis "actor-alpha receptor $I$ is a major predictor of mortallity and new-onset heart lailure in patients with acute myocardial infarction: the CytokineActivation and Long-Term Prognosis in Myocandial Infarction (C-ALPHA) study. Circulation 2005; 111:863-70.

34. Ankrusk $P$, Ueland $T$, Multer $F$, et al. Elevated circulating levels of $C-C$ chemokines in patients with congestive heart failure. Circulation 1998; 97:1136-43.

35. Weinberg EO, Shimpo M, Hurwitz S, Tominaga $\mathrm{S}$, Rouleau JL, Lee RT. Identification of serum soluble ST2 receptor as a novel heart failure biomarker. Circulation 2003; 107:721-6.

36. Szokodi 1 , Tawi $P$. Foldes $G$, et al. Apelin, the novel endogenous ligand of the orphan receptor APJ. regulates cardiac contractility. Circ Res $2002 ; 91 ; 434-40$.

37. Tatemoto $K$, Hosoya $M$, Habata $Y$, et al Isolation and characterization of a novel endogenous peptide ligand for the human APJ receptor. Biochem Biophys Res Conmun 1998; 251:471-6

38. Hosoya $M$, Kawamata $Y$, Fukusumi $S$, et al Molecular and functional characteristics of APJ. Tissuc distribution of mRNA and interaction with the endogenous ligard apeliti. I Biol Chem 2000; 275:210617.

39. Ishida J, Hashimoto T, Hashimoto $Y$, et al. Regulatory roles for APJ, a seven-transmembrane receptor related to angiotensin-type 1 receptor in blood pressure in wivo. J Biol Chem 2004: 279:26274-9.

40. Foldes G. Horkay F, Szokodi 1 , et al. Circulating and cardiac levels of apelin, the novel ligand of the orphan receptor APJ, in patients with heart failure. Biochem Biophys Res Connun 2003; 308:480-5.

41. MCMuray $\mathbb{J}$, Hillier $\mathrm{C}$. The rise and fall of myotrophin in heart failure. I Am Coll Cardiol $2003 ; 42: 726$. 7.

42. Bennet JA, Riegel B, Bittner $V$, Nichols I. Validity and reliability of the NYHA classes for measuring research outcomes in patients with cardiac disease. Heart Lung 2002; 31:262-70.

43. Dolgin $\mathrm{M}$. Obesity and B-iype natriuretic peptide levels in heart failure. J Am Coll Candiol 2005; 45:967; author reply 967 . 


\section{Bry}

Hemoglobin and N-terminal Pro-Brain

Natriuretic Peptide:

Independent and Synergistic Predictors of

Mortality in Patients with Acute Heart Failure

Results from the International Collaborative of NT-proBNP (ICON) Study

A Baggish", $R$ van Kimmenade , A Bayes-Genis*, M Davis", J Lainchbury l, C Frampton I, Y Pinto", M Richards ll and J Januzzi"

"Massachusetts General Hospital, Boston, USA

University Hospital, Maastricht, The Netherlands

*Hospital de la Santa Creu i Sant Pau, Barcelona, Spain

"Christchurch School of Medicine and Health Sciences, Christchurch, New Zealand 


\section{ABSTRACT}

Objectives: To examine the relationship between anemia, natriuretic peptide concentrations and outcomes in subjects with acute heart failure (HF).

Background: Hemoglobin and amino-terminal pro-brain natriuretic peptide (NTproBNP) are both independent predictors of mortality in patients with chronic HF. Their predictive power for mortality in the setting of acute HF is not known. No studies have examined their use in combination.

Design: In an international prospective cohort design, we evaluated the relationships between hemoglobin, NT-proBNP, and 60-day mortality in 690 patients with acute HF.

Results: The median hemoglobin for the entire cohort was $13.0 \mathrm{~g} / \mathrm{dL}$ (interquartile range 11.6-14.3). The WHO criterion for anemia was met by $44 \%(n=305)$ of the cohort. The 60 -day mortality rate for anemic patients was $16.4 \%$ versus a rate of $8.8 \%$ in non-anemic patients ( $\mathrm{p}<0.001$ ). Anemia was an independent predictor of short-term mortality $(\mathrm{OR}=1.72,95 \% \mathrm{CI}=1.05-2.80, \mathrm{p}=0.03)$, as was an $\mathrm{NT}$-proBNP concentration in excess of $5180 \mathrm{pg} / \mathrm{ml}(\mathrm{OR}=2.32,95 \% \mathrm{CI}=1.36-3.94 \mathrm{p}=0.002)$. Consideration of four risk groups: not anemic/low NT-proBNP (reference group, $n=220$ ), anemic/ low NTproBNP ( $n=152)$, not anemic/ high NT-proBNP $(n=165)$, and anemic/ high NT-proBNP $(\mathrm{n}=153)$ revealed respective 60 -day mortality rates of $5.0 \%$ (referent), $9.2 \%(\mathrm{OR}=1.93$, $95 \% \mathrm{Cl}=0.85-4.36 ; \mathrm{p}=0.12), 13.9 \%(\mathrm{OR}=3.07,95 \% \mathrm{Cl}=1.45-6.50, \mathrm{p}=0.003)$, and $23.5 \%$ $(\mathrm{OR}=5.84,95 \% \mathrm{CI}=2.87-11.89, \mathrm{p}<0.001)$.

Conclusions: Anemia was common in this cohort of subjects with acute HF, and was related to adverse short-term outcome. Integrated use of hemoglobin and NT-proBNP measurements provides powerfull additive information and is superior to the use of either in isolation.

Keywords: heart failure, anemia, natriuretic peptides, prognosis 


\section{INTRODUCTION}

Brain natriuretic peptide (BNP) and its N-terminal congener NT-proBNP, are cardiac peptides secreted from ventricular myocardium in response to elevations in transmural pressure and are useful adjuncts for the diagnosis of acute heart failure (HF).$^{1 / 3}$ Natriuretic peptide testing provides not only important diagnostic information, but also prognostic information in the setting of acute $\mathrm{HF}^{4.5}$

Other biomarkers may be additively useful for prediction of adverse outcomes in HF. Hemoglobin may be such a marker. Low hemoglobin may be a consequence of the neurohumoral and hemodynamic abnormalities underlie HF and simuitaneously may be a trigger for decompensation and a contributor to progressive myocardiall remodeling, symptom severity, and reduced survival. ${ }^{6,7}$ Recent reports have shown anemia to be a prevalent and important comorbidity in patients with chronic HF; however, its prognostic impact in the setting of acutely decompensated disease has not been well characterized. ${ }^{8.9}$

Levels of natriuretic peptides and serum hemoglobin may reflect different pathophysiologic components of $\mathrm{HF}$ and, as such, might have additive prognostic value. Using data from the International Collaborative of NT-proBNP (ICON) study, we proposed to define the relationship between anemia at presentation and short-term mortality in patients with acute HF. We then examined the integrative roles of natriuretic peptide and hemoglobin measurements in improving prognostic accuracy over either strategy used alone.

\section{METHODS}

\section{Study Subjects}

We used baseline and follow-up information from the ICON Study, a multicenter registry comprised of trial data assessing the role of NT-proBNP for the diagnosis of acute HF. ${ }^{10}$ The ICON Study population consists of patients from three previously reported prospective clinical trials of NT-proBNP testing from Christchurch, New Zealand, Barcelona, Spain and Boston, Massachusetts, USA. ${ }^{1.11 .12}$ In addition, previously unpublished data from patients in a HF registry at the University Hospital of Maastricht, The Netherlands were also included. All data sources had compatible inclusion/exclusion criteria, and all studies collected similar clinical information, including standard demographics, medical history, drug therapy, presenting symptoms and signs (including severity of breathlessness by the New York Heart Association [NY'HA] classification), physical examination, radiographic studies (typically plain chest radiographs), electrocardiography results and results of hematology, blood chemistry and NT-proBNP testing.

Of the 1256 patients in ICON, $720(57 \%)$ were diagnosed with acute HF. Of those with acute HF, $690(96 \%)$ had available hemoglobin data and were therefore considered eligible for this analysis. The diagnosis of acute HF was determined as described in each study. ${ }^{1,11,12}$ 


\section{Baseline Data}

Blood samples for the measurements of hemoglobin and NT-proBNP concentrations were obtained at the time of enroliment. Hemoglobin concentrations were measured in an unblinded fashion at each institution, using conventional lab methods. NT-proBNP was measured using a vallidated, commercially available immunoassay (Elecsys proBNP, Roche Diagnostics, Indianapolis, חN), using established methodology. This assay has been reported to have $<0.001 \%$ cross-reactivity with bioactive BNP, and in the constituent studies in this report, this assay had inter-run coefficients of variation ranging from $0.9 \%$ to $5.5 \%$. For the purposes of this report, NT-proBNP levels are expressed in $\mathrm{pg} / \mathrm{ml}$ (to convert $\mathrm{pg} / \mathrm{ml}$ to $\mathrm{pmol} / \mathrm{l}$, multiplly $\mathrm{x} 0.118$ ). Historical information, physical findings, and the results of routine diagnostic testing obtained during the initial presentation were considered. Creatinine clearance values were calculated by the Modified Diet in Renal Disease (MDRD) equation. ${ }^{13}$

\section{Endpoints}

The primary endpoint of this analysis was 60 -day mortality. Death information was ascertained from hospital medical records, death certificates and telephone follow-up with referring physicians.

\section{Statistical Analysis}

Data are presented as medians with intra-quartile ranges (IQR) for non-normally distributed variables and means \pm standard deviations (SD) for all other continuous variables. Patients were categorized into anemic and non-anemic using the current World Health Organization definition of anemia (hemoglobin of less than $13.0 \mathrm{~g} / \mathrm{dL}$ [male] and less than $12.0 \mathrm{~g} / \mathrm{dL}$ [female]). ${ }^{14}$ In addition, patients were also subdivided into hemoglobin quartiles and deciles for survival analysis. To perform multi-marker stratification, we categorized patients into two groups based on presentation NTproBNP level $(>5180 \mathrm{pg} / \mathrm{mL}$ vs. $\leq 5180 \mathrm{pg} / \mathrm{mL})$, as previous receiver-operator curve analysis had determined this to be the optimal cut-point for predicting 60-day mortality in acute $\mathrm{HF}$. $^{10}$

Differences in baseline variables between survivors and non-survivors were analyzed using analysis of variance for continuous variables and Pearson's chi-square testing for categorical variables. Survival curves were calculated using the Kaplan-Meier method and differences between the curves were evaluated using the log-rank statistic. Univariate screening of baseline variables was used to identify candidate independent predictors of 60-day mortality. Multivariable analysis with forwand step-wise logistic regression, including all candidate variables with $p$-values $\leq 0.10$, was performed to identify independent predictors of 60 -day mortality. We included a term combining hemoglobin and NT-proBNP concentrations to evaluate for synergy. In addition, we controlled for variation in survival rates between the four contributing clinical centers. Results are presented as odds ratios (OR) with 95 percent confidence intervals (CI). 


\section{RESULTS}

\section{Baseline Characteristics}

Table 1 provides details regarding patients with acute HF that survived $(\mathrm{n}=606,87.8 \%)$ and those that died $(n=84,12.2 \%)$ by 60 days. Patients deceased by 60 days were more likely to be older, to have a history of prior coronary artery disease, to present with fever or the absence of paroxysmal nocturnal dyspnea, and to thave a left bundle branch block on electrocardiogram. Gender, history of prior HF, tobacco use, presenting cardiac rhythms, NYHA functional class and chest radiograph findings were similar between the two groups.

The mean hemoglobin for the entire cohort was $12.65 \pm 2.1 \mathrm{~g} / \mathrm{dL}$ with means of $12.7 \pm 2.1$ $\mathrm{g} / \mathrm{dL}$ for surviving patients and $12.0 \pm 2.0 \mathrm{~g} / \mathrm{dL}$ for those deceased by 60 days $(\mathrm{p}=0.003$ ). WHO anemia was more common in non-survivors $(60 \%)$ than in survivors $(42 \%$, $\mathrm{p}=0.003$ ). Patients who died by 60 days were more likely than survivors to have higher serum creatinine $(1.41 \mathrm{mg} / \mathrm{dl}, \mathrm{IQR}=1.02-2.10$ vs. $1.12 \mathrm{mg} / \mathrm{dl}, \mathrm{IQR}=0.87-1.50, \mathrm{p}<0.001)$, a correspondingly lower creatinine clearance $\left(43.9 \mathrm{~mL} / \mathrm{min} / 1.73 \mathrm{~m}^{2}, 1 \mathrm{QR}=30.92-64.03\right.$, vs. $60.7 \mathrm{~mL} / \mathrm{min} / 1.73 \mathrm{~m}^{2}, \mathrm{IQR}=42.90-79.22, \mathrm{p}<0.001$ ) and a higher likelihood of detectable serum cardiac troponin-T $(93.3 \%$ vs. $78.4 \%, \mathrm{p}<0.001)$. Significantly higher median NT-proBNP levels were observed in patients deceased by 60 days than in survivors $(9448 \mathrm{pg} / \mathrm{ml}, \mathrm{IQR}=3805-22178$ vs $4077 \mathrm{pg} / \mathrm{ml}, \mathrm{IQR}=1740-9989, \mathrm{p}<0.001)$.

\section{Predictors of 60-Day Mortality}

By multivariate analysis both the presence of anemia (adjusted $\mathrm{OR}=1.72$, $95 \% \mathrm{CI}=1.05-2.80 ; \mathrm{p}=0.032$ ) and an NT-proBNP level $>5180 \mathrm{pg} / \mathrm{ml}$ (adjusted $\mathrm{OR}=2.32,95 \% \mathrm{CI}=1.36-3.94 ; \mathrm{p}=0.002$ ) were independently associated with death by 60 days. Increasing age, fever and decreasing GFR were also found to be significant independent predictors of death within this period (Table 2). 
Table 1 Comparisons of partents with acute $\mathrm{HF}$ as a function of 60 -day survival.

\begin{tabular}{|c|c|c|c|}
\hline characteristic & $\begin{array}{l}\text { Alye al } 60 \text { days } \\
(1-606)\end{array}$ & $\begin{array}{l}\text { Deceased at } 60 \text { days } \\
(n=84)\end{array}$ & pralue \\
\hline Age (means SD) & $74.4+117$ & $70,5+106$ & 0.002 \\
\hline Male Gonder & $572 \%$ & $32.4 \%$ & 0.833 \\
\hline Past medigal hiltory & & & \\
\hline Myprtenston & $620 \%$ & $5 \times 2 \%$ & 0056 \\
\hline Coronary artery diease & $507 \%$ & $65 \% \%$ & 00017 \\
\hline Prigr adte myocardialinarewon & $33.8 \%$ & $42,2 \%$ & 0.12 \\
\hline Pror lieart falure & $517 \%$ & $54.8 \%$ & 0.593 \\
\hline Pror do structive alurays disease & $283 \%$ & $262 \%$ & 0.561 \\
\hline Loop diuretic ase pier to presentation & $58.9 \%$ & $699 \%$ & 0.056 \\
\hline Symptoms/signs & & & \\
\hline Paroxysmal nocturnal duspriea & $33.2 \%$ & 19.096 & 0009 \\
\hline Orthoprea & $5 \sqrt{6 \%}$ & $48.4 \%$ & 0.685 \\
\hline Lower extremity edema & $46.5 \%$ & $452 \%$ & 0.823 \\
\hline chest pain. & $335 \%$ & $325 \%$ & 0.861 \\
\hline Cough & $328 \%$ & $27.4 \%$ & 0.361 \\
\hline Fever & $4,1 \%$ & $107 \%$ & 0.009 \\
\hline lincreased spufum & $183 \%$ & $167 \%$ & 0.713 \\
\hline NIA Glass 4 & $442 \%$ & $50 \%$ & 0.319 \\
\hline Physical Examination & & Writy & W+14 \\
\hline Pulse rate (meantsD) & $928 \pm 25.8$ & $955 \times 260$ & 0.381 \\
\hline Jigular venous distension. & $48.8 \%$ & $560 \%$ & 0.222 \\
\hline S3 gallop & $69 \%$ & $83 \%$ & 0.639 \\
\hline Lover extremity edema & $563 \%$ & $52 \%$ & 0501 \\
\hline Rales & $687 \%$ & $679 \%$ & 0882 \\
\hline Wherzing & $16.9 \%$ & $107 \%$ & 0.151 \\
\hline ECG findings & & 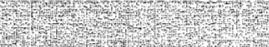 & \\
\hline Sinus roythr & $59.6 \%$ & $643 \%$ & 00408 \\
\hline Alral ibinutser. & $34.5 \%$ & 32,16 & 0671 \\
\hline Left ventricular hyper trophy & $107 \%$ & $8.3 \%$ & 0.490 \\
\hline Eeff bunde branch block & $150 \%$ & $250 \%$ & 0020 \\
\hline Chest $x$ ray findings & & (1) & \\
\hline Intersititial edena & $176 \%$ & $298 \%$ & 016 \\
\hline Intillate. & $117 \%$ & $167 \%$ & 0106 \\
\hline Plevialefusion, & $26 \%$ & $226 \%$ & 0.440 \\
\hline Cepralization of vessels & $29.4 \%$ & $357 \%$ & 0235 \\
\hline Cardionegaly & $370 \%$ & $39.3 \%$ & 0680 \\
\hline Laboratorvinidings & & & \\
\hline Henoglobin gial (neantsp). & $127 \pm 206$ & $120+197$ & 0.003 \\
\hline Woild Healih Orgenization Anernio & 42113 & $596 \%$ & 0,003 \\
\hline Creatinin, ngidl (nedian, $(Q R)$ & $1,12(0.87-1,50)$ & $44(1,02-2,10)$ & 60001 \\
\hline Creatinine clearance (median (OR) & $6070(420079.22)$ & $43.90(30.92 .64 .03)$ & 60001 \\
\hline Troponin $\mathrm{T}>0.00 \mathrm{ng} / \mathrm{m}$ & $78.4 \%$ & $93.3 \%$ & 80.001 \\
\hline Troponin T $>0.01 \mathrm{ng} / \mathrm{ml}$ & $475 \%$ & $77.3 \%$ & $<0,001$ \\
\hline NT proBNP pg/ml (median IQR) & $4077(1740.9989)$ & $9448(3805-22179)$ & <0.001 \\
\hline
\end{tabular}


Table 2: Independent piredictors of 60-day motallity.

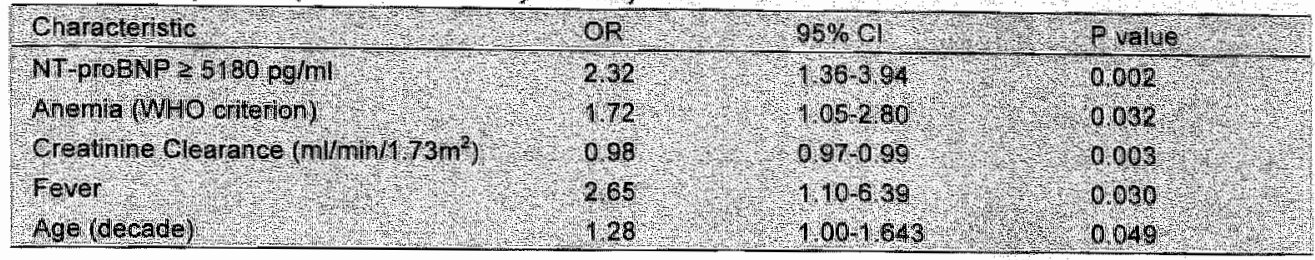

\section{Hemoglobin and 60-Day Mortality}

Patients with anemia had a 60 -day mortality rate of $16.4 \%$ versus $8.8 \%$ in non-anemic patients ( $<<0.001$; Figure 1). There was a step-wise increase in 60 -day mortality with increasing hemoglobin quartile, from $8.7 \%$ in the highest hemoglobin quartile to $16.0 \%$ in the lowest hemoglobin quartile (Figure 2). When expressed as a function of hemoglobin decile, lower rates of mortality at higher hemoglobin deciles were observed along with no increase in mortality in the highest deciles.

Figure 1: 60-day Kaplan-Meler survival curves for patients with acute HF categorized as anemic or nonanemic at the time of presentation. Anemia was defined using the WHO criterion of $<12 \mathrm{~g} / \mathrm{dL}$ for men and $<13 \mathrm{~g} / \mathrm{d}$ l for women.

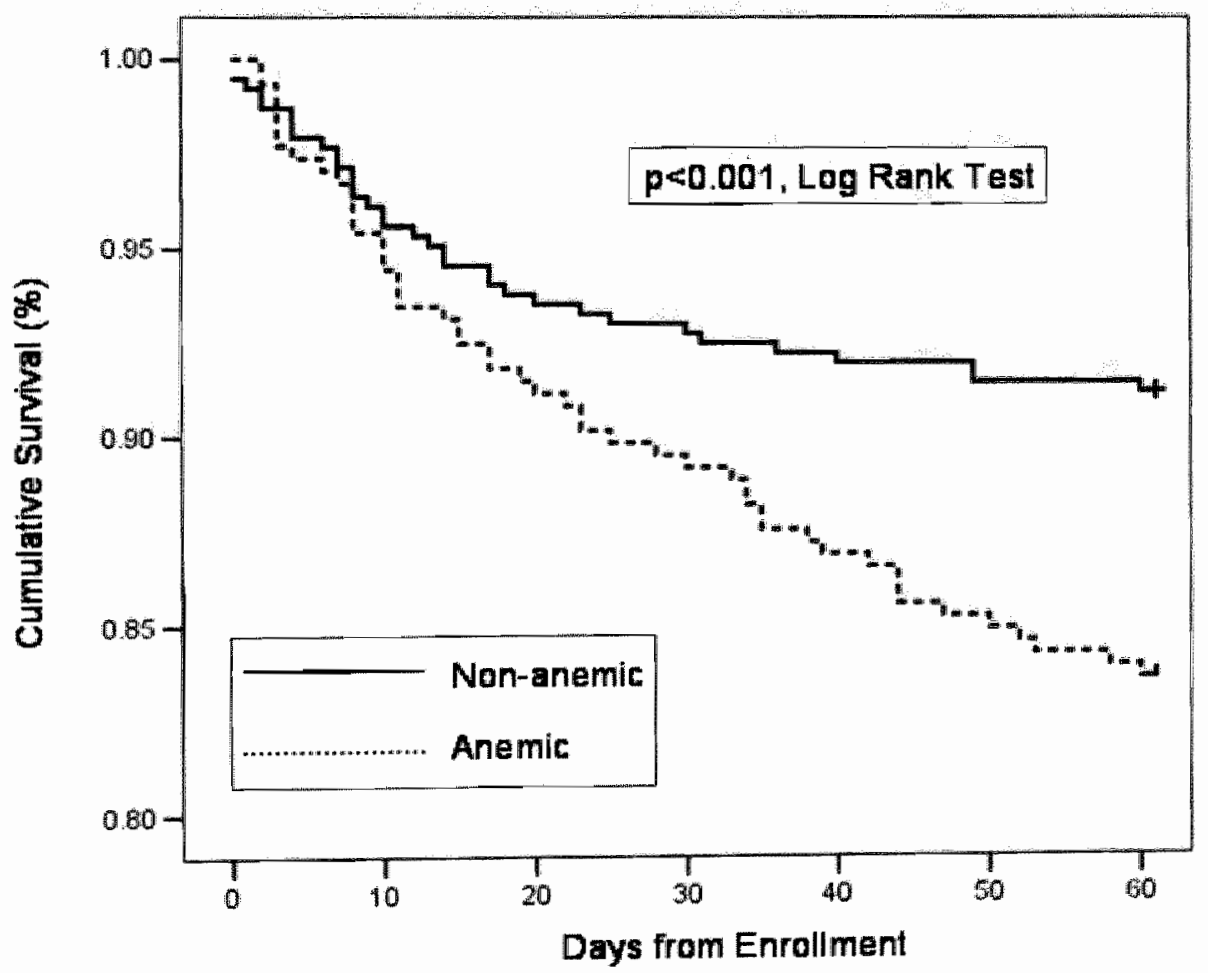


Figure 2: 60-day mortality rates for patients with acute HF divided into hemoglobin quartiles of $<11.2$ g/dL (Quartile 1, $n=163$ ), 11.21 to $12.70 \mathrm{~g} / \mathrm{dL}$ (Quartile $2, n=167$ ), 12.71 to $14.10 \mathrm{~g} / \mathrm{dL}$ (Quartile $3 \mathrm{n}=18 \mathrm{~B}$ ), and $>14,10 \mathrm{~g} / \mathrm{dL}$ (Quartile 4, $n=172$ ).

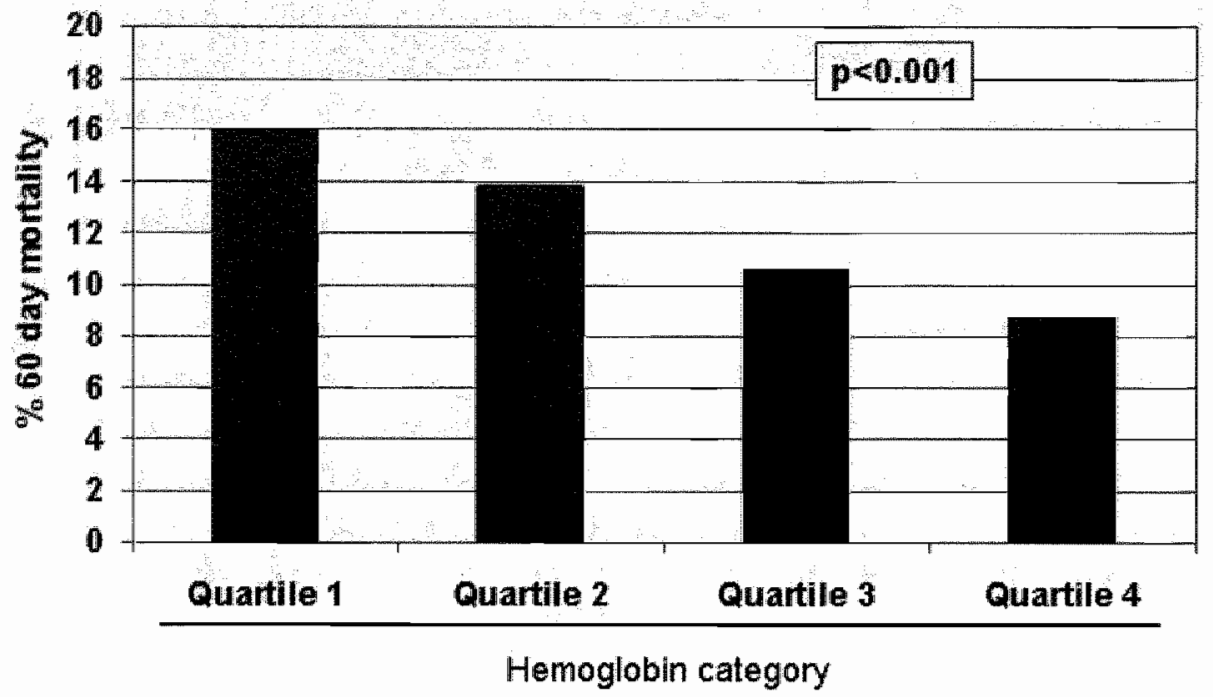

\section{Anemia, NT-proBNP and 60-day mortality}

We categorized the cohort into four groups determined by anemia status and NTproBNP level: non-anemic/NT-proBNP $\leq 5180 \mathrm{pg} / \mathrm{ml}(\mathrm{n}=220,31.9 \%)$, anemic $/ \mathrm{NT}$ proBNP $\leq 5180 \mathrm{pg} / \mathrm{ml}(\mathrm{n}=152,22 \%)$, non-anemic/NT-proBNP $>5180 \mathrm{pg} / \mathrm{ml}(\mathrm{n}=165$, $23.9 \%)$, and anemic/NT-proBNP $>5180 \mathrm{pg} / \mathrm{ml}(n=153,22 \%)$. We assessed the rates of mottality in each of these groups. Kaplan-Meier survivall curves (Figure 3 ) demonstrate the impact of hemoglobin and NT-proBNP concentration on the rates of mortality. When the cohort was divided in this manner, we observed 60-day mortality rates of $5.0 \%, 9.2 \%, 13.9 \%$, and $23.5 \%$ (log rank p value $<0.001$ ), respectively. 
Figure 3: 60-day Kaplan-Meier survival cunves for patients with acute HF categorized by the presence of absence of anemia and by NT-proBNP concentration at the time of initial evaluation.

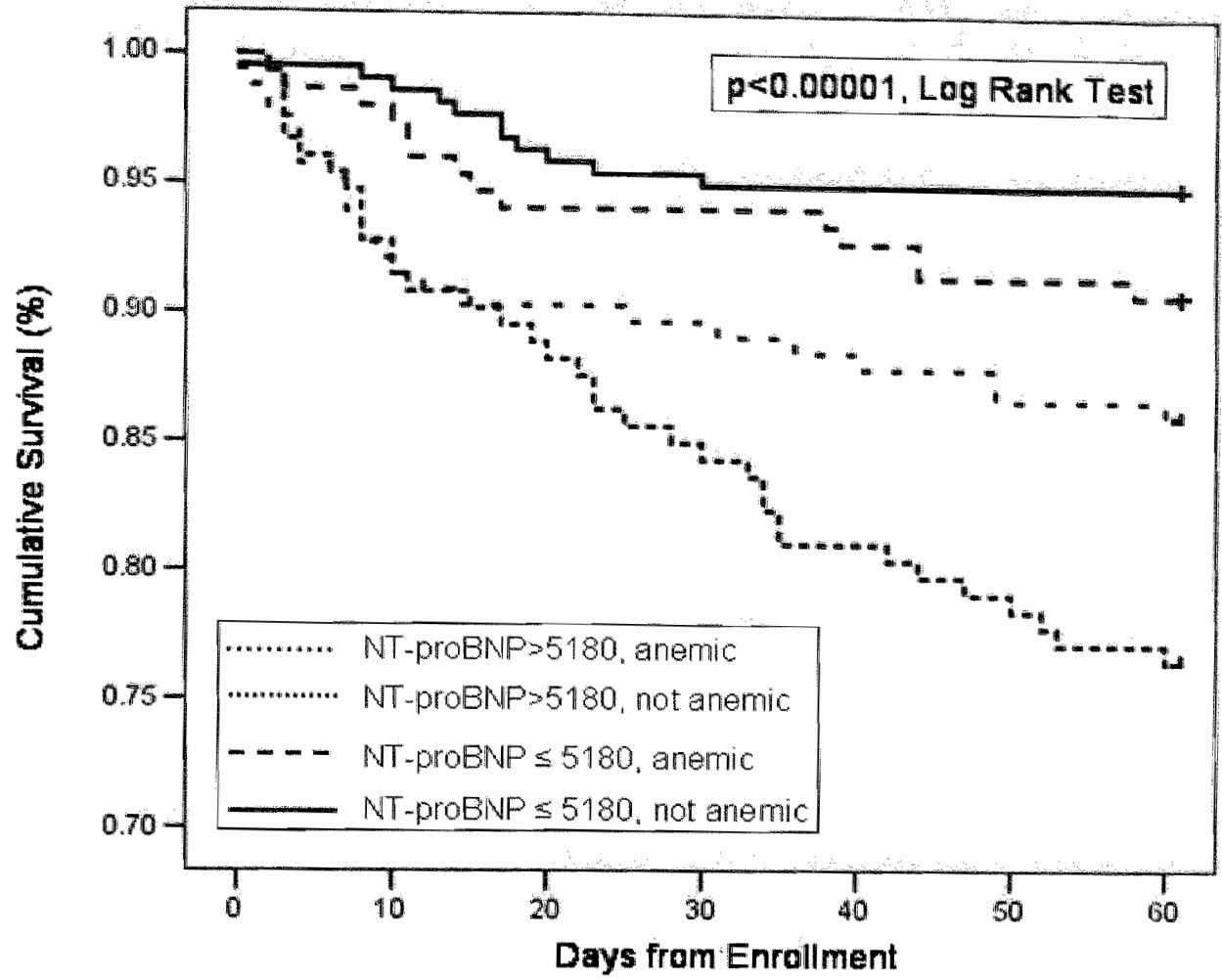

To further clarify the risk related to anemia, elevated NT-proBNP or both, we examined the OR for death in each of these four diagnostic groups (Figure 4). Using nonanemic/NT-proBNP $\leq 5180 \mathrm{pg} / \mathrm{ml}$ as the referent group, we observed a trend toward rising risk of death by 60 days in subjects with anemia/NT-proBNP $\leq 5180 \mathrm{pg} / \mathrm{ml}$ $(\mathrm{OR}=1.93,95 \% \mathrm{CI}=0.85-4.36 ; \mathrm{p}=0.12)$. Non-anemic subjects with NT-proBNP $>5180$ $\mathrm{pg} / \mathrm{ml}$ had a significantly increased risk of death compared to the reference group $(\mathrm{OR}=3.07,95 \% \mathrm{CI}=1.45-6.50, \mathrm{p}=0.003$ ), while the combination of a markedly elevated NT-proBNP plus WHO-defined anemia was a stronger predictor of 60-day death $(\mathrm{OR}=5.84,95 \% \mathrm{CI}=2.87-11.89, \mathrm{p}<0.001)$. 
Figure 4: Fisk of 60-day mortality following presentation with acute HF, expressed as a function of anemia and NT-proBNSP concentration.

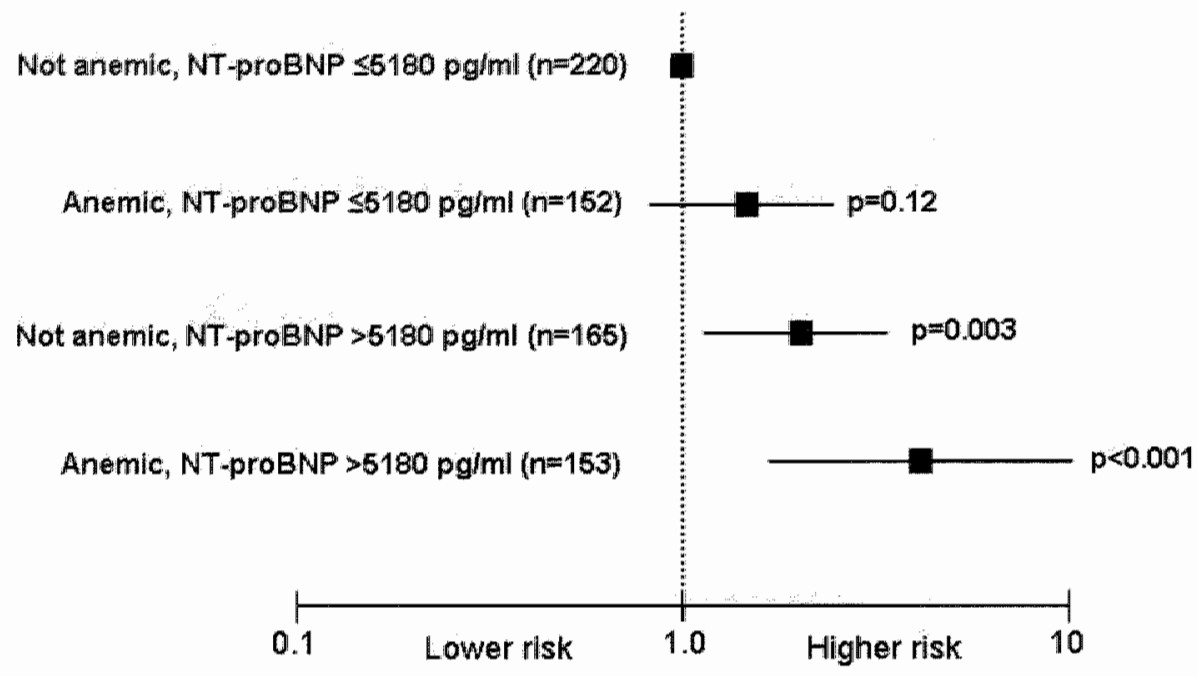

In a multivariable logistic regression model containing age, presence of fever, creatinine clearance, NT-proBNPP $>5180 \mathrm{pg} / \mathrm{ml}$, and the combination of elevated NT-proBNP plus WHO-defined anemia, an elevated NT-proBNP concentration in the absence of anemia was still statistically significantly related to 60 -day mortality $(\mathrm{OR}=2.00,95 \% \mathrm{CI}=1.70$ $3.45, \mathrm{p}=0.02)$, but the combination of an NT-proBNP $>5180 \mathrm{pg} / \mathrm{ml}$ plus WHO-defined anemia remained the strongest predictor of death in acute $\mathrm{HF}(\mathrm{OR}=4.26 ; 95 \% \mathrm{CI}=2.06$ $10.01, \mathrm{p}<0.001$ ).

\section{DISCUSSION}

In patients with acute $\mathrm{HF}$, we found that anemia was common and that anemia and NTproBNP level, both previously recognized independent predictors of mortality in patients with chomic HF, are also independently and additively prognostic in patients with acute HF. We suggest that a strategy integrating these variables is superior to the use of either in isolation for predicting short-term risk for death in those with acute HF. Extensive work has defined the role of natriuretic peptide assays for the diagnosis of acute HF, and more recently, for prediction of mortality in patients with this syndrome. 15,16 The biomarker-guided approach to diagnosis and risk stratification of patients with acute HF appears to be superior to that based on conventionall clinicall assessment of disease severity. "However, as is the case for any single assay, the use of natriuretic peptide testing in isolation might incompletely indicate risk for patients with acute $\mathbb{H F}^{\mathrm{F}}$.

HF is a systemic illness often involving renal dysfunction, loss of lean muscle mass and hyperactivity of both the renin-angiotensin-aldosterone pathway and sympathetic nervous systems. 
A surrogate marker for the presence and severity of these non-cardiac abnormalities may thus be a useful addition to NT-proBNP testing for risk stratification. We suggest that hemoglobin, a widely available, inexpensive and highly reliable assay, may reflect these extra-cardiac processes. This hypothesis may explain in part the independent value of this marker for predicting mortality in patients with acute $\mathrm{HF}$.

Among patients with acute HF, anemia is likely to be both a marker of mortality risk and a contributor to symptom severity and disease progression. Possible causes of anemia in patients with HF include cytokine-mediated anemia of chronic disease, reduced erythropoietin activity due to renal dysfunction, hemodilution, malnutrition, and angiotensin converting enzyme inhibition. ${ }^{1823}$ A recent report suggests that angiotensin converting enzyme inhibition, a cornerstone of $\mathrm{HF}^{*}$ therapy, may be associated with increased levels of the hematopoetic inhibitor $\mathrm{N}$-acetyl-seryl-aspartyllysyl-proline. ${ }^{24}$

The relationship between low hemoglobin levels and adverse outcome in HF is incompletely understood. Anemia may have an impact on HF severity, progression and mortality through diminished oxygen carrying capacity of blood which leads to increased cardiac work, elevated adrenergic tone, increased demand-related ischemia and renal hypoxia. ${ }^{25,26}$ Anemia has also been linked to myocyte hypertrophy and an increase in left ventricular wall mass. ${ }^{27}$ In subjects with chronic stable HF, anemia was associated with worse NYHA functional class, lower peak oxygen consumption, the prevalence of diastolic dysfunction and a lower one-year survival rate. ${ }^{28-31}$ In one report, both anemia and polycythemia were associated with higher death rates in the setting of chronic HF. A recent study reported a compelling association between elevated serum erythropoietin levels and an increased risk of death and hospitalization during a 24 month follow-up period in outpatients with chronic symptomatic $\mathrm{HF}^{32}$

In recognition of the importance of anemia with respect to long-term prognosis in chronic HF, it is surprising that, prior to this report, little data regarding the relationship(s) between anemia and outcomes in acutely decompensated HF has been reported. Ezekowitz, et al., reported the negative prognostic impact of anemia in a large community based population of patients with "new onset" $\mathrm{HF}$, gathered from retrospective database review. ${ }^{33}$ Importantly, their analysis showed anemia of chronic disease to be the dominant etiology of anemia, yet the association of anemia with decreased survival remained significant even after adjustment for cause. In the OPTIME-HF trial, a study evaluating the impact of intravenous milrinone on patients with decompensated heart failure, a hemoglobin below $11.3 \mathrm{~g} / \mathrm{dL}$ was associated with higher in-hospital mortality, 60 -day mortality and rehospitalization rates. ${ }^{34}$ A recent report from the Val-HeFT investigators confirmed the impact of anemia on mortality in patients with chronic HF and further demonstrated that individual afficted with chronic HF who experience a reduction in hemoglobin over a twelve month period had worse outcomes than those with stable anemia. ${ }^{35}$

Our data, the first prospective analysis of the impact of hemoglobin on mortality in community-based patients with acute $\mathrm{HF}$, demonstrates the markedly adverse prognostic impact of anemia on this patient population. In addition, we demonstrate the incremental utility of combining hemoglobin and NT-proBNP for risk stratification of patients with acute $\mathrm{HF}$. 
Several additional findings merit consideration. We analyzed hemoglobin as a binary variable, using the WHO criterion for anemia, as well as by quartiles and deciles. Quartile analysis revealed that patients with intermediate hemoglobin levels (11.2-14.1 $\mathrm{g} / \mathrm{dL}$ ) had an intermediate risk of 60-day mortality but importantly, that risk in the highest and lowest quartiles matched that observed in binary categorization. Therefore, it appears that short-term mortality rates increase in parallel with decreasing hemoglobin, and that there is no sharp, risk-defining threshold. Analysis of the decile subdivision provided an opportunity to evaluate the mortality rate in patients at the polycythemic end of the spectrum. Our data, though containing a small number of individualls with true polycythemia and not powered to evaluate this as a dedicated endpoint, does not suggest that high hemoglobin values are associated with increased short-term mortality rates in patients with acute HF, as it suggests for subjects with chronic HF. In our analysis we detected a strong correlation between fever and survival to 60 days. The relatively low prevalence of fever in our cohort raises the question of the validity of this association. The reproducibility of this relationship and the basis for it deserve further study. It is possible that HF complicated by severe infection has a worse prognosis than HF triggered by other factors.

We provide a simple and powerful tool for short-term mortality prediction in patients with acute HF based on the simple measurement of hemoglobin and plasma NTproBNP. Enrollment of patients occurred in four clinical centers with international distribution increases the generalizability of our results and avoids questions of limited generalizability that are inherent in the analysis of selected populations recruited to randomized controlled trials of therapy. A limitation to the study is the collection of only a single hemoglobin measurement at presentation. As such, we could not address the potential importance of hemoglobin change over time in patients with acute HF. As with any incompletely understood syndrome, the potential for omitted confounders exists, although we did control for variables associated with anemia and other potential HF prognostic measures including NYHA class, signs of hemodilution (such as volume overload), serum troponin and renal function.

In conclusion, we have shown that NT-proBNP and anemia are important independent predictors of mortality by 60 days in patients with acute HF. The combined use of these easily measured prognostic markers for risk stratification of patients with acute HF provides useful information and is superior to the use of either in isolation. Given the clear association between anemia and increased mortality in patients with both acute and chronic heart failure and the recent availability of non-transfusion based therapy for this condition, prospective studies of aggressive anemia management in patients with HF are warranted.

\section{REFERENCES}

1. Lainchbury JG, Campbell E, Frampton CM, Yandle TG, Nicholls MG, Richards AM. Brain natriuretic peptide and m-rminal brain natriuretic peptide in the diagnosis of heart failure in patients with acute shortness of breath. J Am Coll Cardiol 2003;42:728-35.

2. Maised AS. Krishnaswamy P, Nowak RM, et al. Rapid measurement of B-type natriuretic peptide in the emergency diagnosis of heart failure. N Engl J Med 2002;347:161-7. 
3. Jamuzzi JL, Jr. Camargo CA, Anwaruddin S, ef al. The N-terminal Pro-BNP investigation of dyspnea in the emergency department (PRIDE) study. An / Cardiol 2005;95:948-54.

4. Bettencourt P. Azevedo A, Pimenta J, Frioes F, Ferreira S, Ferreira A. N-teriminal-prob-bain natriurstic peptide predicts outcome after hospital discharge in heart failure patients. Circulation 2004:110:2168-74.

5. Groenning BA. Raymond 1 , Hildebrandi PR, Nilsson JC, Batmann M, Pedersen F. Diagnostic and prognostic evaluation of left ventricular systolic heart failure by plasma $\mathrm{N}$-terminal pro-brain natriuvetic peptide concentrations in a large sample of the genenal population. Heart 2004;90:297-303.

6. Anand 1, McMurray J, Whitmore J, et all. Anemia and its relationship to elinical outcome in hear failure. Circulation 2004;110:149m54.

7. Silverberg DS, Wexter D, Bum M, et al. The use of subcutaneous ergthropoietin and intravenous iron for the treatment of the anemia of severe, resistant congestive heart failure improves cardiac and renal function and functional cardiac class, and markedly reduces hospitalizations. I Am Coll Cardiol $2000 ; 35: 1737-44$.

8. Sharma $\mathbb{R}$, Francis DP, Pitt B, Poole-Wilson PA, Coats AJ, Anker SD. Haemoglobin predicts survival in patients with chronic heart failure: a sulostudy of the ELITE II trial. Eur Heart J 2004:25:1021-8.

9. Tanner $\mathrm{H}$, Moschovitis $\mathrm{G}$, Kuster $\mathrm{GM}$, et al. The prevalence of anemia in chronic heart failure. Int 』 Cardiol 2002;86:115-21.

10. Januzzi J,, wan Kimmenade R, Lainchbury JG, Bayes-Genis A. Pinto Y, Richards AM. NT-probNP Testing for Diagnosis and Short-Tern Prognosis in Acute Congestive Heart Failure: Ar International Pooled Analysis of 1256 Patients. The Internationall Collaborative of NT-proBNP (ICON) Study. Eur Heart J $2006 ; 27: 330-7$.

11. Bayes-Genis A, Santalo-Bel M, Zapico-Muniz E et al. N-terminal probrain natritutic peptide $(\mathrm{NT}$. proBNP) in the emergency diagnosis and in-hospital monitoring of patients with dyspnoea and ventricular dysfunction. Eur J Heart Fail 2004:6:301-8.

12. Januzzi JL, Carmargo $C A$. Anwarrudin $S$, ef al. N-ierminal ProBNP for Urgent Evaluation of Shortness of Breatly: The ProBNP Investigation of Dyspnea in the Emergency Department (PRIDE) Study. Am J Cardiol 2005;95:948-54.

13. Levey AS, Bosch JP, Lewis JB, Greene T, Rogers N, Roth D. A more accurate method to estimate glomerular filtration rate from serum creatinine: a new prediction equation. Modification of Diet in Renal Disease Study Group. Ann Intern Med 1999;130:461-70.

14. Nutritional Anemias: Repont of a WHO Scientific Group. Genewa: World Health Organization 1968

15. Hartmann $F$, Packer $M$, Coats AJ, ef al. NT-proBNP in severe chronic heart failure: rationale, design and pretiminary results of the COPERNICUS NT-proBNP substudy. Eur I Heart Fail 2004;6:343-50.

16. Gardner RS, Ozalp $\mathbb{F}$, Murday AJ, Robb SD, McDonagh TA. $\mathrm{N}$-terminal pro-brain natriuretic peptide. A new gold standard in predicting mortality in patients with advanced heart lailure. Eur Heart I $2003 ; 24: 1735-43$

17. Maisel $A$, Hollander JE, Guss D, et al. Prifruary results of the Rapid Emergency Department Heart Failure Outpatient Trial (REDHOT). A multicenter situdy of B-type natriuretic peptide levels, emergency department decision making, and outcomes in patients presenting with shortuess of breath. $J$ Am Coll Cardiol 2004; 44:1328-33.

18. Rauch haus $M$, Koloczek $V$, Volk $H$, et al Inflammatory cytokines and the possible inmunologiogl role for lipoproteins in chironic heart falure. Int J Cardiol 2000;76:125-33.

19. Deswal A, Petersen NJ, Feldman AM, Young JB, White BG, Mann DL. Cytokines and cytokine receptors in adwanced hear failure: an analysis of the cylokine database from the Vesnamone trial. (VEST). Circulation 2001:103:2055-9.

20. Anker SD. Ponikowski PP, Clark AL. et al. Cylokines and neurohomones relating to body composition alterations in the wasting syndrome of chronic heart faillure. Eur Heart J 1999;20:683-93,

21. Al-Ahmad A, Rand WM, Manjunath G, et al. Reduced kidney function and ancmia as risk factors for moriality in patients with lef ventricular dysfunction. I Am Coll Cardioll 2001;38:955-62.

22. Androne $\mathrm{AS}$, Katz $\mathrm{SD}$, Lund $\mathrm{L}$, et al. Hemodilution is common in patients will advanced heart failure. Cinculation 2003;107:226-9.

23. Fyhrquist F, Karppinen K, Honkanen $T$, Saijonmaa $O$, Rosenlof $K$, High serum crythropoietin lwveds are normalized during treatment of congestive heart failure with enalapril. J Intern Med 1989;226:257-60. 
24. Wan der Meer $\mathrm{P}$, Lipsic $\mathrm{E}$, Westenbrink $\mathrm{BD}$, et al. Levels of hematopoiesis inhibitor $\mathrm{N}$-acetyl-serylaspartyl-fysyl-proline partially explain the occursence of anvemia in heart failure. Circulation $2005 ; 112: 1743-7$.

25. Weiskopf $\mathrm{RB}$, Wiele $\mathrm{MK}$, Feiner $\mathrm{I}_{\text {, }}$ et all. Human cardiowascular and netabolic response to acute, severe isovolemic anemilä. Jama 1998;279:217-21.

26. Obayashi $K$, Ando $Y$, Terazaki $H$, et al. Mechanism of anemia associated with autonomic dysfunction in rats. Auton Neurosci $2000 ; 82: 123-9$.

27. Olivetti $G$, Langrasta $C, \mathbb{F} . Q$. Myocyte cellular hypertrophy and hyperplasia contribute to wentricular wall remodeling in anemia-induced cardiac hypertrophy in rats. An J Pathol 1992;141:227-239.

28. Horwich TB, Fotiarow GC, Hamilton MA, Maeleellan WR, Borenstein J. Anemia is associated with worse symptoms, greater impaiment in functional capacity and a significant increase in mortality in patients with advanced heart fallure: J Am Coll Cardiol 2002;39:1780-6.

29. Mozaffarian $D, N y e, \mathbb{R}_{\text {, Levy }}$ WC. Anemia predicts mortality in severe heart fatlure: the prospective randomized amlodipine survival evaluation (PRAISE). J Am Coll Cardiol 2003;41:1933-9.

30. Kosiborod M, Smith GL, Radford MJJ, Foody JM, Krumbolz HM. The prognostic importance of anemia in patients with heart failure. Am J Med 20013;114:112-9.

31. Nair D, Shlipak MG, Angeja B, Liu HH, Schiller NB, Whooley MA. Association of anemia with diastolic dysfunction among patients with coronary artery disease in the Heart and Soul Study. Am J Cardiol 2005;95:332-6.

32. George J, Patall $S$, Wexler D, et al. Circulating erythropoietin levels and prognosis in patients with congestive heart failure: comparison with neurohormonal and inflammatory markers. Arch Intem Med $2005 ; 165: 1304-9$.

33. Ezckowitz JA, McAlister FA, Armstrong PW. Anemia is common in heart failure and is associated with poor outcomes: insights from a cohort of 12065 patients with news-onset heart failure. Circulation 2003;107:223-5.

34. Felker GM, Leimberger JD, Califf RM, et al. Risk stratification after hospitalization for decompensated heart failure. I Card Fail 2004;10:460-466.

35. Anand IS, Kuskowski MA, Rector TS, et al. Anemia and clange in hemoglobin over time related to mortality and morbidity in patients with chronic heart failure: results from Val-HeFT. Circulation $2005: 112: 1121-7$. 


\section{GENERAL DISCUSSION}

Heart fallure is a disease that concerns us all. Since the life-time risk to develop heart failure is 1 out of 5," statistically everybody who is surrounded by at least 4 persons will either be confronted with someone beloved suffering from this disease, or will becone a patient himself. Therefore, it need not elaborated why the struggle against heart failure is a daily (and nightly ...) task of many individuals, among which only a minority is a cardiologist.

To optimally treat a patient suspected of suffering from heart failure, it is important to diagnose or exclude heart failure as soon as possible. Yet, despite impressive advances in many fields, primary care doctors succeed in properly diagnosing heart failure in onlly one-third of these patients. ${ }^{2-4}$ This rather disappointing score is not due to ignorance or incompetence but simply because the syndrome of heart failure lacks pathognomonic clinical symptoms and signs, and more importantly lack an easily accessible gold standard diagnostic. Hence, the final diagnosis is often made with the help of more sophisticated imaging methods such as echocardiographic techniques, Magnetic Resonance Imaging (MRI) and, finally, the decisive "retro-scope".

When BNP and NT-proBNP were launched as promising serological markers for the diagnosis of heart failure, our hospital was among the very first in the Netherlands to introduce natriuretic peptide testing into daily clinical routine. In a fruitiul cooperation between the Departments of Cardiology and Clinical Chemistry, we studied the benefits and the pitfalls of NT-proBNP testing in daily clinical practice in order to facilitate the use of serological markers, especially NT-proBNP, in the syndrome of heart failure.

In Chapter 1 we propose cut-off values for diagnostic NT-proBNP testing in acutely dyspnoeic patients. These cut-points were established in the International Collaborative On NT-proBNP (ICON) Study, by means of multivariable logistic regression techniques and verified by bootstrapping. We found that the optimal strategy was to implement an age independent rule-out cutpoint (i.e. $300 \mathrm{pg} / \mathrm{ml}$ ) combined with age dependent rule-in cutpoints. $(450 \mathrm{pg} / \mathrm{ml}$ for $<50$ years; $900 \mathrm{pg} / \mathrm{ml}$ for $50-75$ years; $1800 \mathrm{pg} / \mathrm{ml}$ for $>75$ years).

Our strategy was driven by clinical considerations. For patients under 50 years, the minimum sensitivity for the diagnosis of acute heart failure by using NT-proBNP concentrations was set at $95 \%$ because of the severe consequences of a missed diagnosis of heart failure in the younger patient. In patients above 75 years, due to the age-related increase in basal NT-proBNP production, optimal specilicity was warranted in order to prevent overdiagnosis and treatment for acute $\mathrm{HF}$ in the older patient. In the intermediate age group, i.e. patients 50 to 75 years old, a balance in sensitivity and specificity was sought. To determine the cut-point for ruling out acute heart failure, a similar procedure as for the diagnosis was used to identify an NT-proBNP concentration with optimal negative predictive value.

Since gender has independent effects on NT-proBNP concentrations as well, ${ }^{5-7}$ we also examined further categorization by gender. Interestingly, while female sex was associated with a trend towards higher median NT-proBNP concentrations among those 
without acute heart failure, the NT-proBNP concentrations in female patients with acute heart failure were not significantly higher than those in male patients with acute heart failure. Therefore, further stratification by gender was not necessary in our cut-off scheme.

By opting for a strategy using age-dependent rule-in cut-points and a single ageindependent rule-out cutpoint without differentiating for gender, we were able to provide a simply applicable cut-off scheme which correctly diagnoses or excludes heart failure in $84 \%$ of the patients with acute dyspnea, solely by applying NT-proBNP concentrations (i.e. not taking any clinical factors into account)

In $16 \%$ of our study population of acutely dyspnoeic subjects, NT-proBNP was less conclusive; the so-called "grey" zone or intermediate zone. In Chapter 2, we further analyse this specific subset of acutely dyspnoeic patients.

Among the individuals with an NT-proBNP concentration in the grey zone, those with acute heart failure were more likely to be older, to be in atrial fibrillation, to have a prior history of heart failure as well as histories and physical examination findings referable to heart failure, when compared to subjects without acute heart failure. In contrast the 'grey zone' patients without heart failure were more likely to have histories, symptoms, and signs consistent with either prior or acute obstructive airway diseases or airway infections.

We found that several factors were independently associated with a diagnosis of acute heart failute among grey zone patients, namely the use of loop diuretics on presentation, complaints of paroxysmal nocturnal dyspnea, jugular venous distention and the absence of a cough. Taking these clinical parameters into account can assist the physician to decide whether an intermediate elevation of NT-proBNP indicates heart failure.

An important yet fascinating difficulty in the interpretation of serum concentrations of natriuretic peptides and particularly NT-proBNP, is the correlation between NT-proBNP and renal function. Observational studies have shown that renal function correlates inversely with elevated NT-proBNP concentrations. However, it is unclear whether this correlation is caused by accumulation due to a decreased clearance or whether this is due to a parallel diminished cardiac function and thus an increase in production. The latter would implicate that any elevation of NT-proBNP in patients with renal impairment reflects the tight relationship between the heart and the kidneys, the socalled "cardio-renal axis".

In Chapter 3, we analysed the relation between renal function, NT-proBNP concentrations and outcome in the 720 heart failure patients included in the ICON Study. We confirm the previously described correlation between Glomerular Filtration Rate and NT-proBNP concentrations $(r=-0.34 ; p<0.001)$. For further NT-proBNP analyses, we dichotomised our patients to above or below the median NT-proBNP concentration $(=4647 \mathrm{pg} / \mathrm{mll}$ ). For analyses of renal function, patients were divided according to GFR above or below $60 \mathrm{~mL} / \mathrm{min} / 1.73 \mathrm{~m}^{2}$, which was also nearly the median of this group.

Of all 720 heart failure patients, 89 patients $(12.4 \%)$ died within 60 days. In multivariate analyses, both GFR $<60 \mathrm{ml} / \mathrm{min} / 1.73 \mathrm{~m}^{2}$ and NT-proBNP concentrations above the median strongly and independently predicted 60 days mortality. Moreover, in a secondary analysis, the combination of both GFR $<60 \mathrm{ml} / \mathrm{min} / 1.73 \mathrm{~m}^{2}$ and NT-proBNP level above the median was even a stronger predictor of mortality than each parameter 
alone. These findings also illustrate that NT-proBNP and BNP can be used even in the presence of renal impaiment.

Kaplan-Meier curves also demonstrated that the vast majority of deaths within 60 days occurred in the subjects with an NT-proBNP concentration above the median and a GFR $<60 \mathrm{~mL} / \mathrm{min} / 1.73 \mathrm{~m}^{2}$, with low rates of mortality in the other categories including the group of patients with an NT-proBNP below the median and a GFR $<60$ $\mathrm{mL} / \mathrm{min} / 1.73 \mathrm{~m}^{2}$.

Since the combination of heart failure with renal impairment has such a bad prognosis, some authors even consider heart failure complicated with renal impaiment as a special entity: "the cardio-renal syndrome". This cardio-renal syndrome has been defined as the development of a rise in creatinine concentration of $\geq 0.3 \mathrm{mg} / \mathrm{dL}$ during admission in patients with the clinical diagnosis of acute heart failure., 8

In order to study the dynamic aspects of renal. function and NT-proBNP, we also divided our population into subjects with an increase in creatinine level during hospital admission $\geq 0.3 \mathrm{mg} / \mathrm{dL}$, in subjects with a decrease in creatinine level $\geq 0.3 \mathrm{mg} / \mathrm{dL}$ and into a remaining group of subjects with a "stable' creatinine concentration and subdivided each group according to NT-proBNP concentration above/below the median. We found that patients with suffering from the combination of an NT-proBNP above the median and a rise in creatinine of $\geq 0.3 \mathrm{mg} / \mathrm{dL}$ have a significantly worse prognosis when compared to any other category. Consequently, we state that NT-proBNP can better delineate the cardiac part in the 'cardio-renall syndrome' than the clinical diagnosis of heart failure.

In Chapter 4 , we describe an invasive study performed in 178 hypertensive subjects in order to study the renal clearance of natriuretic peptides. Our intention was to compare the clearance of BNP $(3.5 \mathrm{kDa})$ and NT-proBNP $(8.5 \mathrm{kDa})$ with Cystatin-C $(13 \mathrm{kDa})$, a Small Molecular Weight Protein as well, but also a novel marker of renal function. This is mainly due to the fact that the clearance of Cystatin-C only depends on kidney function, while the release into the circulation is virtually independient of body constitution or any (patho)physiological process.

We collected blood samples from both the renal arteries and veins for determination of BNP, NT'proBNP, and Cystatin-C and, subsequently, we invasively measured remal blood flow in the kidneys by the ${ }^{133}$ Xenon washout technique.

Our study confirmed the previously described strong correlation between glomerular filtration rate and serum concentrations of Cystatin-C $(r=-0.72 ; p<0.001)$. We also confirmed the previously published (moderate) correlation between GFR and serum concentrations of NT-proBNP and BNP $(r=-0.32$ and $p=60.00 \rrbracket$ for both $)$.

In our next step, we dichotomised our study group into subjects with a $C F \mathbb{R} \geq$ $60 \mathrm{ml} / \mathrm{min} / 1.73 \mathrm{~m}^{2}$, versus subjects with a GFR $<60 \mathrm{ml} / \mathrm{min} / 1.73 \mathrm{~m}^{2}$. No significant differences were found between the fractional extractions of either BNP, NT-proBNP or Cystatin-C in both groups.

We did find a correlation between the fractional extractions of BNP and NT 4 proBNP and the fractional extraction of Cystatin-C $(r=0.39 ; p<0.001$ and $r=0.50 ; p<0.001$ respectively), which confirms that NT-proBNP and BNP are indeed cleared as small Molecular Weight Proteins. However, echocardiography revealed that the e/a ratio was significantly lower in the patients with renal impaiment $(0.79+1 / 0.22$ verstis $1.01+/$ - 
$0.39 ; \mathrm{p}<0.001$ ) and that the left ventricular mass index, although of borderline significance, was higher in this group.

This indicates that patients with renal impaiment frequently have diastolic dysunction, which causes elevation of BNP and NT-proBNP serum concentrations. ${ }^{10}$ We conclude therefore that the moderate correlation between NT-proBNP or BNP and GFR $(r=0.32)$, when compared to Cystatin-C $(r=0.72)$ and GFR, is due to the fact that cardiac production is more important for the total NT-proBNP concentration than accumulation due to a decreased clearance. Extrapolating our data to heart failure patients, our findings suggest that when changes in NT-proBNP or BNP are paralleled by changes in renal function, Cystatin-C could be used to correct for any possible changes in NTproBNP or BNP concentration due to accumulation. Importantly, since we did not include many patients with a GFR $<30 \mathrm{ml} / \mathrm{min} / 1.73 \mathrm{~m}^{2}$, these findings can not be extrapolated to subjects with more severe renal impaiment.

Our observations in chapter 4 underscore the findings in the ICON Study as described in Chapter 3 .

Not only renal impairment, also obesity has been suggested to hinder the interpretation of natriuretic peptide lewels. While renal impairment is associated with elevated levels of BNP and NT-proBNP, obesity is associated with lower NT-proBNP and BNP concentrations. Several hypotheses tried to explain this relation. BNP is for instance also cleared by the Natriuretic Peptide Receptor type C (NPR-C) which is abundantly expressed in adipocytes. A possible explanation therefore, is an increase in clearance in obese subjects. Secondly, it is known that obese heart failure patients have a better prognosis when compared to normal weight or underweight patients. For that reason, it could very well be that lower levels of these peptides indeed reflect relatively healthier hearts. Lastly, heart failure is a clinical diagnosis lacking true pathognomonic signs. The gold standard of heart failure is, up till now, based on the interpretation of clinical signs as a possible jugular vein distention, swollen ankels and complaints of dyspnea on exertion. Especially in the obese subject, these signs are more difficult to interpret since obesity mirnics or hides such signs. Therefore, it could very well be that this correlation is based on the erronous inclusion of obese subjects without heart failure and consequently, lower concentrations of BNP and NT-proBNP.

In order 10 asses the nature of this association in a more mechanistic way, we chose an interventional rather than an observational approach. We repetitively measured both BNP and NT-proBNP concentrations in 22 morbidly obese patients who were undergoing bariatric surgery. We found that, while the Body Mass Index (BMI) of these patients rapidly decreased in time, both serum concentrations of BNP and NT-proBNP simultaneously rose. Since NT-proBNP is not cleared by the NPR-C, we can conclude that the negative correlation between natriuretic peptides and Body Mass Index is neither caused by false inclusion of obese subjects without heart failure nor elicited by an increase in clearance, but has to be caused by a decrease in production. Whether this decrensed production truly resembles lower tilling pressures or whether the production of proBNP is inhibited because of other factors that play a role in obesity is the subject of future research.

Others had already shown that NT-proBNP is a good predictor of prognosis. "1-i4 In Chapter 1,2 and 4 we confirm that NT-proBNP is indeed the best predictor of shortterm mortality in patients suffering from acute heart failure. Yet, one must bare in mind 
that (in patients with acute heart failure), NT-proBNP especially resembles acute myocardial stretch. However, prognosis in heart failure not only depends on the quantity of acute myocardial stretch (i.e. filling pressure) but myriad other myocardial and systemic factors, processes and complications.

On the level of the myocardial tissue, several processes play a role in the progression of the disease. Besides apoptosis, necrosis, remodeling and fibrosis, inflammatory processes also affect the myocardial tissue. Previous work from Sharma et al. ${ }^{15}$ has shown that galectin -3 , a $26 \mathrm{kDa}$ protein produced by activated cardiac macrophages, plays a role in the progession of heart failure. It is also known from cancer studies that galectin-3 is measurable in the circulation and that serum levels are elevated in sonve cases of dissiminated adenocarcinomata. ${ }^{16}$ We therefore hypothesized that galectin-3 serum concentrations could predict (short-term) outcome in patients with acute heart failure. In order to study the potential prognostic role of galectin-3, we measured galectin-3 serum concentrations in the PRIDE study population. Briefly, this population consists of 599 patients suffering from acute dyspnea of which acute heart failure was the final diagnosis in 209 subjects. ${ }^{17}$

As to be expected, NT-proBNP was a better marker for diagnosing acute heart failure in this population. However, multivariate analysis showed that galectin-3 was superior to any other parameter as an independent predictor of 60-day mortality (OR 10.3, p<0.01) or the combination of death/recurrent HF within 60 days. (OR $14.3, \mathrm{p}<0.001$ ). We believe therefore that there may be a potential role for galectin- 3 in the estimation of prognosis in heart failure and subsequently, for therapy descision making.

Another more systemic serum marker associated with heart failure, is hemoglobin. A decrease in hemoglobin concentration in heart failure patiens may be caused by neurohumoral and/or hemodynamic anomalies associated with heart failure. ln addition, anemia can be a trigger for (acute) heart failure and can contribute to remodeling, symptom severity, and mortality. ${ }^{18}{ }^{19}$ Since anemia can reflect the systemic involvement in the pathophysiology of the syndrome of heart failure, we studied the single and combined role of NT-proBNP and hemoglobine in the prognostification of patients with heart faihure in our ICON Study population. As cut-off values for the presence or absence of a low hemoglobin level, we chose the World Health Organization definition of anemia: hemoglobin of less than $13.0 \mathrm{~g} / \mathrm{dL}$ (male) and less than $12.0 \mathrm{~g} / \mathrm{dL}$ (female). ${ }^{20}$ For NT-proBNP analyses, we divided our patients into two groups, based on NTproBNP concentration $>5180 \mathrm{pg} / \mathrm{mL}$ vs. $\leq 5180 \mathrm{pg} / \mathrm{mL}$; the optimal cut-point for predicting 60-day mortality in acute heart failure). ${ }^{21}$

Multivariate analysis showed that both the presence of anemia and an NT-proBNP level $>5180 \mathrm{pg} / \mathrm{ml}$ were independently associated with 60 days mortality. We further categorized our study population into four groups determined by the presence/absence of anemia and a NT-proBNP level above/below $5180 \mathrm{pg} / \mathrm{ml}$. Using non-anemic with a "low" NT-proBNP as the reference group, we found a (non-significant) trend towards a higher 60 days mortality rate in patients with anemia but a "low" NT-proBNP. Nonanemic subjects with a 'high' NT-proBNP had a significantly thigher risk of death when compared to the reference group but the combination of elevated NT-proBNP plus anemia was the strongest predictor of 60 -day mortality. 
These data point out that combining NT-proBNP with haemoglobin concentrations, i.e. a cardiac marker with a systemic determinant, can also aid in estimating the prognosis in patients with acute heart failure.

\section{Future perspectives}

In this thesis, the implementation of serological markers of heart failure in daily clinical routine is discussed. In our work, we focussed on the establishment of cut-off values for NT-proBNP concentrations in the diagnosis of heart failure, the background of influences of renal impairment and obesity on NT-proBNP concentrations, and the progniostic value and interaction with NT-proBNP of other (novel and conventional) márkers in heart fadlure like galectin-3, hemoglobin and glomerular filtration rate.

We believe that by now, the natriuretic peptides have established their role in the diagnosis and estimation of prognosis in patients with heart failure. Hence, we envision that the natriuretic peptides will become the cornerstone of a multi-marker strategy in heart failure. In fact, it is surprising that such a strategy has not yet been established in the complex syndrome of heart failure.

In that perspective it is interesting to compare the disease we call heart failure with leukaemia. Leukaemia is a disease with an annual incidence in the United States of 30,800 new patients. ${ }^{22}$ This morbidity affects the production of white blood cells and causes them to reproduce uncontrollably and crowd out existing healthy cells. Haematologists and oncologists over the years have succeeded to further classify this syndrome, based on course (acute versus chronic) but especially based on histological (myeloid versus lymphocytic/lymphoblastic) and immunological features (e.g. AMLM4Eo). By emphasizing the biology of this disease, taking this from their benches to the patients' bedsides and then use this biology to classify clinical practice, enabled them to study the effects of different therapeutical options in each subgroup and thus establish algorithms for each form of leukemia so that every patients receives the most optimal therapy for improvement of their prognosis.

The annual incidence of heart failure in the United States of 550,000 subjects outnumbers incidence of leukaemia in the same population by far. ${ }^{23}$ Surprisingly, and quite regrettably, up till today most cardiologists only dissect this large group of patients into documentable etiology (i.e. ischaemic or valvular) or not, and, by the presence or the absence of a decreased left ventricular ejection fraction (systolic versus diastolic heart failure). And while diastolic heart failure even makes up $20-50 \%$ of all cases of heart faihure, ${ }^{24}$ so far only one study specifically studied the effects of therapy in this subgroup $^{25}$ so that for the treatment of heart failure the "one-size-fits-all" approach is still valid. This clearly and painfully shows that in heart failure, the failure is not only in the hearts of the patients but also in the minds of the doctors: our current shallow classification might even be the true Achilles' heel in the syndrome of heart failure.

We believe that a serologically based multimarker strategy might be able to tackle this problem in heart failure. As already discussed by Lee and Vasan, such a panel of serological markers may consist of neurohormonal markers, biomarkers of myocyte injury and matrix remodelling and markers of (cardiac) inflammation ${ }^{26}$ but possibly also by markers of non-cardiac complications such as renal impairment and anemia. 
The next logical step but intellectual leap in heart failure is to design studies that truly investigate whether all heart failure patients should be treated equally. The study of novel therapeutical options such as specific anti-fibrotic or anti-inflammatory agents studied in our own group, ${ }^{27}$ might be the ideal pilot-studies for adopting the leukemia strategy in heart failure in order to provide every heart failure patient the most optimal therapy.

\section{REFERENCES}

1. Lloyd-Jones DM, Larson MG, Leip EP, et al. Lifetime risk for developing congestive heart failure: the Franingham Heart Study. Circulation 2002; 106:3068-72.

2. Wright SP, Doughty RN, Pearl $A$, et al. Plasma amino-terininal pro-brain nairuretic peptide and accuracy of heart-failure diagnosis in primary care: a randomized, controlled trial. I Am Coll Carcliol $2003 ; 42: 1793-800$.

3. Struthers $A D$. Identification, diagnosis and treatment of heart failure: could we clo better? Cardiology 1996; 87 Suppl 1:29-32.

4. Wheeldon NM, MacDonald TM, Flucker CJ, Mckendrick AD, McDevin DG, Struthers AD. Echocardiography in chronic heart failure in the community. Q .J Med 1993; 86:17-23.

5. Endin M, Passino C, Del Ry S, Prontera $C_{s}$ Galetta $F$, Clerico A. Influence of gender on circulating cardiac natriuretic hormones in patients with heart lailure. Clin Chem Lab Med 2003; 41:686-92.

6. Raymond I, Groemning BA, Hildebrandi PR, et al. The influence of age, sex and other variables on the plasma level of $\mathrm{N}$-terminal pro brain narriuretic peptide in a large sample of the general population. Hear $2003 ; 89: 745-51$.

7. Redfield MM, Rodeheffer RJ, Jacobsen SJ, Mahoney DW, Bailey KR, Burnet JC, Ir. Plasma brain natriuretic peptide concentration: impact of age and gender. J Am Coll Cardiol 2002: 40:976-82.

8. Stevenson LW, Nohria A, Mielniczuk L. Torrent or Torment From the Tubules? Challenge of the Cardiorenal Connections. J Am Coll Cardiol 2005; 45:2004-2007.

9. Shlipak MG, Massie BM. The Clinical Challenge of Cardiorenal Syndrone. Circulation 2004: 110:1514. 1517.

10. Lubien $\mathrm{E}$, DeMaria A, Krishnaswamy $\mathrm{P}$, et al. Utility of B-natriuretic peptide in detecting diastolic dysfunction: comparison with Doppler velocity recordings. Circulation 2002; 105:595-601.

11. Bettencourt P, Azevedo A. Pimenta d, Frioes F. Ferreina S, Ferreitu A. N-Teminal-Pro-Brain Natriuretio Peptide Predicts Outcome After Hospital Discharge in Heart Failure Palionts. Circulation 2004; $110: 2168-2174$.

12. Hartmann F, Packer M. Coats AJS, at al. Prognostic Impaci of Plasma N-Terminat Prow Brain Natrititic Peptide in Severe Chronic Congestive Heart Failure: A Substudy of the Carvedilot I'rospective Randonized Cumulative Survival (COPERNICUS) Trial. Chrolation 2004; 110:1780 1786.

13. Gustalsson F, Steensgaard-Hansen F, Badskjater J, Poulsen AH, Corell P, Hildebrand P. Diagnostic and Prognostic Performance of N-Terminal ProBNP in Primary Care Patients With Suspected Heart fialure. I Card Fail 2005; 11:15-20.

14. Richards AM, Doughty R. Nicholls MG, el al. Plasma N-terminal pro-brain matriuretic peptide and adrenomedullin: prognostic utility and prediction of benefit from carvedilot in chronic ischemic left ventricular dystunction. Australia-New Zealand Heart Faillure Group. J Am Coll Cardiol 2001; 37:1781 7 .

15. Sharma UC, Pokharel $S$, van Brakel TJ, et al. Galectin-3 marks activated macrophages in failuwe-prone hypertrophied hearts and contributes to cardiac dysfunction. Circulation 2004; $110.3121-8$.

16. lurisci 1. Tinari $N$, Natoli $C$. Angelucei D, Cianchetti $\mathbb{E}$, llacobelli $S$. Concentrations of gallectin-3 in the sera of nomal conttrols and cancer patients. Clin Cancer Res 2000;6:1389-93.

17. Januzzi JL, Jr., Camargo CA, Anwaruddin $\mathrm{S}$, et al. The $\mathbb{N}$-terminal Pro-BNP Investigation of Dyspnea in the Envergency departmeni (PRIDE) study. Am J Cardiol 2005; 95:948-54.

18. Anand I. MeMurray JJ, Whitmore J, et al. Anemia and its relationship to clinical outcome in bearl failure. Circulation 2004; 110:149-54. 


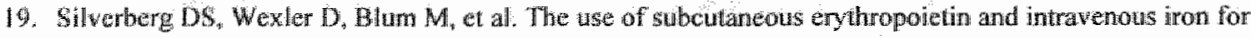
the treatment of the anemia of severe, resistant congestive heart failure improves catriliac and renal function and functional cardiac class, and narkedly reduces lospitalizations. I Am Coll Cardiol 2000; $35: 1737.44$.

20. Wumitional Aremias: Report of a WHO Scientific Group. Geneva: World Health Organization. 1968.

21. Jamuxzi $J \mathbb{L}$, Jr., wan Kimmenade RRI, Lanchbury JG, Bayes-Genis A, Pinto YM, Richards AM. NTproBNp Testing for Diagnosis and Short-Tarm Prognosis in Acute Congestive Heart Failure: An International Poolded Analysis of 1256 Patients. The International Collaborative of N1 wroBNP (ICON) Sudy. Cur Heart I 2006; $27: 330-337$.

22. Jemal $A$, Thomas $A$, Murray $T$. Thun M. Cancer slatistics, 2002. CA Cancer J Clin 2002; 52,23-47.

23. Lewy $\mathrm{D}$, Kenchatiath $\mathrm{S}$, Larson $\mathrm{MG}$, et al Long-term trends in the incidence of and surviwal with heart Gailure. N Engl J Med 2002; 347:1397-402.

24. Jessup M. Brozena S. Heart failure. N Engl J Med 2003; 348:2007-18.

25. Yusuf $S$, Pfeffer MA, Swedberg K, et al. Effects of candesartar in patients with chronic heart failure and preserved left-wentricular ejection fraction: the CHARM-Preserved Trial. Lancet 2003,362:777-81.

26. Lee DS, Vasan RS. Novel markers for heart failure diagnosis and prognosis. Curr Opin Cardiol 2005; $20.201-10$.

27. Schellings MW, Baumann $M$, wan Leeuwen RE, et al. Imatinib Attenuates End-Organ Damage in Hypertensive Homozy gous TGR(miken2)27 Rats. Hypertension 2006.im press. 


\section{SUMMARY}

Heart failure is highly prevalent yet difficult to diagnose, especially in the acutely dyspnoeic patient. Serological tests seem to be promising tools that could improve the clinician's capability to diagnose or exclude heart failure in patients suffering from acute dyspnea. This thesis summarizes our efforts to optimize the use of serological tests, especially aminoterminal proBrain Natriuretic Peptide (NT-proBNP), in the daily clinical practise of heart failure.

Chapter 1 describes the details and characteristics of the International Collaborative on NT-proBNP (ICON) study. In this international multicentre study, we examined NTproBNP concentrations among 1256 acutely dyspnoeic patients with and without acute heart failure and we identified the optimal cut-points for diagnosis and prognosis. We found that the optimal strategy to positively confirm acute heart failure was to use agerelated cut-points of $450 \mathrm{pg} / \mathrm{ml}, 900 \mathrm{pg} / \mathrm{ml}$, and $1800 \mathrm{pg} / \mathrm{ml}$ for ages $<50$ years, $50-75$ years, and $>75$ years of age. To rule out heart failure, an age-independent cut-point of $300 \mathrm{pg} / \mathrm{ml}$ was optimal to exclude acute heart failure. Applying this cut-point strategy in our study population demonstrated that NT-proBNP alone was valuable for diagnostic evaluation in $83 \%$ of all subjects with acute dyspnea. Among those with acute heart failure, a presenting NT-proBNP concentration $>5180 \mathrm{pg} / \mathrm{ml}$ was strongly predictive of death on short term.

In order to further improve diagnostic accuracy in acute dyspnea, we analyzed in Chapter 2 more in detail the subset of patients in the ICON study where the NT-proBNP concentration did not allow to either confirm or reject the diagnosis of heart failure: moderately elevated BNP between the rule-in cutpoint and their rule-out cutpoint, the so-called 'grey zone'. As discussed above, $17 \%$ of our total population had a 'grey zone" NT-proBNP concentration. Of this group, $54 \%$ were diagnosed with acute heart failure. Among these subjects, heart failure patients were more likely to be older, to have a history of heart failure, to be in atrial fibrillation and to have elevated troponin T concentrations, when compared with those without heart failure. In multivariate analysis, the use of loop diuretic on presentation, paroxysmal nocturnal dyspnea, jugular venous distention, and the absence of a cough were associated with a diagnosis of acute heart failure among 'grey zone' patients. Adding this specific clinical information to NT-proBNP could improve the diagnostic accuracy among subjects with intermediate NT-proBNP concentrations. Thus, an intermediate level of NT-proBNP in a subject taking diuretics increases the likelihood of heart failure. Furthermore, heart failure subjects with diagnostic NT-proBNP concentrations had the highest mortality rates, subjects without heart failure and NT-proBNP below $300 \mathrm{pg} / \mathrm{ml}$ had the lowest mortality rates; subjects with "grey zone" NT-proBNP had intermediate outcomes, irrespective of their final diagnosis. 
Plasma concentrations of Brain Natriuretic Peptide (BNP) and NT-proBNP, both established cardiac biomarkers, are inversely related to renal function. This relation has been interpreted to indicate an accumulation of these peptides with declining glomerular filtration rate.

However, renal impairment and cardiovascular disease often coincide and it remains possible that elevated natriuretic peptides in subjects with renal impaiment truly reflect cardiac involvement rather than decreased clearance.

Since we were interested in the interaction between NT-proBNP and renal impairment, we studied in Chapter 3 the individual and integrative role of NT-proBNP and parameters of renal function for prognosis in heart failure. Therefore, we dichotomised all heart failure patients in the ICON study according to NT-proBNP concentration and baseline glomerular filtration rate. The primary endpoint was 60 days mortality. We found that a GFR $<60 \mathrm{ml} / \mathrm{min} / 1.73 \mathrm{~m}^{2}$ or a NT-proBNP $>4647 \mathrm{pg} / \mathrm{ml}$ were botll independent predictors of short-term mortality but that the combination was the most powerful predictor of 60 days mortality. In addition, we also divided our patients according to changes in renal function during admission. Among subjects with an NTproBNP above the median, those with a creatinine rise $\geq 0.3 \mathrm{mg} / \mathrm{dL}(=26.5 \mu \mathrm{mol} / \mathrm{L})$ had the worst prognosis while in subjects with a NT-proBNP below the median, prognosis was not influenced by either impaired renal function at presentation or the development of renal impairment during admission. This indicates that NT-proBNP can be interpreted in the presence of renal impairment.

Chapter 4 describes an invasive study of the interaction between BNPNNT-proBNP and renal function. In this study, we measured concentrations of BNP, NT-proBNP and Cystatin-C in the renal arteries and veins of 178 hypertensive patients undergoing renal arteriography and combined these findings with invasive renal blood flow measurements. These data enabled us to compare the renal handling of BNP, NTproBNP and Cystatin-C. Our study confirms that patients with renal impairment have elevated levels of natriuretic peptides but also typical echocardiographic abnormalities compatible with diastolic dysfunction. We found that the renal clearance of BNP and NT-proBNP parallels the renal clearance of Cystatin-C. Our findings surmise that in mild renal impaiment, (i.e. GFR $>30-40 \mathrm{ml} / \mathrm{min} / 1.73 \mathrm{~m}^{2}$ ) natriuretic peptide plasma concentrations are minimally influenced by a decreased clearance. However, combining measurements of (NT-pro)BNP with Cystatin-C might distinguish changes related to modifications in renal function from changes in cardiac production, which often coincides.

BNP also correlates negatively with Body Mass Index (BMI). Since BNP is cleared by adijocytes, it is unclear whether this correlation reflects increased clearance or decreased cardiac production. The cleavage equivalent amino-terminal proBNP (NTproBNP) is not cleared by adipocytes. In another interventional study, discussed in Chapter 5, we investigated the inlluence of obesity on plasma levels of BNP and NTproBNP. We repeatedly measured plasma levels of BNP and NT-proBNP in 22 patients that underwent bariatric surgery. Since plasma levels of both peptides increase while BMI dramatically decreases, this increase can not be attributed to a diminished clearance by adipocytes. We propose that production of BNP and NT-proBNP may be 
decreased in obesity. This suggests that adipose tissue may decrease production of BNP and NT-proBNP by a yet unidentified mechanism.

Since measurement of NT-proBNP provides information on cardiac myocytes, but not on other cell types involved in heart failure, we also compared the prognostic role of several other serological markers that reflect other pathophysiological mechanisms active in failing hearts as well. In Chapter 6 , we evaluated the prognostic role of NTproBNP, apelin and galectin-3 in the ProBNP Investigation of Dyspnea in the Emergency Department (PRIDE) study population. This population consists of 599 patients presenting with dyspnea at the Emergency Department, of which 209 had acute heart failure.

NT-proBNP was superior to both apelin and galectin-3 for diagnosing acute heart failure, however, an elevated level of galectin-3 was the best independent predictor of 60-days mortality or the combination of death/recurrent heart failure within 60 days.

Our data demonstrate the potential utility of galectin-3 as a useful marker for evaluation of patients with suspected or proven acute heart failure, while apelin measurement was not useful for these indications. Moreover, the combination of galectin-3 with NTproBNP was the best predictor for prognosis in subjects with acute heart failure.

Anemia is a parameter that resembles the chronic or systemic effects of heart failure. We also evaluated in the ICON Study the relationships between hemoglobin, NTproBNP, and 60-day mortality. The World Health Organisation criterion for anemia (i.e. bemoglobin of less than $13.0 \mathrm{~g} / \mathrm{dL}$ [male] and less than $12.0 \mathrm{~g} / \mathrm{dL}$ [female]) was met by $44 \%$ of the cohort. Anemia was an independent predictor of short-term mortality that was inferior but additional to NT-proBNP. We found that anemia was common in our cohort of subjects with acute heart failure and that anemia is related to adverse shortterm outcome. Integrated use of hemoglobin and NT-proBNP measurements provides powerful additive information and is superior to the use of either in isolation. 


\section{SAMENVATTING}

Hartfalen is een frequent voorkomende ziekte die vaak moeilijk te diagnosticeren is, vooral in de patiëntenpopulatie die lijdt aan acute kortademigheid. Het stellen van de diagnose met behulp van bepaalde bloedtesten is een veelbelovend nieuw hulpmiddel voor artsen om accurater hartfalen te kunnen vaststellen danwel te kunnen uitsluiten. Dit proefschrift somt onze inspanningen op om het gebruik van deze bloedtesten met name het aminoterminaal proBrain Natriuretic Peptide (NT-proBNP), in de dagelijkse klinische praktijk te optimaliseren.

Hoofdstuk 1 beschrijft de details en karakteristieken van de International Collaborative On NT-proBNP (ICON) studie. In deze internationale multi-centra studie bestudeerden we de NT-proBNP concentraties in 1256 patienten met acute kortademigheid die well of niet door hartfalen werd veroorzaakt en aan de hand daarvan hebben we de neest geschikte afkapwaardes voor het bepalen van de diagnose en de prognose vastgesteld. De meest optimale methode on hartfalen te diagnosticeren is om leeftijdsaflankelijke afkapwaardes te gebruiken van $450 \mathrm{pg} / \mathrm{mL}, 900 \mathrm{pg} / \mathrm{mL}$, en $1800 \mathrm{pg} / \mathrm{mL}$ voor respectievelijk de leeftijdscategorieën $<50$ jaar, 50-75 jaar en $>75$ jaar in combinatie met een leeftijdsonafhankelijke afkapwaarde van $300 \mathrm{pg} / \mathrm{mL}$ om hartfalen uit te sluiten. Door deze afkapwaardes te hanteren, was NT-proBNP diagnostisch in $83 \%$ van alle patienten met acute kortademigheid. In de groep met acuut hartfallen was het hebben van een NTproBNP $>5180 \mathrm{pg} / \mathrm{ml}$ een sterke voorspeller voor overlijden op korte termijn.

Voor verdere verbetering van de diagnostische accuratesse bij acute kortademigheid, analyseren we in hoofdstuk 2 de groep patiënten in de ICON studie met een NTproBNP concentratie die ligt tussen hun afkapwaarde om hartfalen te diagnosticeren en de afkapwaarde om hartfalen uit te sluiten, het zgn. "grijs gebied", meer uitgebreider. Zoals hierboven beschreven, heeft $17 \%$ van onze totale populatie een "grijs gebied" NT-proBNP. In deze groep werd in $54 \%$ de diagnose "acuut hartfalen" gesteld. Pat"ënten met hartfalen in deze groep waren, in vergelijking met de patiënten die geen hartfalen hadden, in de regel ouder, hadden meestal een voorgeschiedenis van harffalen, waren vaker in boezemfibrilleren en hadden vaker een verhoogde troponine $T$ concentratie. In multivariate analyse blijkt dat het gebruik van lisdiuretica bij opname, paroxysmale nachtelijke kortademigheid, het hebben van gestuwde halsvenen en de afwezigheid van hoesten, in patiênten met een "grijs gebied" NT-proBNP concentratie geassocieerd zijn met hartfalen. Door deze informatie te combineren met NT-proBNP kan de diagnostische accuratesse in deze patiënten met intermediäre NT-proBNP concentraties verbeterd worden. Bowendien hebben de patiënten met hartfalen met een diagnostische NTproBNP concentratie de hoogste kans op overlijden op korte termijn, hebben patiénten zonder hartfalen met een NT-proBNP concentratie lager dan $300 \mathrm{pg} / \mathrm{ml}$ de minste kans op overlijden en hebben indiwiduen met een "grijs gebied" NT-proBNP een intermediaire kans op overlijden, ongeacht hun diagnose. 
De plasma concentraties van het Brain Natriuretic Peptide (BNP) en NT-proBNP, beide algemeen geaccepteerde cardiovasculaire biomarkers, vertonen een omgekeerde correlatie met nierfunctie. Aangenomen werd dat deze relatie bij een verminderde uitscheiding werd veroorzaakt door een opstapeling van deze eiwitten.

Echter, het hebben van hart- en vaatziekten en een vermindering van nierfunctie gaat vaak samen en een andere mogelijkheid is derhalve dat een verhoogdle spiegel van natriuretische peptiden inderdaad cardiovasculaire pathologie weerspiegelt in plaats van een verminderde uitscheiding.

Aangezien de interactie tussen NT-proBNP en een nierfunctie ons interesseert, bestudeerden we in hoofdstuk 3 de afzonderlijke en gecombineerde waarde van NT-proBNP en nierfunctie parameters voor de prognose van hartfalen. We verdeelden daarvoor alle hartfalen patiënten in de ICON studie volgens $\mathrm{N}$-proBNP en glomerular filtration rate (GFR) Ons primaire eindpunt was de 60 dagen overleving. Zowel een GFR $60 \mathrm{ml} / \mathrm{min} / 1.73 \mathrm{~m}^{2}$ als een NT-proBNP $>4647 \mathrm{pg} / \mathrm{ml}$ waren beiden onafhankelijke voorspellers van de korte termijn overleving maar de combinatie van beide was de sterkste voorspeller van de 60 dagen mortaliteit. Vervolgens deelden we onze patiënten in op basis van een verandering in nierfunctie gedurende de opname. In de patiënten met een NT-proBNP boven de mediaan hadden degene waarvan het serum creatinine gedurende de opname $\geq 0.3 \mathrm{mg} / \mathrm{dL}$ ( $=26.5 \mu \mathrm{mol} / \mathrm{L}$ ) steeg de slechtste prognose, terwijl in patiënten met een NT-proBNP lager dan de mediaan de prognose niet werd beïnvloed door noch een slechte nierfunctie bij opname noch een vermindering in nierfunctie gedurende de opname. Dit suggereert dat NT-proBNP concentraties ook geïnterpreteerd kunnen worden bij een verminderde nierfunctie.

Hoofdstuk 4 beschrijft een invasieve studie naar de interactie tussen BNP/NT-proBNP en nierfunctie. In deze studie hebben we de concentraties BNP, NT-proBNP en Cystatin-C gemeten in de nierarteries en niervenen van 178 hypertensieve patiënten die een nierangiogram ondergingen en we hebben dit gecombineerd met invasieve metingen van de renal blood flow. Hierdoor konden we de renale verwerking van BNP, NTproBNP en Cystatin-C vergelijken. Onze studie bevestigt niet alleen dat patiënten met een verminderde nierfunctie verhoogde spiegels van natriuretische peptiden hebben maar ook dat ze typische echocardiografische tekenenen van diastolische dysfunctie vertonen. We vonden eveneens dat de renale klaring van BNP en NT-proBNP parallel loopt aan de renale klaring van Cystatin-C. Onze bevindingen houden in dat in gevallen van een matig verminderde nierfunetie (d.w.z. GFR $>30-40 \mathrm{ml} / \mathrm{min} / 1.73 \mathrm{~m}^{2}$ ), de plasma concentraties van de natriuretische peptiden slechts minimaal worden beïnvloed door een verminderde klaring. Het combineren van het meten van (NT-pro)BNP met Cystatin-C zou verder de mogelijke veranderingen in NT-proBNP die veroorzaakt worden door veranderingen in klaring kumnen onderscheiden van veranderingen in cardiale productie, twee processen die vaak parallel lopen.

BNP vertoont eveneens een negatieve correlatie met de Body Mass Index (BMI). Aangezien BNP ook wordt afgebroken in vetcellen, is het onduidelijk of deze correlatie veroorzaakt wordt door een verhoogde afbraak of door een verminderde productie. NTproBNP, de splitsingsequivalent van BNP, wordt niet afgebroken in vetcellen. In hoofd- 
stuk 5 bespreken we onze andere interventionele studie, waarin de invloed van overgewicht op de plasma spiegels van BNP en NT-proBNP bespreken. Hiervoor hebben we op verschillende tijdstippen de BNP en NT-proBNP plasmen spiegels gemeten van 22 patiënten die gewichtsreductie chirurgie ondergingen. Aangezien de plasma spiegels van beide eiwitten stegen terwijl de BMI drastisch daalde, kunnen we deze stijging nitet verklaren uit een verminderde afbraak in vetcellen. We stellen derhalve dat in overgewicht de productie van BNP en NT-proBNP verminderd is. Onze studie suggereert dat vetweefsel de productie van BNP en NT-proBNP verlaagt via een nog ongekend mechanisme.

Aangezien NT-proBNP in hartfalen vooral acute uitrekking van hartspiercellen weerspiegelt, hebben we ook naar serologische markers gekeken die andere pathofysiologische processen vertegenwoordigen. In hoofdstuk 6 evalueren we de prognostische rol van NT-proBNP, apelin en galectin-3 in de ProBNP Investigation of Dyspnea in the Emergency Department (PRIDE) studie populatie. Deze populatie bestaat uit 599 patienten die zich met acute kortademigheid presenteerden op een Eerste Hulp post en waarvan 209 patiënten acuut hartfalen hadden.

NT-proBNP was superieur t.o.v. apelin of galectin-3 als diagnosticum voor acuut hartfalen, alhoewel galectin-3 spiegels eveneens significant hoger waren in individuen mét acuut hartfalen in vergelijking met individuen zónder acuut hartfalen. Echter, een verhoogd galectin-3 was de beste onafhankelijke voorspeller voor 60-dagen mortaliteit of voor de combinatie van overlijden/heropname voor hartfalen binnen 60 dagen.

Onze data tonen aan dat galectin-3 potentieel toepasbaar is als prognostische marker in de evaluatie van patiënten met de verdenking op of bewezen acuut hartfalen, terwijl apelin niet bruikbaar is voor deze toepassing. Bovendien is de combinatie van galectin-3 met NT-proBNP de beste voorspeller voor de prognose van individuen met acuut hartfalent.

Anemie of bloedarmoede weerspiegelt de chronische en systemische effecten van hartfalen. We hebben in de ICON studie eveneens gekeken naar de relatie tussen hemoglobine, NT-proBNP, en 60-dagen overleving. In deze studie voldeed $44 \%$ alan het Wereld Gezondheids Organisatie criterium voor bloedarmoede, $\mathrm{d}, \mathrm{w}, \mathrm{z}$. henoglobine gehalte minder dan $13.0 \mathrm{~g} / \mathrm{dL}$ voor mannen en minder dan $12.0 \mathrm{~g} / \mathrm{dL}$ voor vrouwen. Het hebben van bloedarmoede was een onafhankelijke voorspeller voor overlijden op korte termijn met weliswaar een minder voorspellende mar wel toegevoegde waarde t.o.v. NTproBNP. We vonden dat bloedarmoede frequent voorkwam in onze patiëntengroep met acuut hartfalen en tevens gerelateerd was aan een ongunstige prognose. Het gecombineerd interpreteren van hemoglobine met $\mathrm{NT}$-proBNP uitslagen verschaft sterkere prognostische informatie die superieur is aan beide parameters afzonderlijk. 
120 


\section{DANKWOORD}

Promoveren doe je nooit alleen en dit boekje is dan ook alleen tot stand gekomen dankzij de hullp van velen.

Prof. Pinto, beste Yigal. Bedankt dat je me hebt overtuigd om onderzoek te gaan doen! Ondanks tegenslagen in het begin wist jij als geen ander hoe je me moest motiveren om elk probleem juist om te buigen tot een uitdaging. lk kan terugkijken op een geweldige periode waarin ik ontzettend veel geleerd heb en zeker niet alleen over Cardiologic. Ik ben er dan ook trots op de eerste te zijn van de ongetwijfeld lange rij van promovendi waarvan jij de promotor bent. Bedankt!

Prof. van Dieljen-Visser, beste Marja. Jouw afdeling Klinische Chemie was voor mij meer een soort van "café De Zoete Inval". Nooit klopte ik tevergeefs aan bij de Klinische Chemie om te proberen "iets" in een bepaalde populatie te meten. Ook bij het tot stand komen van de artikelen heeft jouw kritische blik een belangrijke rol gespeeld in de verbetering vart de manuscripten. Bedankt hiervoor.

Prof. Crijns, als hoofd van de afdeling heeft u vanaf uw komst naar Maastricht het wetenschappelijk onderzoek naar hartfalen in een ritme-minded Maastricht krachtig ondersteund. Hoewel u slechts zijdelings bij mijn promotie betrokken was, bent u mij op afstand toch altijd blijven volgen. Die keren dat ik plots van de stafgang werd gepllukt om "even" mijn resultaten te bespreken en waarvoor uw overvolle agenda toch moest wijken heb ik iedere keer als zeer aangenaam en inspirerend ervaren. Dank hiervoor.

Jim, when Newton stated that he had been able to look further because he was standing upon the shoulders of giants, he must have learned from Nostradanus about our cooperation. You have been the "big Lou" on whose shoulders I have been standing. Not only are you a fantastic boss/collegue but allso a great friend and am looking forward to our future collaborations.

I would also like to thank the other ICON investigators: Aaron, John and Tony for their work and input. Furthermore, prof Richards, many thanks for your efforts concerning the ICON Study and I am very proud that you agreed to become a nember of the reviewing committee of my thesis. 
Jaap, jij zorgde letterlijk en figuurlijk voor "chemie" in mijn onderzoek. Mede dankzij jouw inzet is dit boekje er gekomen. Ik wens je veel succes met jouw verdere werkzaamheden bij de Klinische Genetica en uiteraard op de jeu-de-boules baan. Ook Paul, Jart, Snježana en Vincent bedankt voor al jullie hulp.

Mireille, bedankt voor de ontzettend aangename samenwerking en de gezellige "Validates". Ook de andere dames van de CardioResearch: Daniëlle, Moniek, Heidi, Suzanne, Elisabeth, Aimée, Violette en Monique, bedankt voor het prikken van de Validatepatienten en al jullie verdere assistentie.

Uiteraard een woord van dank voor mijn collega-promovendi op de kamer: Jop, Luc, Thrang, Robby, Wanda, Dominique, Klaartje, Cees en uiteraard ook Randy. Bedankt voor de supergezellige tijd samen en veel succes met jullie verdere carrière!!! Umesh, our Galectin-Ghurka, many thanks for your amicability and advice. I wish you and your little family all the best.

Prof. de Leeuw, u was in mijn promotie dé internist in hart en nieren. Hartelijk dank voor uw medewerking en bijdrage in de Vallidate-studie en de nierangio-studie. Ook een woord van dank aan de overige mensen van de Interne Geneeskunde: Bram Kroon, Roger Rennenberg en Boy Houben. Ook jullie bedankt voor de hulp bij deze projecten.

Dat een onderzoeksproject razendsnel kan worden uitgevoerd heeft onze studie naar de relatie tussen BNP, NT-proBNP en Body Mass Index wel bewezen. Daarom een woord wan dank aan Jeroen, François, prof. Buurman en prof. Greve. Dankzij jullie had ik in een mum van tijd mijn eerste publicatie op zak!

Ook een woord van dank aan Bianca en Jacqueline voor het inplannen van afspraken en alle overige secretariële zaken. Verder ook mijn dank aan de overige dames van het secretariaat Cardiologio voor al die vlaaien die we in de loop der tijd samen hebben verorberd.

Eveneens gaat mijn dank uit naar iedereen van Novartis, en in het bijzonder naar Sonja, Thomas en Elsbeth. Zelfs bij tegenslagen tijdens de studie was de sfeer altijd positief en zelfs motiverend. Voor mij was de Validate-studie een belangrijke leerschool en daardoor zeer zeker het fundament onder mijn promotie. Bedankt!

Bij mijn onderzoek naar NT-proBNP kwam ik gaandeweg in contact met Roche Diagnostics. Ook deze samenwerking verliep in een uiterst aangename en gemoedelijke sfeer. Ben, mijn HARTelijke dank voor al je hulp en assistentie! Ich möchte auch den Mitarbeitern von Roche Diagnostics in Mannheim, insbesondere Ildiko und Bernhard, von Herzen danken für die gute Zusammenarbeit, die in meinen Augen stets durch eine freundliche und professionelle Arbeitsweise geprägt war. Vielen Dank! 
Pap en Mam, hoewel jullie deze fase van mijn carrière wat meer op afstand hebben meegemaakt waren jullie altijd benieuwd naar de stand van zaken. Bovendien was ik nooit zover gekomen dankzij alle hand-en spandiensten in het verleden en m.n. in mijn Leuvense jaren. Hartstikke bedankt!!! Ook mijjn zus en broers: Maril, Arjan en Joost, ook jullie bedankt voor alle steun in de loop der jaren.

In de wetenschappelijke literatuur is er een bepaalde hiërarchie in de volgorde van namen. De laatste naam in een wetenschappelijk artikel is voorbehouden aan degene die het geheel mogelijk heeft gemaakt en ondersteund. Zonder deze persoon was de studie of het project meestal niet mogelijk geweest. Lieve Floor, ondanks jouw werk en drukke studie was je altijd razend benieuwd naar mijn studies en als ik weer eens op reis moest dan was je trots op me. Daarom denk ik dat het meer dan vanzelf spreekt dat deze positie jou toekomt. Bedankt voor alles en bij deze: Floor. 


\section{CURRICULUM VITAE}

Roland van Kimmenade werd geboren op 20 juni 1977 te Weert. In 1995 behaalde hij zijn eindexamen gymnasium aan het Bisschoppelijk College te Weert. In ditzelfde jaar begon hij met de studie Geneeskunde aan de Katholieke Universiteit te Leuven alwaar hij in 2002 met het predikaat met grote onderscheiding het artsexamen behaalde. Direct na het behalen van dit diploma begon hij als arts-assistent op de afdeling Cardiologie in het Academisch Ziekenhuis Maastricht. Op 1 aprill 2003 startte hij zijn promotieonderzoek waarin hij zich toespitste op de klinische toepasbaarheid van serologische markers in de diagnostiek en prognostiek van hartfalen en waarin hij zich vooral op de rol van NT-proBNP concentreerde. Op 1 april 2005 startte hijj officieel met zijn opleiding tot cardioloog. Het eerste jaar van deze opleiding richtte hij zich nog alleen op zijn wetenschappelijk onderzoek maar vanaf 1 mei 2006 is hij op de afdeling Interne Geneeskunde begonnen aan de klinische aspecten van de opleiding tot cardioloog. 
126 


\section{PUBLICATIONS}

\section{Articles}

1. van Kimmenade $\mathrm{R}$, Smedema JP, van Suylen RJ. Rlyeumatic carditis in an 18 year old man. Heant 2003 ; 89: 1066 .

2. Jantzzi IL, Jr., van Kimmenade RRJ, Lainchbuy IG, Bayes-Genis A, Pinto YM, Richards AM. NTproBNP Testing for Diagnosis and Short-Term Prognosis in Acute Congestive Heart Fallure: An International Pooled Analysis of 256 Patients. The International Collabonative of NT-proBNP (LCON) Study. Eur Iteart J 2006;27:330-337.

3. van Kimmenade $R$, van Dielen $F$, Bakker J, ef al. Is brain natrituretic peptide production deareased in. obese subjects? I Am Coll Cardiol 2006; 47:886-7.

4. van Kimmenade $\mathrm{R}$, Pinto YM, Bayes-Genis A, Lanchbury J, Richards AM, Januzi JL. Usefulness of Intermediate Amino-terminal pro-Brain Natriuretic Peptide Concentrations For Diagnosis of Acute Heat: Failure. Am I Cardiol 2006:in press.

5. wan Kimmenade $\mathbb{R}$, Januzzi IL, Elinor PT, et al. Utility of NT-proBNP. Galdectin-3. and Apelin for the Evaluation of Patients with Acute Heart Failure. 3 An Coll Cadiol 2006 provisonally alcepted.

6. wan Kimmenade $\mathrm{R}_{4}$, Januzzi $\mathrm{JL}_{\mathrm{L}}$, Baggish $\mathrm{AL}$, et al. Aminomteruninal Pro-Brain Natriuretic Peplide, Remal Function and Outcomes in Acute Heart failure. Re-defining the Cardio-Renal Interaction ? 2006 : subimitted.

7. van Kimmenade R, Bakker J, Houben AJ, et al. Renal Handling of BNP and NT proBNP in Hypertensive Subjects. 2006:submitted.

8. Baggish AL, wan Kimmenade R, Buyes-Genis A, et al. Hemoglobin and N-terminal Pro-Brain Natriuretic Peptide: Independent and Synergistic Predictors of Mortalify in Patients with Acute Heart Failure. Results from the International Collaborative of NT-proBNP (ICON) Study, 2006:submitted.

\section{Abstracts}

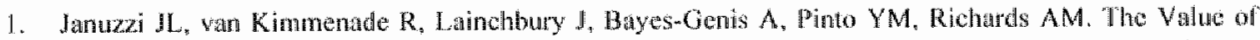

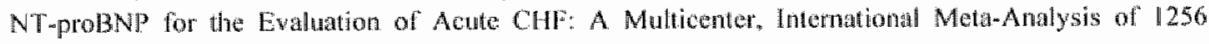
Subjects. I An Coll Carcliol 2005; $45: A 178$

2. van Kimmende RRJ, Bakker JA, Houben AJ, et at. Renal Handing of BNP and NT-probNP in Hypertensive Subjects. Circulation 2005; $112:$ A28.43.

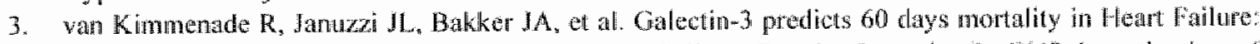
A step towards a Multimalke Strategy in Heart Pailure. Restulls from the Prol3NP Investigation of Dyspnea in the Emergency Depantment (PRIDE) Study. Circulation 2005; $112: A 3167$

4. van Kimmenade $R$, van Dielen F, Bakker JA, et al. BNP Production is Decreased in Obese Subjects. Circulation 2005; $12: A 3545$

5. van Kimmenade R, Januzzi JL, Lainchbury J, et al Combining NT proBNP and GrR to Predic: Prognosis in Patients whth Heart Failure. An Analysis from the International Collabotative of NTproBNP (ICON) Study Circulation 2005; 112:A3550.

6. van Kimmenade $\mathbb{R}$, Panto YM, Lainchbury J, Bayes-Genis A. Rhchards AM, Januzz JL. There is Nothing Grey About il: Dyspnea with Intermediate Aminotemingl Prom Bype Nathuetic Peptide Concentrations. I Am Coll Cardiol 2006; 47:A91. 